UNIVERSIDADE DE SÃO PAULO

INSTITUTO DE FÍSICA

$i$

\title{
ALGORITMOS DE CLUSTER E PERCOLAÇÃO
}

\section{MAURÍCIO BORGES BOUABCI}

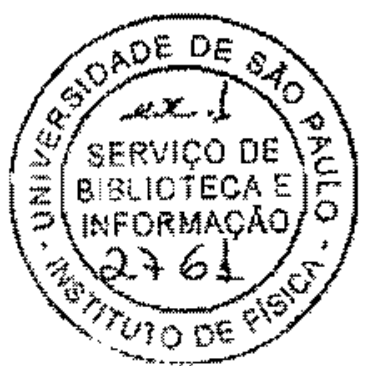

Tese de Doutozado

submetida ao Instituto de Fistca da Universidade de $\$$ 觔 Palo

Orientudor: Prof. Dr. Carlos Eugenio Imbassahy Cameiro

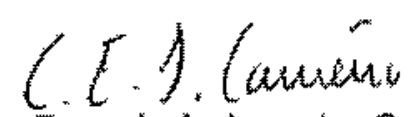

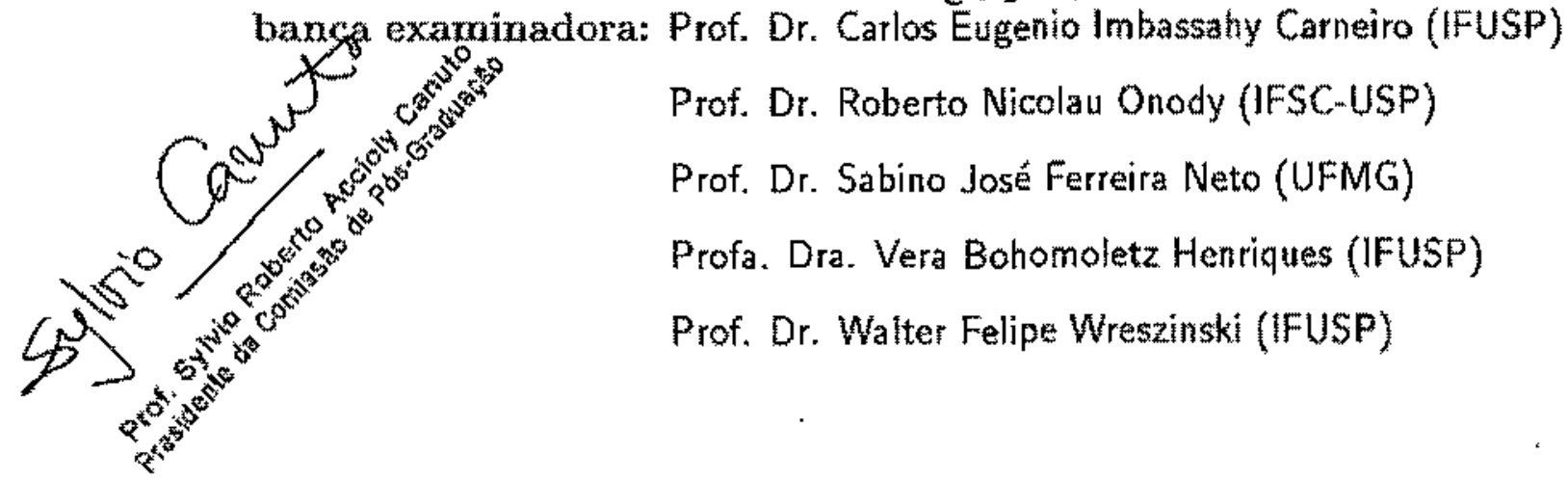




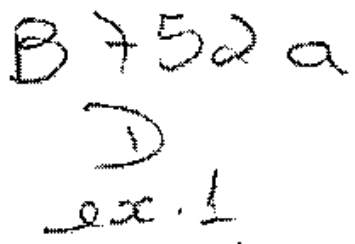

FICHA CATALOGRÁFICA

Preparada pelo Serviço de Biblioteca e Informaçāo do Instituto de Fisica da Universidade de São Paulo

Bouabel, Mauricio Borges

Algoritmos de cluster e percolacao. Sao Paulo 1998.

Tese (Doutoramento) Universidade de São Paulo. Instituto de Física. Departamento de Fisica Geral.

Area de Concentraçäo: Física da Materia Condensada.

Orientador: Prof. Dr. Carlos Eugenio Imbassahy Carneiro.

Unitermos: 1.Fisica da Materia Condensada;

2. Modelos de Percolacao; 3. Algoritmos de cluster;

4. Modelo de Blume Capel.

USP /IF/SBI - 07/98 


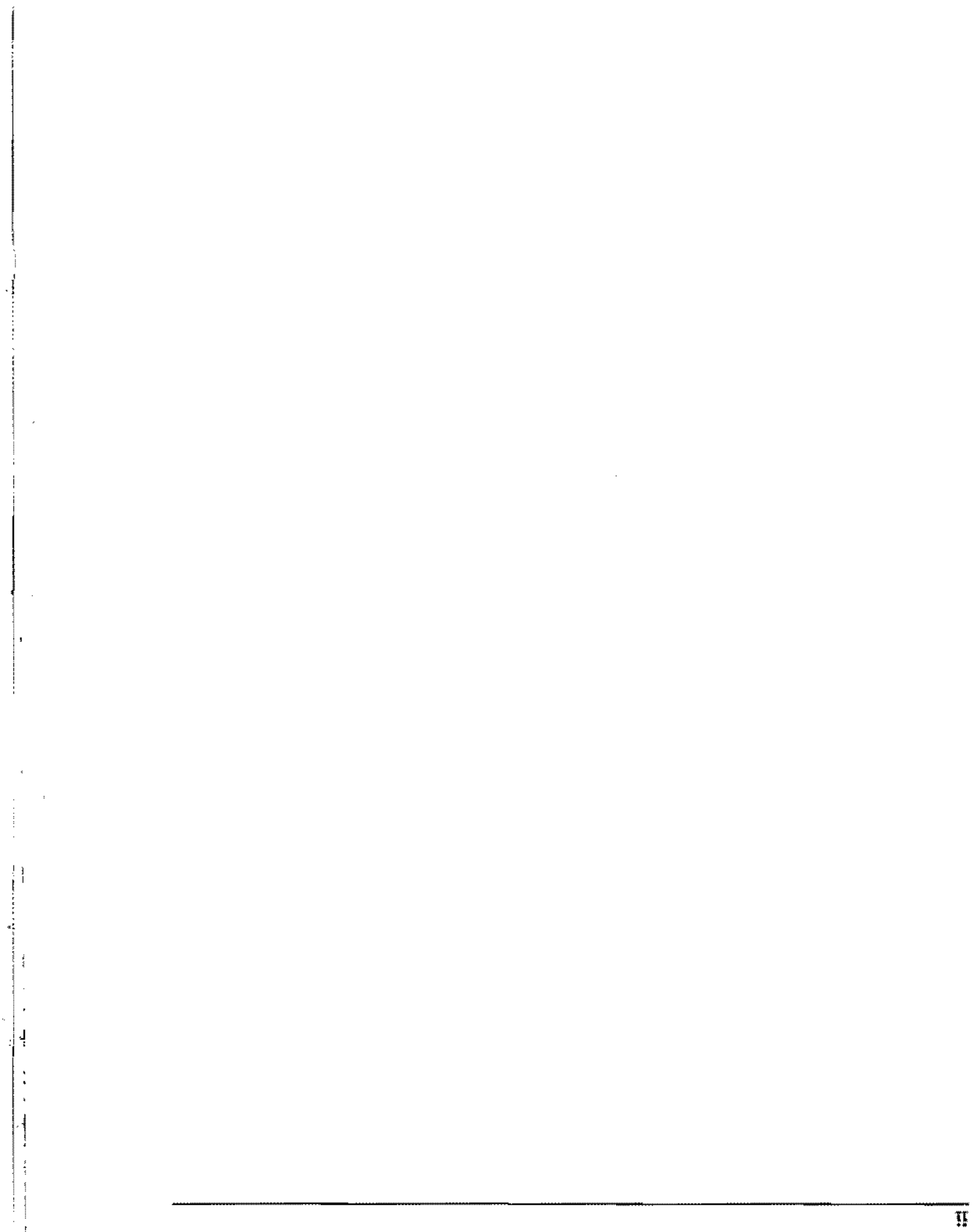


Existem algumas pessoas de nosso relacionamento que são especiais, de quem nos sentimos sempre muito próximos, basta estar junto a elas para nos sentirmos felizes. A elas dedico esta tese. 


\section{Agradecimentos}

Já há dez anos estou no Instituto de Física da USP. Durante todo este tempo tive a alegria de conhecer e conviver com diversas pessoas que certamente deixaräo profunda impressão sobre minha vida, e com as quais espero munca perder contato, atora que estou de saída. Gostaria de aproveitar este espaço para agradecê-las.

Algumas delas tive a felicidade de conkecer logo que entrei na Física, como o Marcelo, a Gisele e o Ipero, de minha turma de graduação, e amigos insubstituiveis. Outros conheci já na Mecânica Estatística, como o Ricardo, a Inês e o Mário Tamashiro, todos ótimos companheiros. Preciso agradecer também à Adriana, que quebrou o código ético da profissão, e além de minha analista informal condenada tu escutar minhas besteiras tornouse também ótima amiga.

Por falar em besteira, agradeço ao pessoal de minha sala, Marcos, Nestor e, mais recentemente, Cristiane, por me aguentarem sem enlouquecer.

Faz também mais de seis anos que trabalho com o Prof. Carlos Eugenio, a quem agradeço por todo este tempo de orientaçäo e paciência. Agradęo também aos Profs. Nestor Caticha e Mário de Oliveira, por estarem sempre dispostos a discutir comigo at respeito de minhas dúvidas, e aos Profs. Walter F. Wreszinski e Antônio Piza, com quem fiz diversos cursos que muito apreciei.

Sempre me senti nuito à vontade no ambiente da Mecănica Estatística, e isto con certeza deve-se à convivência com pessoas como a Carla, Mingo, Suani, Thierry (agregado), Whilk, Sînia, Nara, Rafael ê Neli. Nāo dá para esquecer também do Cristiano, Kaline e 
Roberta, com quem sempre me diverti e aprendi muito.

Mea reconhecimento também a uma turma que se uniu a esta mais recentemente, minha turma da ECA, Rogêrio, Ana Rita, Thiago, Bia, Daniel, Pepa, Kátia, Alo, Edu e Renata, mais a última a se agregar à trupe, a Susana. Adoto vocês.

Nem preciso citar a minha família, sempre um ponto de referência e apoio, que me mimaram a ponto de eu virar isto.

Todas estas pessoas, e outras injustaraente não mencionadas, fizeram muito mais do que me ajudar com a tese, elas ajudaram e enriqueceram minha própria vida, eu seria capaz de falar sobre elas durante uma tese inteira.

A.gradeço também à FAPESP, por ter financiado este projeto, alë́m de viabjilizar minha participação em escolas e congressos cientificos. Fundamental também foi a permissão do Prof. Jorge de Lyra para que eu pudesse utilizar os computadores do Departamento de Física Matútemática.

Por fim, o inicio: agradeço ao Carl Sagan esua série Cosmos, que começaram tudo isto. 


\section{Resumo}

O objetivo principal deste trabalho é o de investigar relaçães entre mapeamentos de medelos de spin em modelos de percolação e existencia de algoritmos de cluster caparzes de simular de forma eficiente o modelo. Apresentamos um mapamento do modelo de Blume-Capel em um modelo de percolaçäo que permite reobter um algoritmo proposto anteriormente por nós através de uma prova de balanço detalhado, o que abre a possibilidade de descrevermos todo o diagrama de fases do modelo em termos de propriedades dos clusterz formados. Isto é particularmente interessante já que o modelo possui um ponto tricrítico, tunca antes analisado em termos de propriedades de percolaçäo. Encontramos também um mapeartento para o modelo de Ashkin-Teller, através dos algoritmos de cluster resultantes investigamos a possibilidade de existência de uma fase de Baxter Assimétrica. Analisamos também questöes relacionadas ao comportamento de tamanho finito de sistemas que apresentam transicöes de fase de primaira ordem axsimếtricas. Finalmente, o algonitmo de cluster desenwolvido para o modelo de BlumeCapel é também generalizado, de forma a podermos aplicalo ao estudo do modelo de Binme-Emery-Griffiths. 


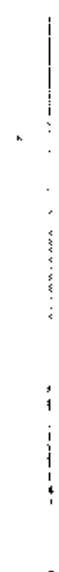

$\stackrel{3}{3}$

$\vdots$

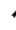

is

i

1

$\because 1$

,

: 


\begin{abstract}
The main goal of this work is to investigate relations between mappings of spin models into percolation models and the possibility of devisiug an efficient cluster algorithm to simulate the model. We present a mapping of the Blume Capel model into a percolation model that results in a ciustert algorithm proposed previously by us through a detailed balance proof, enabling as to describe the whole phase-diagram in terms of cluster properties. This is particularly appealing, since the model has a tricritical point, a feature not yet analysed in terms of percolation properties. We present also a mapping for the Ashkinm-Teller model, and using the obtained cluster algorithms we analyse the possibility of existence of the Asymmetric Baxter phase. We also address questions related to the finite-size behavior of systems in usymmetric furst-order phase transitions. Finally, the cluster algorithm developed for the Blume-Capel model is generalized to the study of the Blume-Emery-Griffiths model.
\end{abstract}




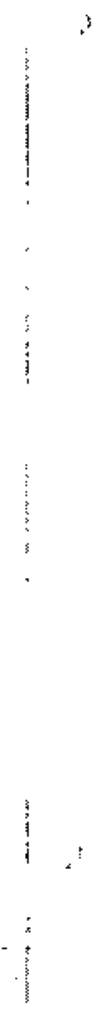




\section{Índice}

Introdução 3

1. Metodo de Monte Carlo - Aspectos Gerais 7

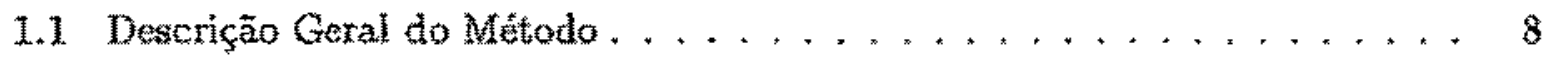

1.2 Simulação de Transiçoes de 2 Ordem . . . . . . . . . . . . . . 10

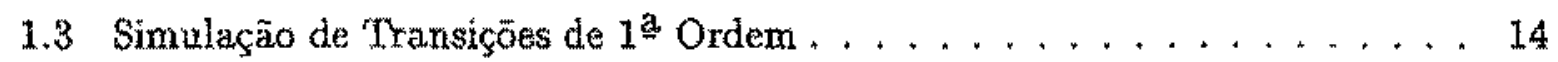

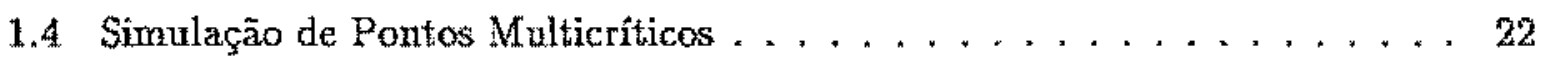

2 Algoritmos de Cluster - Possiveis Abordagens 27

2.1 Algoritmo de Wolt para o Modelo de Ising . . . . . . . . . . . 29

2.2 Algoritmo de Swendsen-Wang para o Modelo de lsing . . . . . . . . . 35

2.3 Mapeamento do Modelo de Ising - Abordagem de Hu . . . . . . . . 38

2.4 Análise dos Algotitmos . . . . . . . . . . . . . . . 42

2.5 Formulação de Kandel-Domany ................. 47

2.6 Algorimo de Hnbetding $\ldots \ldots \ldots \ldots \ldots \ldots$

3 Algoritmos de Cluster e Percolação no Modelo de Ashkin-Teller 33

3.10 Modelo de Ashkin-Teller . . . . . . . . . . . . . . . . . 54

3.2 Algoritmo de Cluster para o Modelo de Ashkin-Teller com Interaçäo de Quatro Spins Ferromatanética. .................... 60 
3.3 Mapeamento do Modelo de Ashkin-Teller com Interaçào de Quatro Spins Ferromagnética em um Modelo de Percolação. . . . . . . . . . 87

3.4 Algoritmo de Cluster para o Modelo de Ashkin-Teller com Interaçăo de Quatro Spins Antiferromagnética ................. 73

3.5 Mapeamento do Modelo de Ashkin-Teller com Interação de Quatro Spins Antiferromagnética am um modelo de percolaçäo. . . . . . . . . . 81

3.6 Resultados Numéricos $\ldots \ldots \ldots \ldots$

4 Mapeamento do Modelo de Blume Capel em um Modelo de Percolaça 97 4.1 O Modelo de Blune Capel . . . . . . . . . . . . . . . . . 98

4.2 Algoritmo de Chster para o Modelo de Blume Capel . . . . . . . . 102

4.3 Mapeamanto em um Modelo de Percolaçăo . . . . . . . . . . . . 106

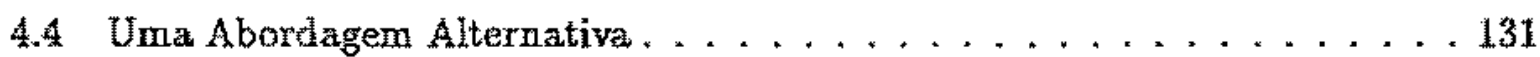

5 Generalizações para o Modelo BEG

5.1 O Modelo de Blume Emery-Grifnths $\ldots \ldots \ldots$. . . . . . . . . .

5.2 Algortmo de Cluster para o Modelo BEG . . . . . . . . . . 136

5.3 Resultados Numéricos $\ldots \ldots \ldots \ldots \ldots 1$ 


\section{Introdução}

O estudo das relaçôes existentets entre modelos termodinâmicos e modelos de percolação teve início em 1969, quando Fortuin e Kastelyn introduziram o chamado Modelo de Clusters Aleatórios [FK72], unificando a descrição de diferentes modelos em termos de um modelo de percolaçäo, e mostrando que é possivel traduzir diversos conceitos termodirârnicos em termos de propriedades de percolaçäo.

Ao longo dos anos, esta conexāo revelon-se extremamente ưtul, tendo sido utilizada como ferramenta de estudo de diversos fenômenos físicos que ocorrem nos modelos de Ising e Potts, como por exemplo descontinuidades da magnetizaçăo espontânea na tempexatura crítica de modelos unidimensionais com potenciais de interaçâo de longo aleance [ACCN88]. Foi também através desta conexão que a desigualdade FKG (FortuinKastelyn-Ginibre [FKG71]) foi introduzida, sendo esta desigualdade de extrema importầncia ma anälise matemática de fenômenos críticos, como por exemplo na determinaçăo de cotas superiores para o valor de expoentes críticos.

Mais recentemente, a conexăo com um modelo de percolação passou a ser utilizada também em simulaçỏes numéricas de modeios de spins [SW87], servindo como base para o desenvolvimento de algoritmos de cluster, que representam uma nova forma de se efetuar a simulaçäo, que pode resultar vantajosa em relaçăo ths técnicas usuais, jú que este tipo de algoritmo pode descorrelacionar as configuraçoes geradas de forma mais eficiente, e tambérn eliminar efeitos de histerese em transiçôes de $1 \stackrel{\text { a }}{\text { ordem. }}$

O objetivo deste trabalho é o de mostrar que um algoritmo de cluster desenvolvido 
anteriormente por nós para o Modelo de Blume-Capel [BC96] corresponde a um mapeamento deste modelo em um modelo de percolaçāo. De certa forma, estaremos seguindo um processo inverso ao que ocorreu com o Modelo de Potts, onde a existência do mapeamento em um modelo de percolação permitin que um algoritmo de cluster para efetuar simulaçōes numéricas fosse desenvolvido. Aqui a situaçăo é inversa: dispomos de um algoritmo de cluster, obtido através de uma prova de balanģo detalhado, e queremos achar o mapeamento em um modelo de percolação que corresponda a este algoritmo.

Este mapeamento parece bastante promissor, porque teremos entâno a possibilidade de estender todas as técnicas mencionadas anteriormente para um modelo muito mais complexo, que possui toda uma linha crítica, alếm de transiçoes de 1 a ordem e um ponto tricrítico. O algoritmo de cluster desenvolvido por nós é constituído tambĕmn por dois tipos diferentes de cluster, o que enriquece a caracterizaçäo do modelo em termos de propriedades dos clusters formados.

Na busca de um mapeanento que nos conduzisse ao algoritmo de cluster proposto, fomos levados a reescrever a Hamiltoniana do modelo em termos de duas novas variáveis tipo Ising. A Hamiltoniana resultante é semelhante a do Modelo de Ashkin-Teller, o que nos motivou a estudar inicialmente um mapeamento para este modelo, na esperança de que esta análise nos auxiliasse no mapeamento do Modelo de Blume-Capel.

Mostramos entẫo que é possível descrever o Modelo de Ashkin- ${ }^{\top}$ Teller em termos de modelos de percolação, mais especificamente em termos de três modelas de percolação distintos, cada um deles apropriado ao estudo de uma certa regiato do diagrama de fases do modelo. Utilizando entĩo os algoritmos de cluster a que estes mapeamentos nos conduzem, efetuamos un estudo numérico do diagrama de fases, a fim de determinar a existência ou nâo da fase de Baxter Assimétrica [DBGK80], questảo ainda controversa na literatura.

Os métodos desenvolvidos para o mapeamento do Modelo de Ashkin-Teller foram realmente úteis para o mapeamento do Modelo de Blume-Capel, que foi assim desenvolvido 
em termos de variáveis de Ising. O algoritmo resultante do mapeamento corresponde ao algoritmo desenvolvido através de uma prova de balanço detalhado, mostrando que as caracteristicas dos clusters formados por este algoritmo estäo diretamente ligadas a propriedades do modtlo termodinâmico.

Finalmente, demonstramos que é possivel generalizar o algoritmo proposto anterionmente para o Modelo de Blume Capel de forma que ele possa ser aplicado também a uma grande regiäo de variaçăo dos parâmetros do Modelo de Blume-Emery-Griffiths, o que abre a perspectiva de que tarnbém neste modelo propriedades termodinâmicas possam ser explicadas em termos de propriedades de percolaçăo. 


\section{Capítulo 1}

\section{Método de Monte Carlo - Aspectos Gerais}

Discutimos neste capitulo aspectos relacionados à utilizaçäa do Método de Monte Carlo exn Mecanica Estatística.

Através do Algoritmo de Metropolis, que constitui a maneira mais direta de implementarmos uma simulação de Monte Carlo, apresentaremos as dificuldades encontradas usualmente em simulaçōes de transições de fases, como o problema da desaceleraçäo crítica em transiçōes de $2^{\text {a }}$ ordem e a presença de estados metaestáveis e curvas de histerese em transiçőes de $1^{\text {a }}$ ordem. Muitas vezes, a decisăo sobre qual a ordem de uma transiçäo nä̆o é uma tarefa făcil, principalmente en regiōes onde existern transiçōes dos dois kipos próximas, como em pontos tricriticos. Nestas regiôes a soluçâo dos problemas mencionados é fundamental para o estudo das propriedades críticas do modelo.

Mostramos também como extrapolar resultados obtidos na simulação de uma rede finita a fim de obternos propriedades críticas de uma rede infinita, como por exemplo os expoentes críticos. 


\subsection{Descrição Geral do Método}

Em Mecânica Estatistica, a utilizaçẵo do Método de Monte Carlo está em geral relacionada ao cálculo de valores médios de quantidades físicas de interesse. A partir de um modelo Hamiltoniano para o sistema fisico estudado, utilizamos geradores de números randômicos para simular a contribuição estatîstica de diferentes estados do modelo [Bin79][BS84][BH92].

A razão parch utilizarmos este mêtodo é a de que em geral não é possivel encontrar-se uma soluçäo analítica para o modelo estudado, e por outro lado o cálculo numérico exato é inviável, devido ao grande número de estados possiveis. Se tentarmos escolher urn certo número de configuraçôes de forma arbitrária, näo conseguiremos uma boa amostragen do espaço de confignraşos to sistema, uma vez que a maioria das configuraçöes escolhídas terão peso estatístico pequeno.

O método de Monte Carlo resolve estes problemas através de uma amostragem por importância: selecionamos um certo número de configuraçōes de modo que elas já satisfaçam a distribuição de probabilidades correta. Para alcançarmos este objetivo, partimos de uma configuração inicial qualquer do sistema e geramos novas configuraçoes estocasticamente através de uma cadeia de Markov. As configuraçöes geradas obedeceräo a distribuiçäo de equilibrio correta se o procedimento utilizado obedecer à condižăo de balanço detalhado (para uma demonstraçäo deste resultado, ver [Dooş]):

$$
W_{\sigma \rightarrow \sigma^{\prime}} e^{-f H(\sigma)}=W_{\sigma^{t} \rightarrow \sigma} e^{-f H\left(\sigma^{\prime}\right)}
$$

onde $W$ representa a probabilidade de transiçäo entre duas configuraçôes, e $\exp (-\beta H(\sigma))$ é proporcional à probabilidade de termos a configuração o: de acordo com a distribuiçáco de Boltzmann.

É necessário também que possamos acessar todas as configuraçôes do sistema, ou seja, o algoritmo deve ser ergódico. 
Após um certo tempo transiente, atingiremos configuracỏes caracteristicas da distribuị̧ă de equilibrio, e para talcularmos então médias estatísticas utilizamos a propriedade de ergodicidade da cadeia de Markov, substituindo a nédia sobre configuraç̋es por uma média sobre o tempo (por uma unidade de tempo entendemos a distância entre duas configuraçós vizinhas da cadeia).

A forma mais direta de efetuamos uma simulacto de Monte Canlo e através do algoritrno de Metropolis, que parte da seguinte escolha para probabilidade de transiçăo:

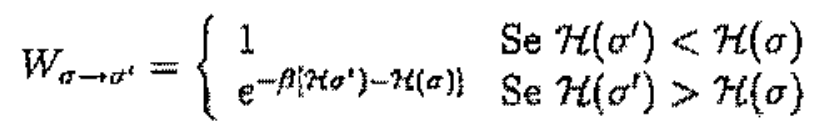

A prova de que esta escolha para as probabilidades de transiçāo satistaz a condiçäo de balanço detaluado é direta.

Como exemplo prático, vamos mostrar como o algoritmo de Metropolis ế aplicado ao Modelo de Ising. A Hamiltoniana do modelo é definida por

$$
X=-x \sum_{\langle i j} a_{i} \sigma_{j} \quad, a_{i}= \pm 1
$$

A partir de uma configuraçăo de spins arbitratia, efetuamos as seguintes etapas:

1. Sorteamos um spin da rede.

2. Calculamos qual será a diferença de energia $\Delta H=H\left(\sigma^{\prime}\right)-H(\sigma)$, se o sinal do spin for invertido.

3. Se $\Delta H<0$, aceitamos a nova conftguração com probabilidade $p=1$.

4. Caso a energia do sistema aumente, calculamos a probabilidade de transiçäo $e^{-\beta(\Delta \mathcal{K})}$.

5. Sorteamos um número randômico $r$ entre 0 e $\mathrm{L}$.

6. Se $r$ for menor do que $W$, acatamos o novo sinal do spin, caso contrátio a configuraçăo de spins näo é alteràda. 
Geramos assim uma nova configuração do modelo. Como ela possui no máximo apenas um spin diferente da conffguração anterior, repetimos as etapas acirat um número de vezes igual ao número de spins da rede, para que as configuraçôes utilizadas no cálculo de médias nào sejam muito correlacionadas. A tentativa de modificarmos um número de spins igual ao número total de spins da rede corresponde à uma unidade de tempo, ou a um passo de Monte Carlo. Calculamos então as quantidades físicas desejadas, e repetimos este procedimento por um certo número predeterminado de vezes, a fim de calcularmos médias estatísticas.

\subsection{Simulação de Transições de $2^{\text {a }}$ Ordem}

Uma grande vantagem do Mếtodo de Monte Carlo é a de que não efetramos nenhuma aproximaţ̧ẵo no modelo estudado. O único erro envolvido é o erro estatistico no cálculo de médias, que será dado por $\sigma / \sqrt{N}$.

Mas para que o erro seja realmente dado pela expressäo acima, é necessánio que os dados utilizados no cálculo da média sejam estatisticamente independentes, o que nem sempre e o caso. Citamos na seção anterior o caso trivial onde apenas um spin da rede é modificado de cada vez, o que obviamente conduz a configuraçỏes muito correlacionadas.

Uma outra fonte mais sutil de correlaçăo entre os dados obtidos ocorre em transiçöes de segunda ordem, onde a divergência do comprimento de correlaçấo conhecido como desaceleração crítica. Grandes blocos de spins na rede passam a agir de forma correlacionada, prejudicando a obtençäo de dados estatisticamente independentes.

Para medirmos este eféto, é conveniente estudarmos o comportamento da função de correlação temporal $C(t)$, definida por

$$
C(t)=\frac{\langle A(t) A(0)\rangle-\langle A(t)\rangle\langle A(0)\rangle}{\left\langle A^{2}\right\rangle-\langle A\rangle^{2}},
$$

onde o operador $A$ representa alguma grandeza física de interesse, como magnetizaçāo ou energia. Na figura (1.1) mostramos o comportamento da funçäo de correlaçäo no modelo 
de Ising, quando estamos na temperatura crítica da rede infinita, e a simulação e efetuada através do algoritmo de Metropolis.

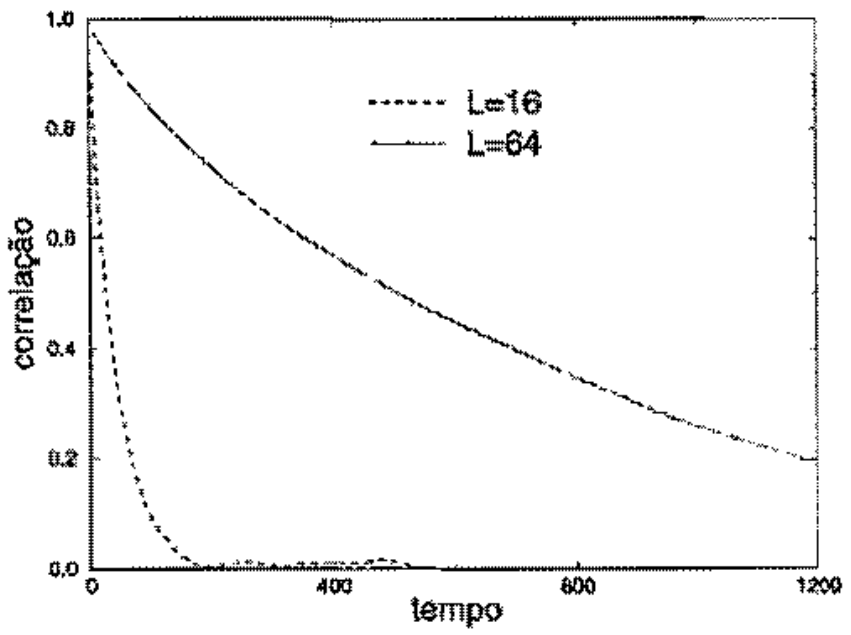

Figura 1.1: Correlaça temporal no Modelo de Iting, para dois amanhos de rede diferentes.

Vemos que em uma rede te tamanho $z=64$ são necessários mais de 1000 passos de Monte Carlo antes que as confoguraçoes obtidas tornem-se estatisticamente independentes. Outro fato a ser notado é que o tempo de correlaçäo aumenta com o tamanho da rede. Esta dependencia pode ser descrita através da seguinte lei de escala [HH77]:

$$
T \sim L^{z}
$$

onde $\tau$ to tempo de correlaçäo, e $z$ e o chamado expoente critico dinamico. Este expoente que mede a real effiência de um algoritmo, porque um exposnte $z$ elevado difucultara a obtencäo de dados estatisticamente independentes em redes de maior tamanho, tormando necessatro um grande unmero de passos de Monte Carlo.

No algoritmo de Metropolis, mudanças na rede propagamme por difusäo, atrayês de um passeio aleatório. Para modificarmos uma configuraçüo crítica de tamanho $\xi$ säo 
necessários $\xi^{2}$ passos, e como $\xi \sim h$ o algoritmo apresenta am expoente crítico $z$ próximo de 2 .

Algoritmos de cluster representam um grande avanço no tratamento deste problema, porque ao efetuarmos mudanças näo-locais na rede tornamos possivel ab obtenção de expoentes críticos dinâmicos menores.

Para efeitos de comparação, fornecemos na tabela abaixo valores assumidos pelo expoente crítico dinâmico dos algoritmos de Metropolis, Wolff e Swendsen-Wang, quando aplicados ao modelo de Ising, de acordo com dados compilados por Barkema e Newan [BN97].

\begin{tabular}{|c|c|c|c|}
\hline dimensão & Metropolis & Wolff & Swendsen-Wang \\
\hline \hline 2 & $2.167(1)$ & $0.25(1)$ & $0.25(1)$ \\
\hline 3 & $2.02(2)$ & $0.33(1)$ & $0.54(2)$ \\
\hline 4 & - & $0.25(1)$ & $0.86(2)$ \\
\hline
\end{tabular}

Na prática, o expoente $z$ é medido a partir da função de correlagãa $C(t) . O$ comportamento desta função na temperatura crítica pode sex escrito como [MKB73]:

$$
C(t)=\sum_{i=1}^{\infty} C_{i} e^{-t / \pi_{i}}
$$

onde $C_{i}$ stio constantes. Todos os tempos de correlação apresentam a mesma dependência com o tamanho da rede $\left(\tau_{i} \sim L^{z}\right)$, e medinos $z$ através do maior tempo de descorrelaçäa, onde os erros envolvidos no ajuste são menores.

Outro aspecto importante a ser levado em consideraçào em transiçóes de $2^{a}$ ordem é o de como extrapolar resultados obtidos en redes finitas a fim de se obter o comportamento de redes infinitas.

Nas proximidades de um ponto crítico, todos os comprimentos que caracterizam o sistema podem ser expressos em termos de um único comprimento, o comprimento de correlaçầ $\xi$. Como este comprimento diverge no ponto crítico, concluimos que o sistema 
nâo possuĩ um comprimento caracteristico, de onde resulta a sua invariância por trans" formaçöes de escala [Hua87].

Em um rede finita, isto näo pode acontecer, porque o comprimento de correlaçăo pode ser no máximo proporcional à dimensāo linear $L$ do sistema, e portanto é em funçäo deste comprimento que as quaritidades físicas devem ser medidas. Esta é a hípótese de tamanho fintto [Bar79], que pode ser escrita como

$$
\xi(T) \approx L,
$$

onde $\xi(T)$ é o comprimento de correlação, que é funçăo da temperatura $T$. Como o comprimento de correlaçato de uma rede infinita diverge como

$$
\xi(T) \sim\left(T-T_{\mathbf{c}}^{\infty}\right)^{-1,},
$$

coneluimos que a temperatura crítica de uma rede infinita irá se aproximar da temperatura critica da rede infinita de acordo com a seguinte lei de escala:

$$
T_{c}^{L}=T_{c}^{\infty}+a L^{-1 / v}
$$

Outras leis de escala podem ser obtidas com o mesmo raciocínio. Por exemplo, sabemos que a susceptibilidade magnética diverge através da lei de escala

$$
x \sim||^{-r}
$$

onde $t=\left(T-T_{t}\right) / T_{t}$. Substituindo as expressões $(1.7)$ e $(1.8)$, encontramos

$$
\chi \sim L^{\gamma t z}
$$

Através de leis de escala como estas, conseguimos extrair o comportamento de quantidades físicas de sistemas infinitos, atrayés da extrapolaçăo dos dados obtidos em redes de tamanhos finitos. 


\subsection{Simulação de Transiçōes de $1 \underline{\text { â }}$ Ordem}

A principal dificuldade na simulaçăo de transiçōes de 1 â ordem refere-se à existência de estados metaestáveis, que dificultan a obtençăo de configuraçöes de equilíbrio do sistema.

Efeitos de metaestabilidade ocorren porque em temperaturas próximas à temperatura de transiçäo a energia livre do sistema possui dois ou mais mínimos (figura (1.2)), que representam diferentes fases do sistema. Separando estas regiōes de mínimo existem barreiras de energia pronunciadas, e configuraçöes com valores para a energia livre correspondentes aos da barreira sã̃o bastante improváveis.

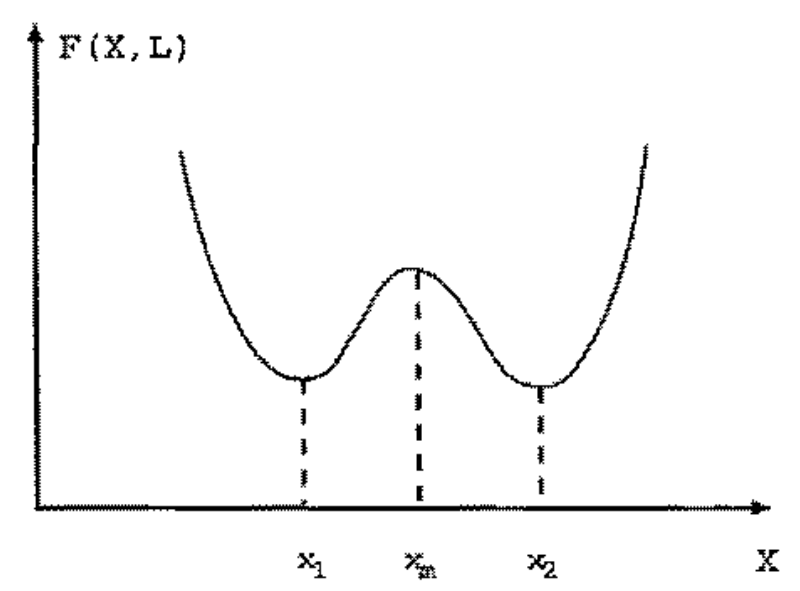

Figura 1.2: Forma típica para a energia livre de um sistema em uma transição de $1^{2}$ ordem entre duas fases distintas.

Se ntilizamos algonitmos locais para efetuar a simulação, para transitarmos entre os diferentes mínimos é necessátio passarmos antes por estas configuraçöes improváveis, o que torna o tempo de relaxaçāo para o estado de equilibrio proibitivamente gxande. Só conseguimos efetivamente transitar entre as diferentes fases quando já nos encontranos bastantes distantes da transiçăo (em relaçăo à algum parâmetro de referência), e uma das fases já se tornou bastante destavotáyel energeticamente. A consequència destes fatores c a observação de curvas de histerese, o que torna a localização de pontos de transiçāo 
bastante imprecisa.

Diversas propostas foram apresentadas com o objetivo de solucionar estas difculdades. Berg Neuhaus [BN91][BN92] desenvolveram un algoritmo multicamônico que sirmula uma distribuị̧āo multicanònica que năo possú máximos tăo pronunciados, o que torna as transiçôes entre as diferentes fases mais frequentes. A distribuiçāo canônica original ê obtida apớs um processo de reconstrução das probabilidades originatis.

Marinari e Parisi propuseram um método batizado por eles de "simalated tempering" [MP92], onde a temperatura é delevada ao status de uma variável dinâmica que assume valores ao longo de um conjunto pré-determinado, sendo que o sistema é sempre mantido em equilibrio. A idêia entre as diferentes fases.

Outro trabalho a ser mencionado é o de Batrouni e Svetitsky [BS87], que utilizam tếcnicas de acelerasă de fourier para aumentar a velocidade de transição entre as difem rentes fases.

A nossa abordagem neste trabalho será a de eliminarmos os estados metaestáteís através da utilizaçắo de algoritmos de claster, o que nos possibilitará transitar antre as diferentes fases de forma direta, zem a necessidade de passarmos antes por configurações pouco prováveis. A principal vantagem deste método em selaçāo aos citados anteriormente é a de que ele nẫo necestita de nenhum parâmetro adicional, a Hamiloniana original simulada de forma tireta.

A utilizaçâo de algoritmos de tuster na simulac se ate aqui ao estudo de modelos com simetria tipo Potts [RTo0]Wans9][RW90], ondé é possivel a utilizaçäo dreta dos algorimos de Swendsen-Wang e Wolf. Por outro lado, simetrias aprestntadas por estes modelos tornam alguns resultados elementares, como por exemplo a localizaçăo da tinha de $1^{a}$ ordem do Modelo de Ising. Transiçóes de 1 a ordem assimétricas, como a que ocorre no modelo de Blume-Capel, representam um grau maior 
de dificulade.

Mesmo após termos sido bem sucedidos na obtenção de estados de equilibrio do sistema, devemos considerar ainda como efetuar uma analise de tamanho finito. Em transiçöes de 1 a ordem o comprimento de correlação $\xi$ năo diverge, e 6 de se esperar que o tamanbo da rede só apareça através de seu volume, sendo esta o comportamento de escala esperado de aualquer quantidade física analisada.

Em transicôs de 1 a orden simétricas, este argumento foi comprovado por uma análise fenomenológica desenvolvida por Binder e Landau [BL84][CLB86], através do estudo de distribuiçōes de probabilidades. Como em uma transição de 1 t ordem duas on mais fases coexistem, a distribuição de probabilidades para as configuraçōes do sistema a.presenta diversos picos, que correspondem às diferentes fases. A abordagem considerada pelos

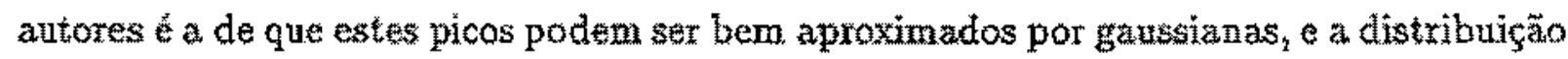
de probabilidades total é dada simplesmente por uma sobreposiçāo de gaussianas. Uma vez que dispomos da distributçă丶o de probabilidades, todas as quantidades físicas de interesse podem ser obtidas através dos momentos da distribuicäo.

Tomando o Modelo de Ising como exemplo, em um ponto do diagrama de Tases onde coexistem duas fases $\left(T<T_{*}, H=0\right)$ a distribuj̣̄a de probabilidades para a magnetização pode ser escrita como

$$
P_{L}(s)=\frac{L^{d / 2}}{2\left(2 \pi k_{B} T X_{L}\right)^{1 / 2}}\left[\exp \left(\frac{\left(-s-M_{L}\right)^{2} L^{d}}{2 k_{B} T^{T} \chi_{X}}\right)+\exp \left(\frac{\left(-s+M_{L}\right)^{2} L^{4}}{2 k_{B} T X_{L}}\right)\right]
$$

onde $M_{L}$ e 0 módulo da magnetizaço em cada um dos mínimos da energia liqre (qua esta centrados om $\neq M_{L}$ ).

Na presença de um campo magnético $H$, estes múntmos serāo deslocados para $\pm M+$ $\chi H$, os pesos ralativos de cada um dos picos da distribuiçẫo de probabilidades nāo serăo mais iguais, sendo necessârio o acréscimo de um fator de Boltzmann, $\exp \left(\frac{ \pm M_{t} L^{4}}{f_{\mathrm{g}} T}\right)$. A 
distribuição de probabilidades passa a ser dada então por

$$
\begin{aligned}
& P_{L}(s)=\frac{L^{d / 2}\left(2 \pi k_{B} T \chi_{L}\right)^{-1 / 2}}{\cosh \left(H M_{L} L^{d} / k_{B} T\right)} \times \\
& {\left[\exp \left(\frac{H M_{L} L^{d}}{k_{B} T}\right) \exp \left(\frac{-\left(s-M_{L}-\chi_{L} H\right)^{2} L^{d}}{2 k_{B} T \chi_{L}}\right)+\exp \left(\frac{-H M_{L} L^{d}}{k_{B} T}\right) \exp \left(\frac{-\left(s+M_{L}-\chi_{L} H\right)^{2} L^{d}}{2 k_{B} T \chi_{L}}\right)\right]}
\end{aligned}
$$

É fácil obter agora os momentos da distribuição em que estamos interessados. A magnetizaçāo será dada por

$$
\langle s\rangle_{L}=\int_{-1}^{+1} s P_{L}(s) d s=\chi_{\mathrm{L}} H+M_{L} \tanh \left(\frac{H M_{L} L^{d}}{k_{B} T}\right),
$$

e a susceptibilidade magnética por

$$
\chi(H, T, L)=\left(\frac{\partial\langle s\rangle_{L}}{\partial H}\right)_{T}=\chi_{L}+\frac{M_{L}^{2}\left(\frac{L^{d}}{k_{B} T}\right)}{\cosh ^{2}\left(\frac{B M_{L} L^{d}}{k_{B} T}\right)}
$$

Vemos através desta expressāo que a susceptibilidade terá un máximo de altura $L^{d}$ e largura $L^{-d}$, comportando-se como uma função delta no limite $L \rightarrow \infty$.

Concluimos então que a representação da distribuição de probabilidades em termos de duas distribuições gaussianas conduz a um comportamento de tamanho finito que depende apenas do volume da rede, $L^{d}$.

No entanto, esta abordagem apresenta alguns problemas. O primeiro deles diz respeito à aproximação em termos de gaussianas centradas nos máximos da distribuição de probabilidades. Embora nas regiōes de pico esta seja uma boa aproximaçāo, esta representaçāo nāo é correta na regiāo de mínimos de probabilidades, onde configurações com contornos de energia desfavoráveis são relevantes no cálculo do peso estatístico de cada configuração.

Uma inconsistência mais séria aparece quando analisamos transiçōes de $1 \underline{\text { a }}$ ordem assimétricas. Em transiçōes simétricas como a do Modelo de Ising, a simetria por inversões $s \leftrightarrow-s$ implica que a transição ocorrerá sempre para $H=0$, independente do tamanho da rede. Em transições assimétricas nāo há porque esperar que a susceptibilidade seja igual dos dois lados da transiçāo, podendo ocorrer que $\chi_{+} \neq \chi_{-}$. Com isto, ocorrerá um 
deslocamento do campo $h$ que controla a transiçäo, em relaçäo ao valor esperado em um sistema infinito.

O problema é que a forma de escala deste deslocamento depende da maneira como escolkemos a constante de normalização para a distribuição de probabilidades [BRK94]. A escolha ptilizada até aqui corresponde à uma formulação onde a curea abaixo de cada pico da distribuiçä́ é igual. Esta escolha conduz a um comportamento de escala para o desiocamento do campo $h$ proporcional a. $L^{-z d}$. Por outro lado, se considerarmos a constante de normalizaçäo escolhida de forma tal que a altura dos diferentes picos (ao inves da área) sejam iguais, encontratemos um comportamento de escala proporcional a $L^{-d}$. Desta forma, não conseguimos concluir qual o comportanento de tamanho finito a ser esperado em transiçöes de $1^{2}$ ordem, e a abordagem via gaussianas torna-se inadequada paxă ầ ẩ̆lise de transiçōes assimếtricas.

Esta ambiguidade fô resolvida por Borgs e Kotechy [BK90] [BK92], que propuseram uma nova teoria para a anălise de efeitos de tamanho finito em transiçōes de $1^{\underline{a}}$ ordem. A teoria consiste em representar a função de partiçăo de díferentes modelos geometricamente, em termos de regioes de mínima energia separadas por contomos energéticos desfavoráveis. Desta forma, ế possivel mostrar que a função de partiçāo de um modelo que descreve a coexistência de $N$ fases, para $h=h_{t}$ (hé um campo que controla a transição, e $h_{t}$ e o seu valor na transiçâa), pode ser aproximada por

$$
Z(h, L) \approx \sum_{q=1}^{N} \exp \left\{-f_{\phi}(h) \beta L^{d}\right\} \quad,
$$

onde $f_{q}(h)$ é uma energia livre metaestável para a fase $q$. Ao efetuarmos esta aproximaçăo em baixas temperaturas, estaremos cometendo erro proporcional a $e^{-L / L_{0}}$, onde $L_{0}$ é uma constante. Dispondo desta aproximação, podemos calcular todas as quantidades físicas que estamos interessados. A conclusão obtida pelos autores é a de que o deslocamento do campo $h$ obedece a uma lei de escala proporcional a $L^{-2 d}$, se a transiçấo for entre duas fases, e a. $L^{-4}$, se a transiçầo envolver um número maior de fases, como a do modelo de 
Blume-Capel.

Uma outra questäo relevante na análise de transiçoes de $\mathbf{i}$ a ordem refere-se à própria classificação da ordem da transiçẫo, como definir se a transiçăo é de $1^{\mathbf{a}}$ ou $2^{2}$ ordem. Em principio, ambas as transiçöes possuem naturezas bastantes distintas: enquanto uma transiçăo de $2^{\text {a }}$ ordem caracteriza-se pela divengência do comprimento de correlação $\xi$, em transições de $1^{1}$ ordem a presença de estados metaestáveis gera a existência de efeitos de histerese. Pela análise de qual dos dois efeitos ocorre a determinaçäo da ordem de uma transição devería ser tarela direta. Mas isto nem sempre é verdade, porque existem ocasiöes onde os dois efeitos podem ocorrer simultaneamente. For exemplo, no modelo de Potts de cinco estados en duas dimensões ocorre o que é chamado de transição fracamente de 1 a ordem, onde, mesmo a transição sendo de 1 a ordem ocorrem efeitos tipicos de uma transição de 2 à ordem, como o aumento do comprimento de correlaçăo $\xi$. Isto torna a análise ainda maís complicada, porque alêm da metaestabilidade temos de simular redes grandes o suficiente para terem dimensấo linear maior que o comprimento de correlaçăo.

Outra forma de caracterizarmos a orden da transiçäo é através do estudo da estrutura gaussiana da distribuiçāo de probabilidades [Bin81]. Com este objetivo, definimos o cumulante de quarta ordem $U_{L}$ da seguinte forma:

$$
U_{L}=\frac{1}{3}\left(1-\frac{\left(E^{4}\right\rangle_{L}}{\left\langle E^{2}\right)^{2}}\right)
$$

Se estivermos estudando uma transiçâo de $2^{\underline{a}}$ ordem, n distribuição de probabilidades apresentará apenas um minimo, e no linite $L \rightarrow \infty$ teremos que $\left\langle E^{4}\right\rangle=\left\langle E^{2}\right\rangle^{2}$, e portanto $U_{L} \rightarrow 0$. Já en uma transição de 1 蕉 ordem flutuaçöes entre as diferentes fases farăo com que o cumulante não se anule, passando a assumir um certo valor mínimo.

Existem tatubém outras técuicas para estudar-se transiçoes de 1 a ordem, baseadas na. construçâo de histogramas [F\$89] para a obtenção da distribuição de probabilidades, e que determinam a ordem da transiçảo a partir de propriedades desta distribuiçāo. 
Considerando uma transiçăo de $1^{\mathbf{a}}$ ordem controlada pela temperatura, onde $q$ fases ordenadas coexistem com uma fase desordenada, tal como pode ocorrer no modelo de Potts de q estados, Borgss e Janke [BJ92] propuseram a utilizaçăo da expressăo (1.15) para determinarmos a temperatura de transiçâo, partindo da observaçäo de que nesta temperatura as energias livres $f_{g}(h)$ das diversas fases tomam-se iguais, e o pouto de transiçäo passa a ser o ponto onde a razão entre o peso estatístico total das diversas fases ordenadas $e$ o peso estatístico da fase desordenada torna-se igual ao túmero total de fases ordenadas:

$$
R(V, \beta) \equiv \frac{\sum_{E S E_{\beta}} P_{\beta}(E)}{\sum E_{2} E_{\beta} P_{\beta}(E)}=q
$$

onde $E_{0}$ é a energia do minimo entre os dois picos, quando estes possuem alturas iguais. A técnica consiste entăo em regularmos primeiramente a altura dos dois picos, até que elas tornem-se iguais, determinando desta forma $E_{0}$. Em seguida ajustamos a temperatura, até que encontremos $R(V, \beta)=q$, e esta será a temperatura de transição.

Uma outra técnica foi proposta ainda por Lee e Kosterlitz [LK90], baseada no comportamento da altura da barreixa entre os dois múnimos de energia livre em função do tamanho da rede. A partir de um histograma para a energia, podemos calcular o número de vezes que um observável $X$ é obtido através da expressão

$$
\exp \left[-A\left(X, L_{1}, M\right)\right]=M Z^{-1}(\beta) \sum_{Z_{1}} \Omega\left(E_{1}, X\right) \exp \left(-\beta E_{1}\right)
$$

onde $M$ é o número de passos de Monte Carlo, $\Omega\left(E_{1}, X\right)$ é o número de estados com energia $E_{1}$. Em uma transiçto controlada pelo campo magnético $X$ é escolhido como aendo a magnetização, e em uma transiçăo controlada pela temperatura $X$ è a energia.

Para valores fixos de $B, L$, e $M$ a quantidade $A(X, L, M)$ terá a mesma forma de $F(X, L)$, a energia livere do sistema, a podemos escrever $\triangle A=A(X)-A\left(X^{\prime}\right)=F(X)-$ $F\left(X^{\prime}\right)=\Delta F$, uma medida le $\Delta A$ corresponde a uma medida de $\Delta F$. 
No ponto de transiçäo, $F(X, L)$ possui dois mínimos pronunciados que correspondem às duas fases que coexistem em $X_{1} \in X_{2}$, separadas por um max́ximo em $X_{M}$, que corresponde a configuraçōes como barreiras de domínios entre as duas fases (ver figura (1.2)). Se definirmos agora um campo de escala $g$ que move o sistema ao longo da fronteira de fases, de tal forma que o ponto crítico corresponda a $g=0$, a linha de 1 ordem a $g<0$ e a fase desordenada a $g>0$, podemos expandir $F(X, L)$ na forma

$$
F(X, L)=L^{d} f_{0}(X, g)+L^{d-1} f_{1}(X, g)
$$

onde a densidade de energia livre fó é mínima e constante para $X_{1} \leq X \leq X_{2}$, e o termo de superficie $f_{1}$ possui um maximo em $X_{M}$. Concluimos entăo que $F$ possui mínimos em $X_{1}(L)=X_{1}-O\left(L^{-1}\right)$ e $X_{2}(L)=X_{2}+O\left(L^{-1}\right)$. Já o máximo possuirá altura

$$
\Delta F(L)=F\left(X_{n}, L\right)-F\left(X_{1}, L\right)=B(g) L^{d-1}+O\left(L^{d-2}\right) \quad .
$$

Esta expressão é vălida em transiçöes de 1 a ordem, onde a energia livre apresenta uma estrutura de minimos.

A idểa agora é classificarmos a ordem da transiçāo através do comportamento de $\Delta F$.

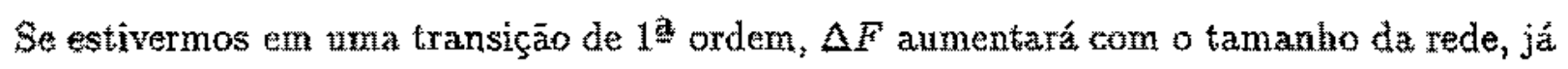
que os minimos tornam-se mais pronunciados, sendo esperado um comportamento com $L^{d-1}$ para tamanhos de rede suficientemente grandes. Já um $\Delta F$ constante corresponde a uma transiçăo de $2^{2}$ orden. Lee e Kosterlitz mostraram que o método pode ser utillizado com sucesso nos modelos de Potts e Ising.

A grande qualidade deste método é o fato dele poder ser utilizado mesmo quardo $L \ll \xi$. Se nos encontramos nas proximidades de um ponto multicrítico, o comprimento de correlaçāo $\xi$ aumeatará, mesmo se a transiçào for de 1 a ordem, inviabializando muitas das técnicas descritas anteriormente.

Talvez a forma mais direta de analisarmos a ordem de una transição de fases seja atravês do comportamento de escala de quantidades físicas como magnetiançẫo, sus- 
ceptibülidade etc. Enquanto que em transiçöes de $2^{\mathrm{a}}$ ordem estas apresentarão um comportamento que dependerá dos expoentes críticos, em uma transiçäo de $1 \stackrel{a}{a}$ ordem esta dependência ocorrerá com potếncias do volume da rede, de acordo com a teoria de Borgs e Kotecký. Mas a situação não é tăo clara, porque a teoria é válida apenas para baixas temperaturas (no Modelo de Ising, ate $T \approx T_{c} / 2$ ), resta ainda entender o comportarnento de escala nas proximidades de um ponto multicrítico. Este estudo nāo foi atể aqui realizado com sucesso, porque para este fim ể necessária a simulação de redes grandes o suficiente para que $L \gg \xi$ e a obtençăo de estados de equilíbrio para redes desta magnitude é virtualmente impossivel, se utilizamos algoritmos convencionais. É netessário que transiçōes entre as diferentes fases possam ser obtidas com facilidade, conforme acontece quando utilizamos algoritmos de cluster.

\subsection{Simulação de Pontos Multicríticos}

Efetuar uma simulaçào nas proximidades de um ponto multicrítico significa enfrentar todos os problemas mencionados até aqui para transiçöes de 1 a e 2 ordem, ao mesmo tempo, além de novos problemas introduzidos pela mistura de eleitos típicos de cada uma das transiçöes.

Explicamos na ûltima seção como utilizar propriedades da distribứção de probabilidades (ou da energia livre do sistema, de forma análoga) de modo a definir o ponto de transiçăo como o ponto onde os máximos possuem a mesma altura. No entanto, nas proximidades de um ponto multicrítico este tipo de análise deve ser efetuado com o máximo cuidado, sendo necessária a utỉlizaçāo de redes bastante grandes para conseguirmos tírar conclusões à respeito do comportamento termodinâmico do sistema.

Isto acontece devido à uma certa mistura entre efeitos típicos de cada espécie de transiçẫo, quando estas se encontram muito próximas. Por exemplo, nas proximidades de um ponto tricrítico uma estrutura com dós picos de energia já ocorre mesmo enquanto 
a transiçào ainda é de 2 à ordem [BS84], é necessấrio uma anălise de tamanho finito com redes bastante grandes para verificarmos que os picos tendem a se colapsar. De forma semelhante, a ausência de efeitos de histerese näo irmplica necessariamente que a transição seja de $2^{\mathrm{a}}$ ordem. Podemos estar lidando simplesmente com urna transiçà fracamente de 1 a ordem, onde ocorre também um aumento do comprimento te correlação 6 , Todos estes fatores tormam bastante delicada a análise do sistema, tornando necessário simular-se redes com dimensäo linear maior que o comprimento de correlação.

Vemos assim qua a simulação nas proximidades de un ponto multicrítico envolve necessarimente a utilizaçăo de redes mäores. Isto representa uma grande limitaça para algoritmos nswais, devido a difouldade experimentata por eles na obtencouto de estados de equlibrio do sistema.

Vamos descrever nesta seção duas técnicas desenvolvidas para a simulą̧äo de pontos tricríticos, em particular para o Modelo de Blume-Capel.

D. P. Landau e R. Swendsen [LS81][LS86] afetuaram um estudo das propriedades tricríticas deste modelo utilizando o formalismo do grupo de renormalizaçăo de Monte Carlo [Ma7o][Swe79!. A localização do ponto tricritico foi obtida através da simulação simultanea de duas redes de tamanhos diferentes, mats com a tatro entre as suas dimensöes lineares igual ao fator de escala da transformagäo do grupo de renormalização. Assim, após termos procedido ama etapa de renormalização da rede maior ficamos com duas redes de igual tamanho, que devem apresentar os mesmos valores parat as funcões de correlaf̧äo, se a Aamiltoniana original sativer em um ponto fxo la tranaformaçāo. A localiząão do ponto tricritico estabelecida como sendo o ponto onde a diferença entre o walor das funços de correlação anula

Outra técnica, baseada em uma forma de escala para a distribuiçäo de probabilidades quando expressa em termos de campos de escala convenientes foi proposta por Bruce e Wilding [BWg2]WMg6]. O procedimento pode ser descrito da seguinte forma, tomando 
como exemplo o Modelo de Blume-Capel:

A partir da funçäo de partíçäo do modelo,

$$
\mathcal{Z}=\sum_{\left(S_{i}\right)} \exp \left[K \phi-\mu \sum_{i=1}^{N} S_{i}^{2}+H \sum_{i=1}^{N} S_{i}\right] \quad S_{i}= \pm 1,0
$$

onde $K K, \mu$ e $H$ sầ definidos em unidades de temperatura, e $\phi=\sum_{\langle i j\rangle} S_{i} S_{j}$, definimos os seguintes observáveis:

A densidade $\rho$,

$$
\rho=L^{-d} \sum_{i} S_{i}^{2}
$$

a densidade de energia,

$$
u=L^{\sim a} K^{-1} \phi
$$

e magnetizaçä,

$$
m=L^{-d} \sum_{i} S_{i}
$$

O comportamento do sistema nas proximidades do ponto tricrítico ê controlado por trếs cumpos de escala [Rie72][LS84], $g, h$ e $h$. Em geral, cada um destes campos é formado por combinaçöes lineares dos campos termodinâmicos $T, \ldots$ w $H$. Como no Modelo de Blume-Capel a energia é invariante por uma inversão no sinal dos spins, sabemos que o ponto tricrítico estará localizado no plano $H=0$, e o campo de escala $h$ coincide corn o tampo magnético $H$. Os outros dois campos de escala, $g$ e $\lambda$, serão ortogonais a $H$, estando localizados no plano $\mu-T$. Escrevemos entâo

$$
\begin{aligned}
& h=H-H_{t} \\
& \lambda=\left(H-\mu_{t}\right)+r\left(K-K_{t}\right) \\
& g=\left(K-K_{t}\right)+s\left(\mu-\mu_{t}\right)
\end{aligned}
$$

onde os subscrito $t$ indica valores teferentes ac ponto tricrítico e os parämetros $t$ e $s$ controlarn a direçäo dos campos $\lambda$ e g. O campo g é escolhido de forma a ser tangente 
à curva de coexistência no ponto tricrítico, o campo $\lambda$ pode assumir qualquer direçäo no plano $\mu-T$ (näo paralela a $g$ ). Defnimos agora operadores de escala na forma

$$
\begin{aligned}
\langle\mathcal{M}\rangle & \equiv L^{-d} \partial \ln Z_{L} / \partial h \\
\langle D\rangle & \equiv L^{-d} \partial \ln Z_{L} / \partial \lambda \\
\langle\varepsilon\rangle & \equiv L^{-d} \partial \ln Z_{L} / \partial g,
\end{aligned}
$$

de onde segue que

$$
\begin{aligned}
\langle\mathcal{M}\rangle & =m \\
\langle\mathcal{D}\rangle & =\frac{1}{1-s p}[\rho-s u] \\
\langle\varepsilon\rangle & =\frac{1}{1-s r}[u-r p] .
\end{aligned}
$$

A idéia é efetuar o seguinte ansatz para o comportamento da distribuição de probabilidades $p_{k}(\rho, u, m)$ no ponto tricrítico (válido para $L$ suficientemente grande):

$$
p_{L}\left(\rho, z_{1}, m\right) \simeq \frac{1}{1-s r} p_{L}^{*}\left(a_{1}^{-1} L^{d-y_{1}} M_{3} a_{2}^{-1} L^{d-y_{2}} D_{1}, a_{3}^{-1} L^{d-k_{1}} \varepsilon\right) \quad,
$$

onde pla uma funçẫo universal invariante por escala, que caracteriza o ponto tricrítico. $a_{i}$ săo fatores métricos nāo universais e y̆ săo expoentes tricríticos.

O ponto tricrítico pode ser obtido agora através do cumulante de quarta ordem,

$$
U_{L}=1-\frac{\left.<m^{4}\right\rangle}{\left.3<m^{2}\right\rangle^{2}}
$$

A invariância por escalas da distribuiçäo $p_{L}$ implica que no ponto tricrítico o cumulante $U_{L}$ será igual para todos os tamanhos de rede.

Na prătica, determinamos inicialmente a linha de transição de 1 a ordem e a sua extensão analítica (regiäo onde a linha já năo $e$ física), localizando entāo o ponto sobre a linha oxde o cunulante $U_{L}$ tornarse invariante por escalas. A linha de $1^{\text {a }}$ ordem é 
encontrada atravĕ́s do método de histogramas, para um dado valor de $T$ fixo ajustamos os valores de $D$ e $s$, até que a distribuiçäo $p_{L}(\mathcal{D})$ torne-se simétrica em $\mathcal{D}-\langle\mathcal{D}\rangle$.

Atrayếs deste mếtodo, e utilizando redes quadradas de dimensōes lineares entre $L=1.2$ $e L=40$, Wilding e Nielaba [WN96] encontraram os seguintes valores para a localizaçäo do ponto tricrítico: $D_{t}=1.9665(3)$ e $T_{t}=0.608(1)$, em excelente acordo com os resultados de Landau e Swendsen, $D_{t}=1.965(15)$ e $T_{t}=0.609(3)$, e com resultados através de cálculos com matrizes de transferência, $D_{t}=1.965(5)$ e $T_{t}=0.610(5)$ [Bea86]. Ao que parece, o método näo é täo sensível a problemàs de tamanho finito mencionados anteriormente, uma vez que o tamanho das redes simuladas é relativamente pequeno. Ressaltamos que, mesmo para estes tamanhos de rede, estatísticas bastante elevadas (20 milhões de passos de Monte Carlo) foram necessárias para a obtençāo de estados de equilíbrio, uma yez que a simulação foi efetuada com o algoritmo de Metropolis usual. 


\section{Capítulo 2}

\section{Algoritmos de Cluster - Possíveis Abordagens}

Neste capitulo discutiremos possiveis abordagens para a formulação de algoritmos de clusters, tomando como referencial o Modelo de Ising.

Foi para o estudo deste modelo que Swendsen e Wang propuseram o seu atgoxitmo [SW87], conhecido agora como algoritmo de Swendsen-Wang, que utiliza um mapeamento do Modelo de Potts en um Modelo de Percolaçăo descoberto por Fortuin e Kasteleyn em 1969 [FK72] como uma nova forma de efetuar-se simulaşos de Monte Carlo do modelo. Mostraremos aqui como escrever a funçăo de partiçăo do modelo de forma a realizarmos a simulação numérica através de algoritmos de clusters, e também como chegar ao mapeamento em um modelo de percolação. Utilizaremos para este fim de uma combinaçầo entre as abordagens elaboradas por Sokal [\$S96] e por Hu [Hu84], que toma a prova bastante elegante e simples. Esta será tanbẻn a aboráagem utilizada por nós em outros capitulos, no descrevermos o mapeamento do Modelo de Blume-Capel e de Ashkin-Teller.

Descreveremos aqui também uma variante do Algoritmo de Swendsen-Warg conhecida como algoritmo de Wolff, desenvolvida por $\mathrm{U}$. Wolf em 1989 [Wol89], e que pode ser interpretada como um algoritmo de Swendsen-Wang com dinâmica modificada. Ao con- 
Algoritmos de Cluster - Possiveis Abordagants

trário do Algoritmo de Swendsen-Wang, năo é necessária aquỉ uma prova de mapeamento, trabalhamos apenas com a condição de balanço detalhado. Este algoritmo é muito mais fácil de ser implementado na prática, além de ter desempenho melhor que o de SwenđsenWang em dimensöes maiores que dós. Ele nos fornece também uma grande maleabilidade na forma de definirmos as probabilidades de formaçăo de clusters, o que levanta a questão sobre qual probabilidade resulta em uma dinâmica mais eficiente, o qual o sìgnificado desta probabilidade especial.

A generalizaçäo destes algoritmos para outros modelos não é de forma alguma trivial, tendo cada caso de ser examinado em particular. Diversas formulaçöes foram sugeridas de forma a possibilitar a aplicaçäo destes algoritmos em outros modelos, mas surge aqui um novo problema, de que muitas vezes as formulaçoes encontradas resultam em dinâmicas pouco eficientes. Descreveremos aqui duas sugestoes diferentes, uma de Niedermayer [Nie88] e outra de Brower e Tamayo [BT92], conhecida como algoritmo de embedding.

Uno grande axanço na compreensāo do porquê de certas definiçōes de clusters funcionarem na prâtica enquanto que outras não, mesmo satisfazendo à condição de balanço detalhado, foi obtido atravès de um trabalho de Kandel e Domany [KD91], que propuseram um formalismo geral para a elaboração de algoritmos de cluster. Através deste formalismo podemos encontrar as diversas formas possiveis de tranformarmos um modelo de spins em um modelo de ligaçöes, e também nos fornece algumas indicaçöes dos motivos que tornam algumas formulaçöes eficientes ou näo.

No entanto, esta formulação está longe de nos dar uma forma fechada de como descobrir qual o algoritmo de cluster apropriado para uma dado modelo, enn geral ela nos fornece apenas os valores das probabilidades de modo que a condiçắo de balanço detalhado seja satisfeita, mas estes valores dependem de qual tipo de ligaçöes estamos considerando, o que deve ser decidido com base em consideraçōes fisicas sobre o modelo.

Como uma forma de exitat-se esta ambiguidade, Cattaudella et al. [CFN+94] sugetiram 
que fosse utilizata como condiçäo adicional que as probabilidades de ligação fossem definidas de forma tal que a transiega de percolaçäo do algoritmo proposto coincidisse com a transição ternodinâmica. Isto de fato $\mathrm{E}$ o que acontece no Modelo de Ising quando efetuamos o mapeamento em um nodelo de percolaçăo, ê um dos problemas encontrados na simulayaño de vidros de spin: se utilizamos uma probabilidade de ligagäo ignal a do modelo de Ising as duas transiçôes näo coinciden, e performance do algoritmo é bastante fraca.

Apresentaremos neste capítulo todas estas técnicas desenvolvidas para a criaça de algorimos de cluster, e que seräo utilizadas em capítulos posteriores como guia para a elaboração de algoritmos eur outros modelos. Discutiremos tamberm os motivos que tornam algumas formulaçōes ineficientes, e como evitar que isto aconteça.

\subsection{Algoritmo de Wolff para o Modelo de Ising}

A Hamiloniana do Modelo definida por

$$
\beta H=-K \sum_{\langle i j\rangle} \sigma_{i} \sigma_{i}, \quad \sigma_{i}= \pm 1
$$

onde a somntória é sobre primeiros vizimhos, e $\beta=1 / \mathrm{h}_{\mathrm{z}} T$.

O algoritmo consiste das seguintes etapas:

1. Sorteamos um spin da rede, chamado de spin semente, por ser o primeiro spin a pertencer ao cluster. 


\section{(1)}

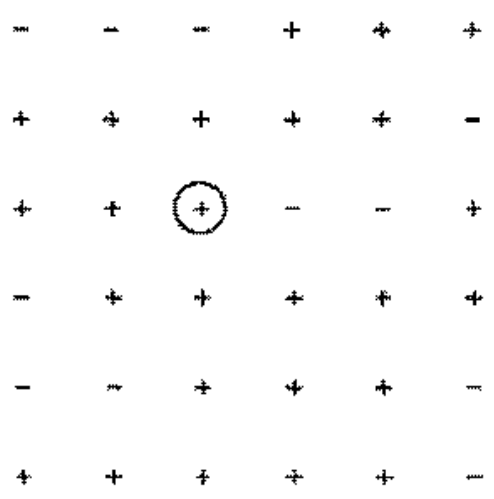

2. Ligamos spins vizinhos que possuem o mesmo sinal do spin semente com probabilidade $p=1-\exp (-2 K)$. Cada spin ligado é um novo spin pertencente a cluster.

(2)

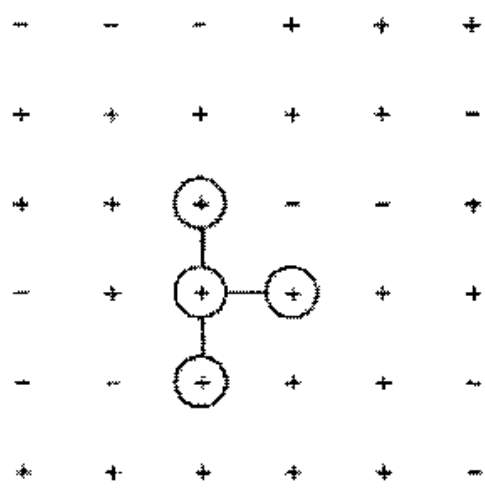


3. Ligatuos os vizinhos dos novos spins pertencentes ao cluster com probabilidade igual a do 㲅em anterior.

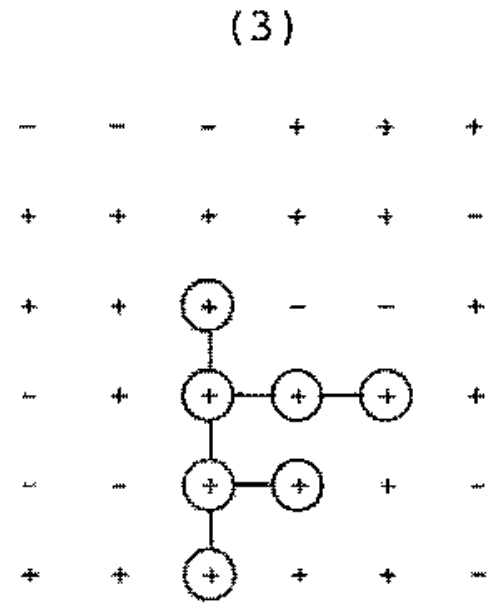

4. Continuamos este processo até que nāo existam mäis novos vizinhos a serem considerados.

(4)

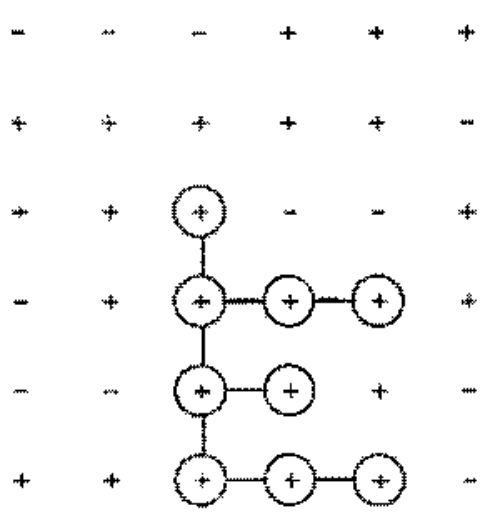


5. Invertemos o sinal dos spins pertencentes ao cluster, com probabilidade $W_{v}=1$.

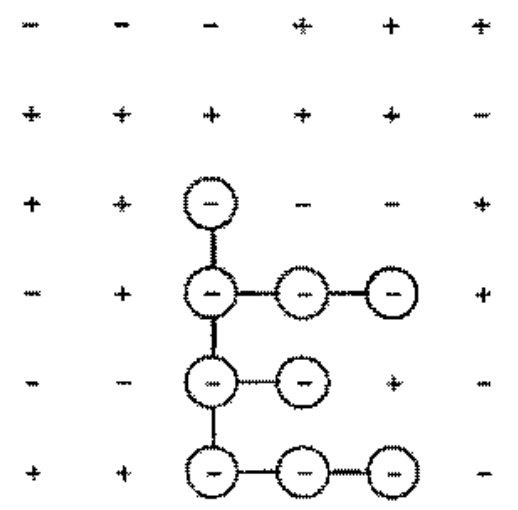

6. A partir da nova configuração de spins obtida reiniciamos o processo, a partir da etapa 1 .

Para que este algoritmo simule as propriedades de equilibrio do modelo é suficiente que ele obedeça a condição de balanģo detalhado:

$$
W\left(\sigma \rightarrow \sigma^{\prime}\right) e^{-\beta h(\sigma)}=W\left(\sigma^{t} \rightarrow \sigma\right) e^{-f \beta\left(\sigma^{\prime}\right)}
$$

ov.

$$
\frac{W\left(\sigma \rightarrow \sigma^{\prime}\right)}{W\left(\sigma^{f}-\sigma\right)}=e^{-\beta \Delta \mathcal{H}}
$$

Vamos começar analisando a diferença de energia entre as configuraçôes inicial e a. final. Notando que a energia interna do cluster năo se modifica após a inversão do sinal de seus spins, e que o restante da rede nâo é modificado, concluimos que a diferença de energia será devida apenas à ligaçoes no contorno do cluster. Assim,

$$
\exp \{-\beta \Delta H\}=\exp \left\{-2 K\left[l_{++}(\partial C)-l_{++}^{t}(\partial C)\right]\right\} \quad
$$


onde $\partial C$ é a superfície do cluster, constituida por vizinhanças entre sítios no cluster e sítios fora do cluster, $l_{++}(\partial C)$ e $l_{++}^{t}(\partial C)$ é o número de vizinhanças entre spins iguais no contorno do cluster, nas configuração inicial e final, respectivamente.

Por outro lado, a probabilidade de transição de um cluster para outro pode ser escrita na forma

$$
W\left(\sigma \rightarrow \sigma^{\prime}\right)=W_{C} W_{v} \prod_{\langle i j>\in \nexists C}\left[1-p\left(\sigma_{i}, \sigma_{j}\right)\right]=W_{C} W_{v} e^{-2 K l_{++}(\partial \mathcal{C})}
$$

onde $C$ significa cluster, $W_{C}$ é a probabilidade de ligarmos os spins do cluster e $W_{w}$ e a probabilidade de virarmos o cluster (que neste caso é igual a um).

Como todos os spins do duster possuem o mesmo sinal, tanto na transiç̃̃o direta quanto na reversa, a probabilidade de ligarmos o cluster ê igual em ambas as transiçöes. A probabilidade de virarmos o cluster também é igual, de modo que na equaçäo (2.3) só devemos considerar o termo da produtória no contorno do cluster, que representa a probabilidade de näo ligarmos o cluster com a sua vizimhança. Observamos entāo que a probabilidade de ligaçâo for escolhida de forma tal a termos obedecida a condição de balanço detalliado.

O algoritmo deve também ser ergódico, o que de fato acontece, porque é sempre possivel criarmos un cluster constituiflo por apenas um spin, o que garante que qualquer configuraçāo de spins possa ser obtida.

No entanto, esta não é a única formulação possível para um algoritmo que traballhe com a criação de um tinico cluster no nodelo de Ising. Por exemplo, poderiamos ter optado por ligarmos também spins diferentes, definindo as probabilidades de ligação da seguinte forma:

$$
\begin{aligned}
& p_{i g}=1-\exp (-3 K) \\
& p_{d i f}=1-\exp (-K)
\end{aligned}
$$


Isto é possivel porque o que importa é que a razt̃o entre a probabilidade de não ligarmos o cluster com a sua vizinhança na transições direta e inversa seja igual a diferença de energia entre estas configuraçoes. Para as probabilidades tomadas como exemplo isto seria obtido da seguinte forma:

$$
\frac{W\left(\sigma-\sigma^{\prime}\right)}{W\left(\sigma^{\prime}-\sigma\right)}=\frac{e^{-3 K_{++}(\partial C)} e^{-K t_{+}(\partial C)}}{e^{-3 K_{++}(\partial C)} e^{-K t_{+-m}(\partial C)}}
$$

onde $t_{+-}$é o número de vizinhanças entre spins diferentes. Observando que

$$
\begin{aligned}
& l_{+-}^{t}=l_{++} \\
& l_{+\ldots}=l_{+4}^{t}
\end{aligned}
$$

vemos que o equilbrio com a diferença de energia entre as configuraçöes continua a ser obedecido.

Notamos assim que o fato de que apenas a razão entre as probabilidades importar na prova de balanço detalhado nos permite deffuir as probabilidades de ligaçăo de um nûmero infinito de formas diferentes.

Mas isto é uma falsa liberdade: na prática resulta que a probabilidade de ligação que une apenas spins iguais é a única que conduz a simulações effcientes. Quando utilkamos outras probabilidades, cono a definida acima, o que acontece é que os clusters formados tornam-se muito grandes, alterando praticamente todos os spins da rede, e efetivamente não modificando quase nada.

que a probabilidade $p=1-\exp (-2 K)$ tem de especial á que ela corresponde a probabilitade encontrada quando mapeanos o Modelo de Ising en um modelo de percolaçäo. Assim, a liberdade fornecida pelo algoritmo de Wolff é ilusória, para conseguirmos uma simulação eficiente é necessário que os clusters formados possuann uma transiçăa de percolação que coincida cơn a transiçăo termodinâmica do modelo estudado. 


\subsection{Algoritmo de Swendsen-Wang para o Modelo de Ising}

Em 1987, Swendsen e Wang inventaram uma forma radicalmente nova de efetuar-se simulaçōes numéricas [SW87], baseados em um trabalho de Fortuin e Kastelyn [FK72], que mapearam o Modelo de Ising em um modelo de percolaçăo. Mostraremos nesta seção como este mapeamento pode ser obtido, e como obter o algoritmo de Swendsen e Wang a partir dele. Para isto, utilizaremos uma abordagens introduzidas originalmente por Sokal [SS96] e por Hu [Hu84], e que serăo utilizadas em outros modelos estudados nesta tese.

A funçăo de partiçäo do Modelo de Ising é dada por

$$
z=\sum_{\{\alpha\}} \exp (-\beta \mathcal{H})=\sum_{\{\sigma\}} \exp \left(K \sum_{\langle i j\rangle} \sigma_{i} \sigma_{j}\right) \quad
$$

Podemos reescrever $\boldsymbol{Z}$ da seguinte forma:

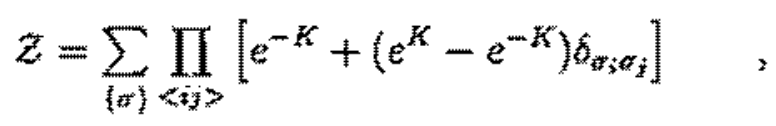

ou

$$
\begin{aligned}
& z=\sum_{\{\sigma\}\langle i j\rangle} \prod_{\langle K} e^{K}\left[e^{-2 K}+\left(1-e^{-2 K}\right) \delta_{q_{i} \sigma_{j}}\right] .
\end{aligned}
$$

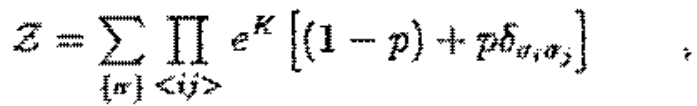

onde $p=1-e^{-2 K}$. O fator $e^{K}$ que aparece na última expressâo é uma constante, sendo portanto desconsiderado daqui por diante (podemos pensar que redefinimos a Hamiltoniana original, acrescentando uma constante de forma tal que o estado fundamental tenha energia zero).

Vamos introduzir agora, em cada vizinhança $<$ ij $>$, uma variável extra $n_{i j}$, que pode 
assumir valores $\pi_{i j}=0$ e 1. A funçäo de partịăa (2.12) pode ser reescrita como

$$
\mathcal{Z}=\sum_{\{p\}} \sum_{\{n\}} \prod_{\langle i j\rangle}\left[(1-p) \delta_{n_{i, j, p}}+p \hat{\delta}_{n ; j, 1} \delta_{\sigma_{i} \sigma_{j}}\right]
$$

Podemos considerar que a variảvel $\{n\}$ representa a existência (ou näo) de uma ligação entre os sítios $\langle i j\rangle,(1=$ ligado, $0=$ ligação ausente $)$. Chamaremos esta função de partição de função de partị̧̧̃o conjunta, e é com respeito a ela que definiremos o algoritmo de Swendsen-Wang para o Modelo de Ising, que consiste das seguinte etapas:

1. Varremos toda a rede criando ligaçôes entre sitios vizinhos a $j$ com probabilidade $p=1-e^{-2 K}$, se $\sigma_{i}=\sigma_{j}$. Se a ligaçäo for aceita, associamos ao par àj uma variável de ligação $n_{i j}=1$. Caso contrário, näo haverá ligação, e $n_{i j}=0$.

2. Identificamos clusters como conjuntos de sitios conectados por ligações $n_{i j}=1$, ou sítios isolados. Dois sítios estäo no mesmo cluster se existe um caminho de ligaçōes entre eles. Desta forma cada spin da rede pertence a un cluster no final do processo.

3. Para cada cluster associamos uma nova variável de Ising, sendo que os dois valores possiveis possuem igual probabilidade $(p=1 / 2)$.

4. Após termos associado novos valores de Ising para cada cluster, repetimos o processo, a partir da etapa 1.

Se somamos sobre a vaxíavel de ligaçăo $n$ voltamos ao Modelo de Ising original. $O$ que acontece se somamos sobre a variảvel de spin?

Ao efetuarmos ssta soma, devemos notar que sítios conectados por ligações $\pi_{\text {ì }}$ devem ter o mesmo sinal de spin, devido a presença do vínculo $\delta_{\sigma_{i} \mu_{j}}$. Assim, cada cluster (conjunto de spins conectadas por ligaçöes) possuí apenas dois estados possíveis, e a funçăo de partição passa a ser dada por 


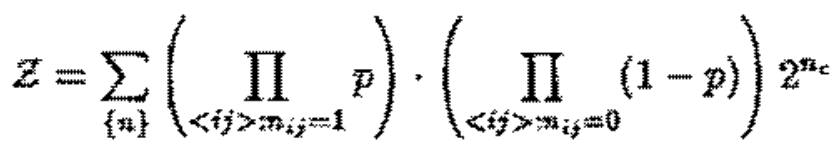

onde $n_{\varphi}$ é o nimero total de clusters to que inclui clusters formados por apenas um spin). Eliminamos assim a variăvel de spin, e esta 6 a funçäo de partiçāo do chamado Modelo de Clusters handômicos (random-cluster model). Este um modelo de percolaçäo generalizado, que corresponderia a um modelo de percolaçäo de ligaçöes usual se tivéssemos apenas um estado de spin possivel. A presença do termo $2^{\mathrm{n}^{*}}$ introduz correlaçōes năo locais no modelo de percolaçũo.

O que o algoritmo de Swendsen-Wang faz é gerar configuracöes com peso estatistico dado pela função de particto $(2,13)$, criando alternadamente noyas configuraços de ligaçōes a partir de configuraçốes de spins, e novas configuracốes de spins a partir de configuraçōes de ligaçöes.

Vimos assim que é possivel mapear o modelo de Ising em um modelo de percolaçä̀, e que podemos utilizar a função de partição conjunta dos dois modelos para a elaboraçäo de um algoritmo de cluster.

A mesma ambiguidade encontrada na defniçăo das probabilidades de ligaça para $o$ algoritno de Wolff tambem acontece aqui. Por exemplo, podemos reescrever a Hamilto niana ma forma

$$
\beta H=-\frac{3 K}{2} \sum_{\langle i j\rangle} \sigma_{i} \sigma_{j}+\frac{K}{2} \sum_{\langle i j\rangle} \sigma_{i} \sigma_{j}
$$

o que resultaria, se seguirmos o mesmo formalismo utilizado acima, em um modelo de percolacäo com duas probabilidades diferentes,

$$
\begin{aligned}
& p_{z y}=1-e^{-3 k} \\
& p_{\text {dif }}=1-e^{-K}
\end{aligned}
$$

onde $p_{i j}$ é a probabilidade de ligarmos spins iguais, a $p_{d i f}$ a probabilidade de ligarmos 
spins diferentes. Formulamos assim o mapeamento de forma a obter probabilidaces de ligaçäo alternativas equivalentes as citadas anteriormente para o algoritmo de Wolf, e concluimos que aqui também existem infinitas formas de efetuarmos o mapeamento.

\subsection{Mapeamento do Modelo de Ising - Abordagem de $\mathrm{Hu}$}

Nesta seçäo apresentaremos outra forma de se mapear o modelo de Ising em um modelo

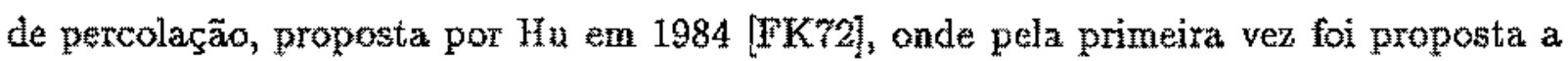

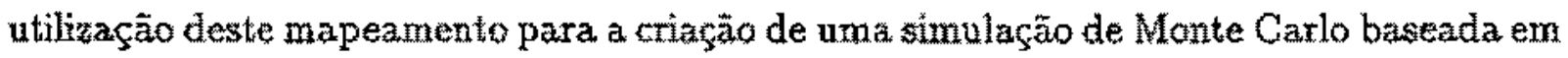
clusters. A formulaçäo de Hu é bastante apropriada para o cálculo de propriedades físicas do modelo de Ising e será utilizada por nós também no cáleulo de propriedades físicas do modelo de Blume-Capel, quando expresso em termos de um modelo de percolaçăo.

A funçäo de partiçäo para o Modelo de Ising na presença de um campo magnético pode ser escrita como

$$
Z_{N}(K, B)=\sum_{(0)} \exp \left[\sum_{\langle i j\rangle} K\left(\sigma_{i} \sigma_{j}+1\right)+B \sum_{i} \sigma_{i}-2 K N_{b}\right]
$$

onde $N_{i}$ é número de vizinhança no grafo $G$, que é o conjunto de todos os sitios e todas as ligacös. $B=H / h_{\text {g }}$, onde $H$ é o campo magnético aplicado. Redefinimos anergia. do sistema de forma que ela se anule para $T=0$, quando $B=0$. Podemos reescrever esta expressão como

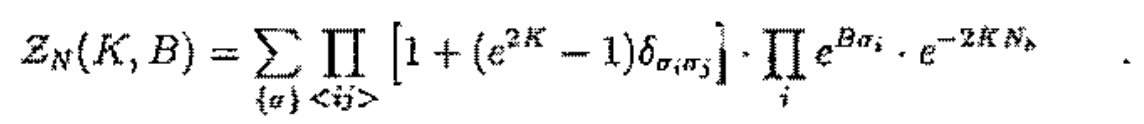

Vamos expandir agora a produtóna sobre ligaças $<i j>$ a unilizar subgrafos $G^{\prime} \subseteq G$ $(G$ e um subgrafo de $G$ onde nem todas as ligaçöes estäa presentes) para representar os termos da expansäo

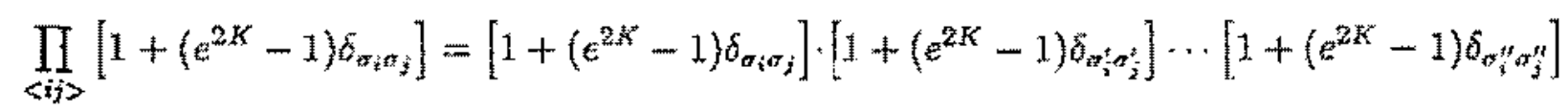




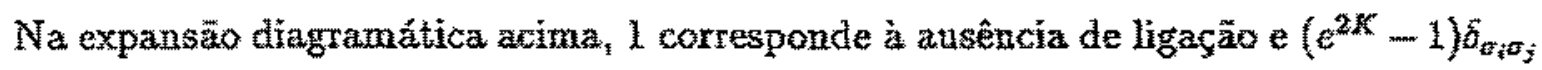
à presença de ligaçäo. Por exemplo, uma rede sem nenuma ligaçäo corresponde a um produto de $1 \%$. Um subgrafo com apenas uma ligaçäo entre os sitios $i^{\dagger}$ e corresponde a $\left[(1)^{N_{b}-1}\left(e^{2 K^{\prime}}-1\right) \delta_{\sigma_{i}^{\prime} \sigma_{j}^{\prime}}\right]$, e assim por diante. Na figura 2.1 representamos um possivel subgrafo $G$ em uma rede $G 4 X 4$.

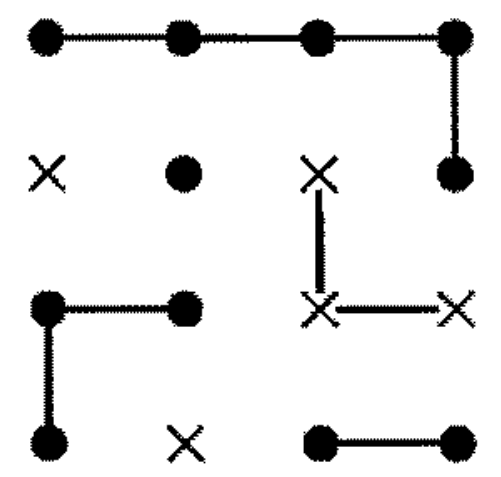

Figura 2.1: Possivel subgrafo $G^{\prime}$ em nma rede $G 4 X 4$. X e representam diferentes estados de Ising.

Se dois sitiog estão conectados através de uma sequeüncia de ligacoes, dìnemos que eles pertencem ao mesmo cluster. $O$ termo $\delta_{\sigma_{j} \sigma_{j}}$ impöe que spins pertencentes ao mesmo cluster possuarn o mesmo sinal. Ao efetuarmos a soma sobre todos os possiveis estados de spin de um subgrafo $G^{\prime}$, aperas termos onde todos os spins de um cluster possuem 0

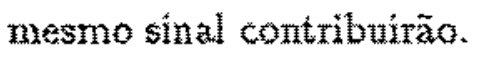

A expressäo (2.18) pode ser recercita então da seguinte forma:

$$
Z_{N}(K, B)=\sum_{G^{\prime} G O} p^{\mu\left(\sigma^{\prime}\right)}(1-p)^{N_{b}-u\left(G^{\prime}\right)} \prod_{\epsilon} 2 \cosh \left[B n_{c}\left(G^{\prime}\right)\right]
$$

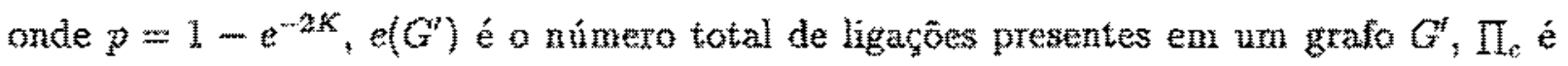
uma producoria sobre todos os clusters existentes em $C^{*} n_{e}\left(C^{\prime}\right)$ é o mumero de sítios do cluster $c$. 
A partir desta expressào podemos calcular a magnetizaçäo, definida por

$$
M(G, p)=\lim _{B \rightarrow 0} \lim _{N \rightarrow \infty} \frac{1}{N} \frac{\partial}{\partial B} \ln Z
$$

ou

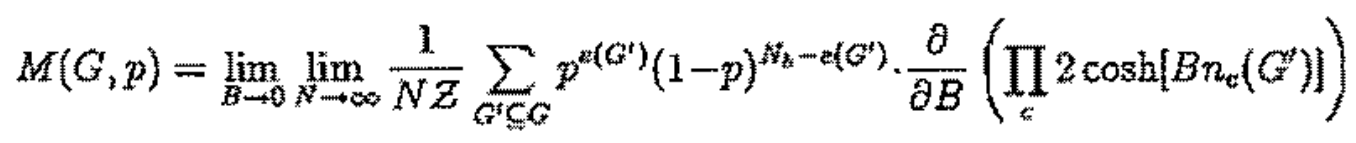

Ao derivarmos em relação a $B$ o termo com a produtória sobre todos os clusters, obtemos a seguinte contribuicào:

$$
\begin{aligned}
\frac{\partial}{\partial B}\left(\prod_{c} 2 \cosh \left[B n_{6}\left(G^{\prime}\right)\right]\right)= & \left(2 \sinh B n_{1}\right) n_{1}\left(2 \cosh B n_{2}\right) \cdots\left(2 \cosh B n_{c}\right)+ \\
& +\left(2 \cosh B n_{1}\right)\left(2 \sinh B n_{2}\right) n_{2} \cdots\left(2 \cosh B n_{c}\right)+ \\
& +\cdots+ \\
& +\left(2 \cosh B n_{1}\right)\left(2 \cosh B n_{2}\right) \cdots\left(2 \sinh B n_{c}\right) n_{c}
\end{aligned}
$$

Quando $B \rightarrow 0, \sinh \left(B \pi_{i}\right) \rightarrow 0$, e apenas contribuiçöes de clusters com um número infinito de spins näo se amulam. Encontramos desta forma que

$$
M=\lim _{N \rightarrow \infty} Z^{-1} \sum_{\sigma^{*} \subseteq Q} \Pi\left(G^{*}, p\right) \frac{N^{*}}{N}
$$

onde $\Pi\left(G^{*}, p\right)=p^{\alpha\left(O^{\prime}\right)}(1-p)^{N_{k}-\left\{\left(G^{\prime}\right)\right.} 2^{x_{*}\left(\sigma^{\prime}\right)-1}$, e $N^{*}$ ê o número total de spins que pertencem aos clusters que percolan. A expressä́ acima mostra que a magnetizaçào no Modelo de Jsing é igual a probabilidade de um sitio da rede pertencer a um cluster que percola.

A susceptibilidade magnética é dada por

$$
x(G, p)=\lim _{B \rightarrow 0^{+}} \lim _{N \rightarrow \infty} \frac{1}{N} \frac{\partial^{2}}{\partial B^{2}} \ln Z
$$

e pode ser expressa como

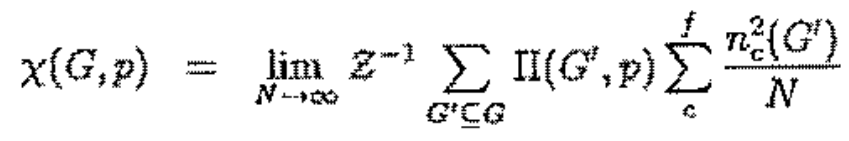

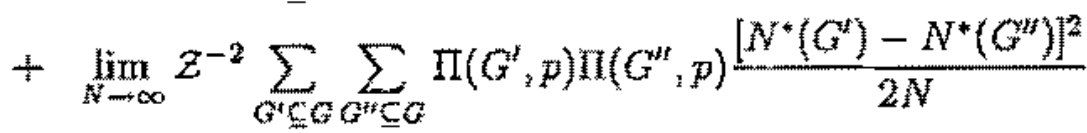


onde $\sum_{c}^{f}$ é uma soma sobre todos os clusters que não percolam. O primeiro termo desta expressäo é o tamanho médio de um cluster escolhido aleatoriamente na rede. O segundo termo se anulará sempre que a probabilidade de ligação p for menor que a probabilidade de percolaça $p_{s .}$ Mesmo para $p>p_{c t}$ podemos argumentar que a contribuição deste termo será finita, porque termos que contribuiräo para a soma possuiräo valores de $N^{*}$ diferentes no máximo por $\sqrt{N}$, e a contribuiçāo permanece finita. Desta forma, a susceptibilidade é dada pelo tamanho médio dos clusters finitos, e ambas quantidades possuem o mesmo expoente crítico.

. H. possível também encontrar uma relação entre a funç̧ăo de conectividade entre pares no modelo de percolaçāo e a função de correlaçāo entre spins. Esta ê dada por:

$$
\left\langle\sigma_{a} \sigma_{b}\right\rangle=\frac{1}{\mathcal{Z} N(K, B)} \sum_{\sigma} \prod_{<i j ; \infty}\left[1+\left(e^{-2 K}-1\right) \delta\left(\sigma_{i}, \sigma_{j}\right)\right] \sigma_{a} \sigma_{b} \cdot \prod_{i} \exp \left(B \sigma_{i}\right) \cdot e^{-2 K N_{b}}
$$

Podemos expandir em grafos esta produtớria de forma completamente anăloga a eletuada anteriormente. Se ss sítios $a$ e $b$ pertencerem ao mesmo cluster de $G^{*}$ eles teräo a mesma componente de spin ${ }_{3}$ e $\sigma_{n} \sigma_{b}$ é igual a 1 . Se eles pertencerem a clusters diferentes, $\sigma_{a} \sigma_{b}$ é igual a 1 ou -1 com igual probabilidade, e a contribuiçăo deste grafo $G^{\prime}$ para a somatótia é zero. Encontramos assim que, para $B=0$,

$$
\left\langle\sigma_{a} \sigma_{b}\right\rangle=\lim _{N \rightarrow+\infty}\left[\sum_{a^{\prime} \subseteq G} p^{r\left(G^{\prime}\right)}(1-p)^{N_{b}-e\left(G^{\prime}\right)} 2^{n_{t}\left(G^{\prime}\right) \cdots 1} \delta\left(c_{a}, c_{b}\right)\right] / \mathcal{Z}
$$

onde $b\left(c_{n z}, c_{n}\right)$ é igual a 1 quando $a$ e $b$ estāo no mesno cluster, e zero quando estäo em clusters diferentes. A expressäo no lado direito desta igualdade alada mais o do que a funçâo de conectividade entre pares do modelo de percolação. Concluinos entäo que os expoentes $\nu_{p}$ e $\nu_{p}$ para o comprimento de correlaçăo nas proximidades de $p_{t}$ e $\eta_{p}$ para a função de conectividade entre pares nás proximidades de $p_{c}$ são iguais aos valores correspondentes no Modelo de Ising. 
Com este formalismo é possível mostrar também que a energia interna e o calor específico sẫo proporcionais ao número médio de ligaçóes el( $\left.G^{\prime}\right)$ e as thutuaçōes de $e\left(G^{\prime}\right)$, respectivamente.

A abordagem de $\mathrm{Hu}$ é uma forma elegante $e$ simples de ae obter o mapeamento do modelo de Ising em um modelo de percolaçẫo, chamado por Hu de Modelo de Percolaçāo de Ligaçöes Correlacionadas.

\subsection{Análise dos Algoritmos}

É possivel interpretar o algoritmo de Wolff como sendo um algoritmo de SwendsenWang modificado, onde após termos construido todos os clusters sorteamos um sítio da rede de forma aleatória e modificamos os spins deste cluster com probabilidade $W_{v}=1$.

Como consequência, o algoritmo de Wolff trabalhará a maior parte do tempo com os clusters de maior tamanho, porque a probabilidade de sortearmos um dado cluster é proporcional ao seu tamanho. Isto ajuda a entender porque este algoritmo possui expoente crítico dinâmico $z$ menor que o do algoritmo de Swendsen-Wang em dimensões maiores do que dois, já que estes sāo os clusters mais relevantes nas proximidades de uma transição de segunda ordem, por refletirem o aumento do comprimento de correlaçăo.

Interpretando o algoritmo de Wolf desta forma, podemos deduzir também a mesma relação encontrada no algoritmo de Swendesen-Wang, entre a susceptibilidade magnética do Modelo de Ising e o tamanho dos clusters formados. A menos de fatores constantes, a susceptibilidade é dada na regiäo paramagnética por

$$
x=\frac{1}{L^{d}}\left\langle\left(\sum_{k} \sigma_{k}\right)^{2}\right\rangle
$$

onde $L$ é a dimensäo linear do sistema, $d$ é a dimensāo e a somatória é sobre todos os spins da rede. Esta expressäo pode ser reescrita como

$$
x=\frac{1}{L^{d}}\left\langle\left(\sum a_{*} c_{x}\right)^{2}\right\rangle
$$


onde 2 te um rốtulo para os clusters, $c_{x}$ é o tamanho do chster $x$ e $a_{x} \dot{e}$ uma variável que pode assumir os valores \pm 1 , dependendo do sinal dos spins que formam o cluster. Desta forma, a susceptibilidade passa a ser dada por

$$
x=\frac{1}{L^{d}}\left(\sum_{x, y} a_{x z} a_{y} c_{x} c_{y}\right)
$$

Como o sinal dos spins de cata chuster não depende do sinal dos outros clusters (os clusters năo interagem entre si) $<a_{x} a_{y}>=\delta_{x y y} e$

$$
x=\frac{1}{L^{n}}\left\langle\sum_{x} c_{x}^{2}\right\rangle=\left\langle\sum \frac{c_{x}}{L^{4}} c_{x}\right\rangle
$$

Por outro lado, a probabilidade de sorteamos um dos clusters de Swendsen-Wang formados é dada por $\frac{t}{z^{t}}$, portanto o tamanho médio do cluster $\dot{e}$

$$
<c>=\left\langle\sum_{x} \frac{c_{x}}{L^{d}} c_{x}\right\rangle
$$

Conchumos então que a susceptibilidade é igual ao tamanho médio dos clusters formados pelo algoritmo de Wolf, da mesma forma que para o algoritmo de Swendsen-Wang.

Uma consequência direta desta relaçầ é que podemos encontrar una leí de escala para o tamanho dos clusters formados. Escrevendo a susceptibilidade como

$$
\chi=\frac{1}{L^{d}} \sum_{i j}\left\langle\sigma_{i} \sigma_{j}\right\rangle=\langle c\rangle
$$

e levaudo em conta que para $T \rightarrow T_{a}$ a função de correlaça entre pares apresenta 0 comporamento crítico

$$
\left\langle\sigma_{i} \sigma_{j}\right) \propto \frac{1}{T^{a-2+1}}
$$

concluimos que o tamanho médio dos clusters formados obedece a lei de escala

$$
\text { (c) } \propto L^{2-\eta}
$$

ou seja a dimensão de Hausdort dos clusters formalos é dada por $D=2-7$. 
O fato da probabilidade de ligaçäo $p=1-e^{-2 \kappa \delta_{\sigma_{i} \sigma_{j}}}$ ser a especial probabilidade que faz com que as transições de percolação e termodinâmica coincidam resulta em diversas consequências físicas desejáveis. Por exemplo, se estivéssemos ligando tambếm spins diferentes, da forma sugerida em seções anteriores, não teriamos encontrado uma relaçăo entre a magnetizaçăo do modelo de Ising e a probabilidade de um dado spin pertencer a um cluster que percola, ou que a susceptibilidade é dada pelo tamanho médio do cluster, porque o argumento apresentado acima não seria vălido (os spins do cluster não possuiriam todos o mesmo sinal).

Fica claro entâo que para a simulação do modelo de Ising esta é a probabilidade conveniente, e que o critério a ser seguido é o de que as transíçóes de percolação e termodinâmicas devem coincidir.

No extanto, a utilizaçäo desta probabilidade em modelos tipo vidros de spin resulta bastante insatisfatória, porque devido a presença de interaçôes antiferromagnéticas e a impossibilidade de satisfazer-se certas ligaçôes (ligaçōes frustradas), as transiçōes de percolação e termodinâmicas deixam de coincidir. É interessante dispormos então de um método que gos permita variar o tamanho dos clusters formados. Vamos analisar aqui de forma mais metódica como podemos variar as probabilidades de ligaçẳo, seguindo a formulação original de Niedermayer [Nies8].

Tomando como exenplo o modelo de Ising, onde a energia de par de spins i e $j$ é dada por

$$
\beta E_{i j}=-K s_{i} s_{j}
$$

e considerando que podemos ligar tanto spins iguats $P(-K)$ quanto spins diferentes $P(K)$, vamos analisar a condiçäo de balanço detalhado, da mesma forma que no algoritmo de Wolff. Tomando como referência duas configuraçōes que diferem apenas por uma inversão do sinal dos spins pertencentes a um dado cluster, e levando en conta que a probabilidade de ligarmos o cluster ê igual nas transiçōes direta e reversa, concluimos que devemos 
ardisar apenas a regiäo de fronteira antre o cluster o restante da rede. Supondo que nesta fronteira existam $m$ spins paralelos e m spins antiparalelos (e o contrário depois de invertemos o sinal dos spins do cluster), encontramos que a condiça de balanço detalhado dada por

$$
\frac{W_{v}\left(\sigma \rightarrow \sigma^{\prime}\right)}{W_{v}\left(\sigma^{\prime} \rightarrow \sigma\right)}=\left[e^{-2 K} \frac{1-P(K)}{1-P(-K)}\right]^{n-m}
$$

Nos algoritmos utilizados até aqui, denininos $P(K)=0$ e $P(-K)=1-e^{-2 K}$, o que toma o lado direito da expressāo acima igual 1 , e portanto podemos abribuir qualquer valor para as probabilidades de transiçāo $W_{y}$, desde que iguais.

Além testa escolha, qualquer par de probabilidades de ligaçă que obedeça a coudiça

$$
\frac{1-P(K)}{1-P(-K)}=e^{2 K}
$$

resultarấ na possibilidade de ecolhermos probabilidades de transiçäo ignais a 1.

A proposta de Niedermayer foi definirmos uma probabilidade de ligaça mais geral, controlada por um parầmetro adicional tos da seguinte forma:

$$
P\left(E_{i j}\right)= \begin{cases}\left.1-e^{m} f_{1} E_{0}-\Sigma_{i j}\right) & \text { Se } E_{i j}<E_{i} \\ 0 & \text { de outra forma }\end{cases}
$$

Através do parâmetro $E_{0}$ podemos variar a probabilidade de ligaçăo, de forma a controlarmos o tamanho do cluster. Mesmo que a condição (2.38) deixe de ser satisfeita, compensamos através das probabilidades de transicäo.

Se $E_{0}$ for menor que o menor valor de energia possivel $(-I)$, todas as probabilidades de ligação se anulatäa, e recairemos no algoritmo de Metropolis.

Se $E_{n}$ for maior que o maior valor de energia possivel, o lado diteito da equacăo (2.37) será sempre igual a um, podemos defnir probabilidades de transiçäo iguais a 1. Quanto maior $E_{0}$, maion a probabilidades de ligaçä e maior o cluster formado. Quando $E_{0} \rightarrow \infty$ toda a rede pertencerá ao cluster.

Se $E_{i}$ for igual ao valor máximo de energia, reobtemos o algoritmo de Wolf (ou Swendsen-Wang) original. 
Para valores de $E_{0}$ entre os valores mínimos e máximos de energia, o lado direito da equaçăo (2.37) deixa de ser igual a 1, e devemos compensar isto através da probabilidade de transição. Conseguimos assìn clusters menores que os criados pelo algoritmo de Wolff, e que podem ser úteis por exemplo para a simulaça de vidros de spin, onde a transição de percolaçäo para clusters de Wolff ocorre para valores de temperatura maiores que a probabilidade de transição.

Apesar de rnuito promissora em teoria, esta forma de variarmos o tamanho dos clusters formados através de um parâmetro adicional resulta na prática em resultados bastantes pobres. Isto acontece porque logo que a probabilidade de transição deixa de ser igual a um ela diminui exponencialmente com o tamanho da fronteira entre o cluster e o restante da rede.

Concluimos assim que năo existe escapatória: se desejamos estabelecer um algoritmo de cluster que simule de forma apropriada o modelo estudado, este deve ser definido de forma tal que consigamos satisfazer a condiçăo de balunço detalhado através apenas de probabilidades de ligaçăo, sem alterarmos as probabilidades de transição. Embora a soluçāo encontrada para o Modelo de Ising seja clara, em outros modelos a escolha de probabilidades de ligaçăo apropriadas está longe de ser trivial. Além disto, podem existir mais do que uma só espécie de cluster relevante para o modelo estudado, em geral cada tipo de transição está associada a um diferente cluster, cada um deles formado por diferentes probabilidades de ligação.

Uma putra questĩo que deve se abordada é a presença de transiçōes de primeira ordem assimétricas, porque para que um cluster possa transitar entre as diferentes fases te deve mudar a sua energia interna. Aqui somos obrigados a recorrer a probabilidades de transiçăo diferentes de 1 , mas ê importante que elas se refiram apenas a parte interna dos clusters formados, nāo introduzindo interaçōes entre diferentes clusters.

Para encerrar esta seçấ, algumas palavas sobre o porquê de algoritmos de clusters 
șerem mais eficientes que simulações usuais através de algoritmos locais. Nas proximidades de uma transiçăo de segunda ordem, o comprimento de correlação $\xi$ diverge ou, no caso de uma rede finita, torna-se da ordem da dimensäo linear da rede. Assim, blocos inteiros de spins tornam-se correlacionados, e é necessârio modificáalos de uma só vez, para que não geremos configurações muito correlacionadas. Esta é uma outra justificativa de porque é tẫo importante que as transiçōes termodinâmicas e de percolaçăo coincidam.

De que forma o mapeamento em um modelo de percolação leva em consideração estas correlaçōes näo locais? Ao mostrarmos a equivalência entre as funç̧oes de partição do Modelo de Ising e do modelo de percolação de ligaçôes correlacionadas, notamos que exa o fator $2^{n_{r}}$ que introduxia estas correlaçoes (ver equaçáo 2.14). Isto acontece porque pode ser possivel dividirmos um cluster em dois pedaços distintos apenas pela retirada de uma particular ligaçäo, e com isto tornamos possivel que spins distantes da ligação retirada possam assumir configuraçóes de spin que antes năo podiam, por pertencerem ao mesmo cluster. Desta forma, uma mudăņa no estado de uma variável local produziu efeito nâ๊olocais.

\subsection{Formulação de Kandel-Domany}

Na generalização de algoritmos de cluster para a simulação de modelos mais complexos, existem dois fatores que podem tornar o algoritmo obtido ineficiente.

O primeiro deles é o tamanlio dos clusters gerados, uma vez que clusters muito grandes resultam em modificações triviais na rede. O segundo fator é que a solução direta deste problema, através da utilização de probabilidades de ligação menores, pode resultar em uma interação entre clusters vizinhos, levando à dinämicas bastante lentas.

O algoritmo ótimo deve levar em consideraçăo as verdadeiras correlaçôs físicas entre os diferentes grans de liberdade. Em 1991, Kandel e Domany desenvolveram tum esquema matemático que automatiza a obtençäo dos valores corretos das probabilidades de ligação, 
de modo que a condiçăo de balaņ̧o detalhado seja satisfeita. Quando estamos lidando com modelos complexos, onde existem diversas probabilidades de ligação, este tipo de abordagem é bastante útil.

Apesar destas vantagens, o esquema năo nos fornece uma receita pronta de como encontrar um algoritmo que funcione, já que a escolha de quais probabilidades de ligaçäo iremos utilizar deve ser baseada en critérios físicos definidos a priori. Além disso, consideramos que os clusters formados iräo efetuar apenas transições que conservem a sua energia interma, o que ê uma limitaçäo séria em transiçôes de primeira ordem assii mettricas, como a do Modelo de Blume-Capel.

A idéia básica do método pode ser entendida através do algoritmo de Swendsen-Wang para o modelo de Ising. Neste algoritmo, a energia interna do cluster nāo se modifica apởs uma transiçäo do cluster, e a probabilidade de transição näo depende do estado dos clusters vizinhos, ou seja, diferentes clusters não interagem. É como se, após a formaçāo dos clusters, a energia do sistema tivesse sido modificada de forma tal que associamos uma energia infinita a qualquer estado onde nem todos os spins pertencentes ao mesmo cluster posstem o mesmo sinal de spin. Da mesma forma, como a probabilidade de transiçăo não depende dos spins vizinhos as cluster, podemos dizex que a energia de interaçăo com a vixinhança foi alterada de forma tal a se anular.

O esquema geral parte de uma Hamiltoniana que pode ser escrita na forma

$$
\mathcal{H}=\sum_{i} V_{i}
$$

onde $l$ pode ser qualquer viainhança entre spins em um modelo de Ising: plaquetas en uma rede quadrada, on qualquer outra partição da Hamiltoniana original que pode set escrita na forma acima.

O próximo passo é atribuirmos estocasticamente para cada $V /$ um valor inteiro $n$ valores possiveis, de uma forma que pode depender da configuraçäo a do sistema. A probabilidade de atribuirmos o valor $i$ para um particular $l$ pode ser representada como 
$P_{i}^{i}(u)$, e é normalizada:

$$
\sum_{i} P_{i}(2)=1
$$

Uma vez atribuidos valores a para cada elemento $l$, construimos uma nova Hamiltoniana dada por

$$
\widetilde{H}_{[i]}=\sum_{l} \ddot{V}_{i}^{l}
$$

onde (para qualquer $\ddot{i})$ :

$$
\tilde{V}_{i}^{j}(u)=V_{i}^{i}(u)-\frac{1}{\beta} \ln \left[P_{i}^{i}(u)\right]+C_{i}^{i}
$$

onde $C_{1}$ säo parâmetros independentes da configuraçä e $\beta$ f o inverso da temperatura.

A seguir, simulamos o modelo de modo a atingirmos uma nova configuraçäo $u$, através de qualquer procedimento cuja probabilidade de transiçă $T_{i}\left(u \rightarrow u^{\prime}\right)$ satusfaça a condiçăo de balanço detalhado com relaça a nova Hamiltoniana:

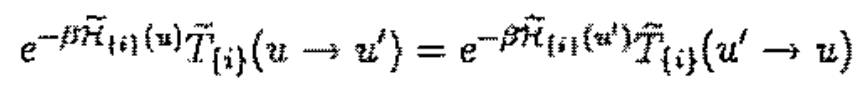

Completamos assim un ctelo do procetimento. Restanramos então a Hamiltoniana ariginal, e recomeçanos o ciclo a partir da configuraf̧ăo $u^{t}$.

A prova de que este esquama satisfaz a condiço de balanco detalhato pode ser encontrada no trabalho original de Kandel e Domany [KD91].

Qual o significado de todo este procedmento? Para compreender isto melhor, vamos considerar o caso particular onde temos duas formas de modifcarmos a interaçäo entre dos spins vizimhos, sendo a primeira definida por

$$
P_{1}^{\prime}(u)= \begin{cases}P_{1} & \text { se } V^{j}(u)=D_{1} \\ 0 & \text { de outra forma }\end{cases}
$$

Se escolhermos as constarates $C_{i}^{\prime}$ como

$$
C_{i}^{*}=\frac{1}{\beta} \ln \left(p_{i}\right)-E_{i}^{*}
$$


encontraremo a seguinte interaçäo modiffcă

$$
\hat{V}_{1}^{l}(\bar{u})= \begin{cases}0 & \text { se } V_{l}(\tilde{u})=E_{i} \\ \infty & \text { de outra forma }\end{cases}
$$

Conforme explicado anteriormente, a simulaçāo é feita com relaçầo à Hamiltoniama modificada 7 . Para cada ligaçăo $l$ à qual associamos o valor $i=1$, vemos da expressäo acima que a sua energia se conservara ou seja, foi "congelada". Dizemos entäo que esta operaçäo de modifcação produz clusters, da mesma forma que a probabilidade de ligação no modelo de Ising.

Uma segunda modiffeacto na Hamiltoniana, $i=2$, Edefinida como sendo a raodiffacão gque resulta em

$$
\widetilde{V}_{d}^{l}(\tilde{u})=0
$$

$O$ indice d referemse a uma operaçäo de eliminaçăo, que é como chamaremos a esta operaçäo. A probabilidade associada a esta operaçāo é dada por

$$
P_{d}^{t}(t)=e^{p\left[V_{i}(t)+C_{t}^{z}\right]}
$$

onde $C_{d}^{\prime}$ deve ser escolhida de forma que $P_{d(t)}^{(t} \leq 1$, para qualquer configuração $u$. Obtemos assim clusters que näo interagem.

No modelo de Ising, a probabilidade de eliminaça dada por

$$
P_{d}^{l}(u)=e^{\left(-K_{1} m_{i} m_{j}+C\right)}
$$

A escolha $C=-K$ faz com que ligaçoes entre spins antiparalslos sejam sempre deletadas, enquanto que ligacôes entre spins paralelos são delatadas com probabilidade

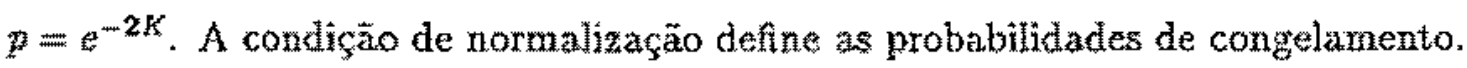

Neste exemplo simples, onde só existem duas possibilidades ta modificacăo da Hamiltoniana, todo este esquema pode parecer um pouco artificial. A sua vantagem real aparece quando estamos tratando de modelos mais complexos, onde diversas nodificacoes 
diferentes na Hamiltoniana podem ser efetuadas, com diversas probabiludades de ligaŗăa. Além disso, podemos considerar operações em divisōes mais complexas da rede, ao invés de apenas sobre ligaçős. Por exemplo, para estudar o modelo de Ising totalmente frustrado, Kandel, Ben-Ay e Domany [KBAD92] introduziram operaçöes definidas sobre plaquetas da rede, de forma a toracr o algoritmo capaz de lidar com ligaçöes frustradas.

Ontro importante aspectó ó de que nesta formulação é fúcil comprender-se fenômenos descritos anteriormente, como a presença de interaçōes entre os clusters, que nesta formulação ocorrem quando escolhemos probabilidades de eliminação que näo correspondem a $\tilde{V}_{\mathrm{a}}(\tilde{u})=0$.

Na formulacăo da algoritmos para os modelos de Ashkin-Teller Blume-Capel, esta formulaf̧ão serả um importante guia na elaboração dos algoritnos.

\subsection{Algoritmo de Embedding}

Um método bastante simples, e que costuma resultar em ótimos resultados é o conhecido por Algoritmo de Embedding, introdutido por Brower e Tamayo [DT92] em 1989, para o modelo $\phi^{*}$, e por Wolf, também em 1089, para o estudo de modelos $0(n)$.

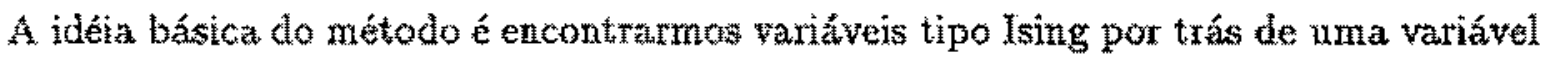
de spin mais geral, e simularmos esta variátel de Ising através de algoritmos de cluster, da forma usual. Em ontras palavras, o que fazemos é separar componentes de sinal e spin na esperança de que cluster formados por spins de mesmo sinal sejam suncientes para reproẻuzirmos ats excitacōes do sistema.

Considere por exemplo uma Hamiltontana de uma só componente, definida por

$$
H(\varphi)=-K \sum_{<x y} \varphi_{x} \varphi_{y}+\sum_{x} V\left(\varphi_{x}\right)
$$

onde $K \geq 0$ e $V(\varphi)=V(-\varphi)$. Decompomos $\varphi$ da seguinte forma:

$$
\varphi_{x}=\left|z_{*}\right|
$$


onde $\varepsilon_{x}$ corresponde ao sinal, e $\left|\varphi_{x}\right|$ à magnitude. A Hamiltoniana passa a ser dada então por

$$
\mathcal{H}(\varphi)=-\sum_{\langle x y\rangle} K_{x y}\left|\varphi_{x}\right|\left|\varphi_{y}\right| \varepsilon_{x} \varepsilon_{y}+\sum_{z} V\left(\left|\varphi_{x}\right|\right)
$$

Definindo $K_{x y}^{*}=K_{x y}\left|\varphi_{x}\right|\left|\varphi_{y}\right|$, obtemos um modelo de Ising com constante de acoplamento $K_{x y}^{*}$, e podemos simulá-lo através de um algoritmo de cluster usual. As magnitudes são simuladas através do algoritmo de Metropolis, o que garante que a condição de ergodicidade seja satisfeita.

A vantagem desta formulação é que ela pode ser utilizada em qualquer modelo onde possamos identificar yariáveis tipo Ising, além de ser fácil de ser implementada computam cionalmente. Muitas vezes, a simulação computacional de algoritmos mais complicados é totalmente equivalente a uma formulação através de um algoritmo de embedding. 


\section{Capítulo 3}

\section{Algoritmos de Cluster e Percolação no Modelo de Ashkin-Teller}

O interesse no estudo do modelo de Ashkin-Teller atraves de algoritmos de cluster foi despertado pelo fato dele possuir, em duas dimensöes, uma linha crítica ao longo da qual ocorre uma variaçäo contínua dos expoentes criticos. Esta característica do modelo torna interessante o estudo de propriedades dinămicas do algoritmo ao longo desta linha.

Com este objetivo, Wiseman e Domany desenvolveram em 1993 [WD93] um algoritmo de cluster capaz de simular a regiào do diagrama de fases onde a interaçăo entze quatro spins do modelo é ferromagnética. Apresentaremos neste capítulo este algoritmo, e mostraremos que é possivel encontrar um mapeamento entre a função de partição do modelo termodinânico e um modelo de percolaţăa. O mapeamento encontrado por nós resulta em um algoritmo de cluster igual ao proposto por Wiseman e Domany, funcionando como uma justificativa fisica para o algoritmo.

Desenvolvemos tambén um novo algoritmo de cluster capaz de simular a regiāo do diagrama de fases onde a interą̧ão entre quatro spins é antiferromagnética, o que é bastante interessante para estudarmos a possibilidade de existência de uma fase de Baxter Assimétrica no modelo, conforme indicado por uma análise via ărvore de Cayley. Em simulaços numéricas esta fase é bastante difícil de ser detectada, por ser bastante estreita, 
o que torna necessário dados bastante precisos. Os resultados muméricos obtidos através de algoritmos de chuster sāo apresentados na ưtima seção do capítulo, e nāo confirmam a. existência desta fase.

Mostramos que também quando a interacăo de quatro spins ê antiferromagnética é possivel efetuamos um mapeamento em um modelo de percolaçäo que resulta nos algoritmos de cluster desenvolvidos, completanto assim a descriçäo de todo o diagrama de fases do modelo em termos de modelos de percolação.

\subsection{O Modelo de Ashkin-Teller}

Modelo de Ashkin-Teller [AT43] pode ser entendio como dois nodelos de Ising superpostos acoplados através de um termo de interaçäo entre quatro spins. A sua Hamiltoniana pode sex escrita (em unidades de temperatura) como

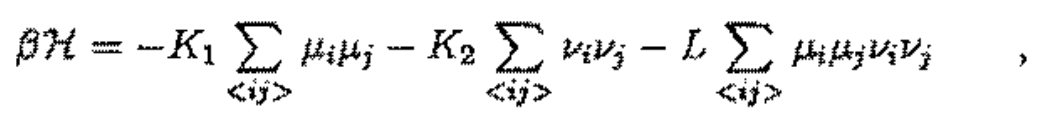

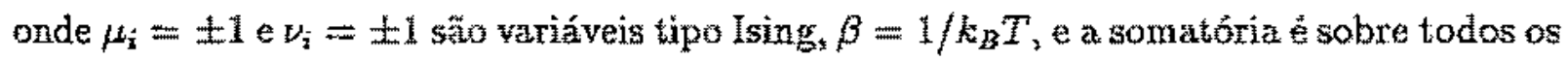
pares de spins primeiro vizinhos na rede considerada. Esta Hamiloniana possui diversas simetrias. Podemos por exemplo permutar qualquer dos acoplamentos $\left(K_{1}, K_{2}, L\right)$. Se a rede considerada for bipartida, potemos sempre inverter o sinal de $/, 3$ ou ambos em uma das subredes, o que faz com que o modelo seja invariante sob transformaçoes

$$
\begin{aligned}
& \left(K_{1}, K_{2}, L\right) \rightarrow\left(-K_{1}, K_{2 q}-L\right) \\
& \left(K_{1}, K_{2}, L\right) \rightarrow\left(K_{1},-K_{2},-L\right) \\
& \left(K_{1}, K_{2}, L\right) \rightarrow\left(-K_{1}, \cdots K_{2}, L\right)
\end{aligned}
$$

Estaremos nos restringindo aqui ao caso particular $K_{1}=K_{2}$, onde o modelo é conhecido tamberm como Modelo $Z(4)$, e ao estudo de redes quadradas cúbicas. 
Embora este modelo näo possa ser resolvido exatamente em uma rede quadrada, é possível alcançar um bom entendimento de seu diagrama de fases através de consideraçōes gerais. A figura (3.1) mostra um esboço de seu diagrama de fases.

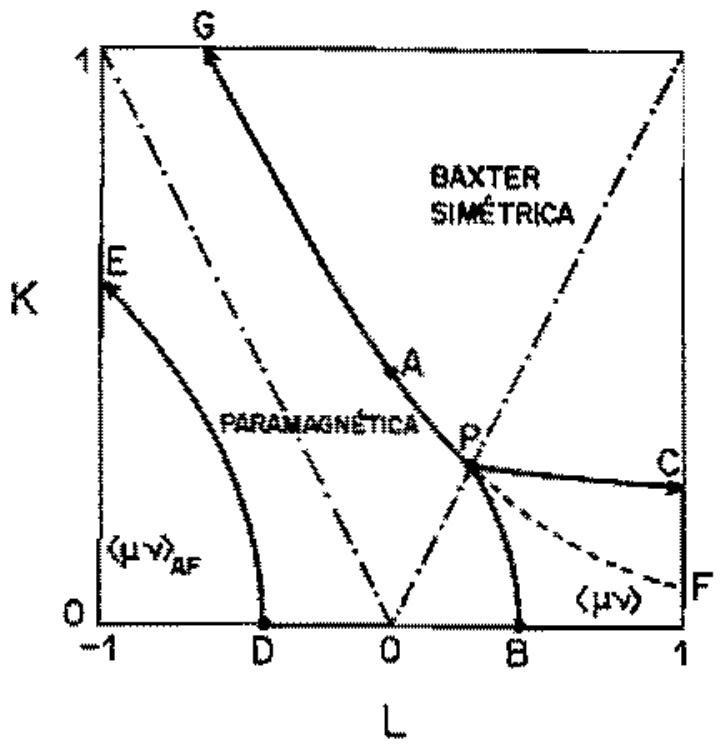

Figura 3.1: Esbogo do diagrama de fasts do Modelo de Ashkin-Tellor em uma rede bidimensional bipatidia.

É suficiente a representaçāo do subespaço $K>0$, já que o diağrama de fases é simétrico em relação a uma reftexão em torno do eixo $K=0$, conforme expresso pela relação (3.4). Sob esta operaçäo de reflaxầ, fases $\mu$ e $y$ ferromagnéticas irão se transformar em fases antiferromagnéticas, vice-versa.

Quando $L=0$ temos dois modelos de Ising desacoplados, que apresentaruto tratusça crítica no ponto $K_{x}=\frac{1}{2} \ln (1+\sqrt{2})$, de acordo como a fómula de Baxter [Bax73] para a temperatura de transiçäo de um modelo de Potts com $q$ estados em uma rede quadrada, $K_{\mathrm{c}}=\ln (1+\sqrt{q})$. Este ponto é representado pela letra $A$ no diagrama de fases. Outros pontos onde o modelo reduz-se à um Modelo de Ising poden ser encontrados em duas 
situaçöes: para $K=0$ teremos um modelo de Ising na variảvel $\mu \nu$, localizado em $K_{c}=$ $\frac{1}{2} \ln (1+\sqrt{2})$ (ponto $B$ ), e também quando $L=\infty$, onde teremos um modelo de Ising com constante de interacäo $\left(K_{1}+K_{2}\right)$.

Ao longo da linha $L=K$ o modelo é equivalente à um modelo de Potts com quatro estados, com interação $K_{\text {potts }}=4 K$. Encontraremos então um ponto critico ferromagnético em $K_{c}=\frac{1}{4} \ln 3$ (ponto $P$ ). Nầ existe resultado rigoroso a respeito da existência ou não de um ponto crítico para o Modelo de Potts de quatro estados antiferromagnético. Resultados numéricos [FS95] indicam que o modelo näo é crítico, o que implica (relaçăo (3.4)) que ao longo da linha $K=-L$ não existem pontos críticos.

Já a curva $G F$ pode ser encontrada através de uma transformaçäo de dualidade [DR79][Bax72], que transforma o modelo exi um outro que possui o mesmo termo singular para a energia livre. Definindo pesos de Boltzmann na forma

$$
\begin{aligned}
& \omega_{0}=e^{2 K+L+K_{0}} \\
& \omega_{1}=e^{-L+K_{0}} \\
& \omega_{2}=e^{-2 K+L+K_{0}}
\end{aligned}
$$

onde $K_{0}$ é uma constante arbittánia que fuxa o zero de energia *. Sob uma transformaçăo de dualidade, o modelo de Ashkin-Teller com pesos de Boltzmann $\left(\omega_{0}, \omega_{1}, \omega_{2}\right)$ é mapeado em am novo modelo de Ashkin-Teller com pesos $\left(\tilde{\omega}_{0}, \tilde{\omega}_{1}, \tilde{\omega}_{2}\right)$ dados por

$$
\begin{aligned}
& w_{0}=\frac{1}{2}\left(\omega_{0}+2 \omega_{1}+\omega_{2}\right) \\
& \tilde{\omega}_{1}=\frac{1}{2}\left(w_{0}-\omega_{2}\right) \\
& w_{2}=\frac{1}{2}\left(\omega_{0}-2 \omega_{2}+\omega_{2}\right)
\end{aligned}
$$

Quando $\omega_{9}=2 \omega_{1}+\omega_{2}$ a transformação é auto-dual. Em termos das constantes de

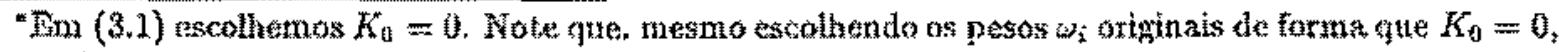

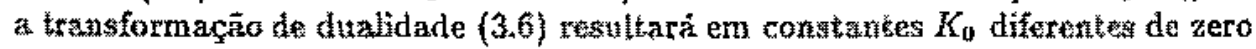


acoplamento esta condição ê expressa por

$$
e^{-2 L}=\sinh 2 K
$$

que corresponde à curva $G F$. Ao longo desta curva, o Modelo de Ashkin-Tetler pode ser transformado em um modelo de dito vértices homogểneo [Bax71] [Bax72], que pode ser resolvido exatamente. Baxter mostrou que a curva (3.7) é crítica apenas para $K \leq \frac{1}{4} \ln 3$, e que sels expoentes críticos variam de forma contínua.

Para $K>\frac{1}{4} \ln 3$, a curva auto dual $G F$ divide-se em duas linhas críticas, uma delas seğuindo em direção ao ponto de Ising $B$ e a outra em direção ao ponto de Ising localizado em $L=\infty$. As suas localizaçoes exatas nāo säo conhecidas exatamente, axsim como a classe do universalidade a qual pertencem.

O ponto $D$ equivale a um modelo de Ising antiferromagnético na variável $\mu \nu$, com interaçäo entre spins $L$. A linha crítica $D E$ corresponde a transiçōes entre esta fase antiferromagnética e a fase paramagnética, sendo a sua localização exata, também desconhecida.

Todas estas linhas críticas dividen o diagrama de fases em diversas fases, que podem ser classificadas da seguinte forma:

- Fase de Baxter Simétrica, onde $\mu$ e $\nu$ ordenam-se de forma ferromagnética tal que $\langle\mu\rangle=\langle\nu>\neq 0$ e $<\mu \nu>\neq 0$.

- Fase $\langle\mu \ldots\rangle$, onde o produto jut está ordenado da forma ferromagnética, mas $\langle\mu\rangle=\langle u\rangle=0$.

- Fase $<\mu \nu>_{A F}$, onde o produto $\mu \nu$ está ordenado de forma antiferromagnética, mas $\langle\mu\rangle=\langle\mu\rangle=0$.

- Fase Paramagnética, onde $\langle\mu \nu\rangle=\langle\mu\rangle=\langle\nu\rangle=0$. 
Algonitmos de Cluster e Pertolaçäo no Modelo de Ashkin-Teller

Este é o cenátio para uma rede bidimensional bipartida, com as diversas fases e transiç̧os existentes. No entanto, em trề dimensöes a situaçäo $\hat{e}$ bastante diferente [Bax71]. Argumentos de dualidade e conexöes com o modelo de 8 vértices näo são mais válidos. Além disto, o operador $L$, que ero duas dimensöes é um operador marginal, passa aqui a ser um operador relevante, capaz de modificar completamente a natureza dos pontos criticos. A figura (3.1) representa o diagrama de Fases do Modelo de AshkinTellex calculado no limite de coordenaçầ infinita de nma árvore de Cayley, conforme trabalho de F. A da Costa el. [COSB7][AC97].

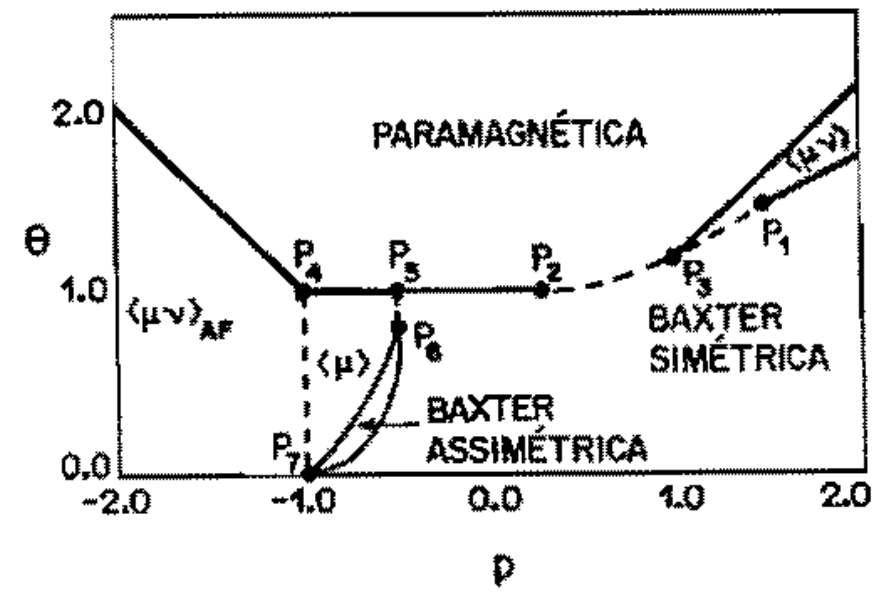

Figura 3.2: Diagrama de fases do Modelo de Ashkin-Teller obtido atravás do limite de coordenaçăo infinita de uma árvore de Cayley. $\theta=K^{-1} z$, onde $z$ é o número de coordenação da rede, e $p=L / K$. Pontos $P$ representam pontos multicriticos.

En relaçäo ao diagrama do modelo bidimensional, notamos agora que existem duns novas fases:

- Fase $\langle\mu\rangle$ onde $\mu$ está ordenada ferromagneticamente, enquanto $\langle\nu\rangle=\langle\mu \nu\rangle=0$.

- Fase de Baxter Assimétrica, onde $\langle\mu>\neq 0,<\nu>\neq \neq,<\mu$ is $>\neq 0$, com $\langle\mu>\neq<\nu>$. 
A existência da fase de Baxter Assimétrica foi sugerida inicialmente por resultados de simulaçōes de Monte Carlo [DBCK80], e encontrada posteriommente através de uma abordagem via árvore de Cayley [COS87]. Cálculos anteriores através da aproximaçäo de campo médio, assim como expansöes em séries [DBCK80] nẫo haviam detectado a existência desta tase. Resultados de nossas simulaçôes indicam que ela não existe, ao menos em uma rede cúbica.

Um argumento simples mostra a possivel existencia desta fase [COS87]. Considera una rede de Bravais com coordenaçāo z, e vamos assumir que no limite de temperatura zero as fases $\langle\mu\rangle$ e Baxter Simétrica estâo presentes e săo contínuas. Definindo $=K^{\prime} \beta^{-1}$, a

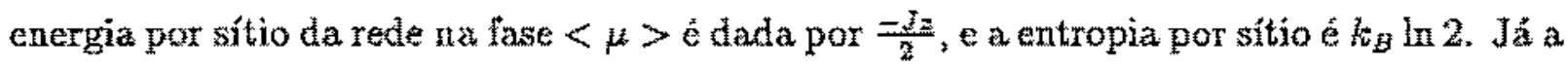
fase de Baxter simétrica terá energia por sitio $\frac{-J \pm(p+q)}{2}$, onde $p=L / K$, e năo terá entropia residual. Comparando a energia livre das duas lases conclumos que, para temperaturas suficientenente baixas, a fase $\langle\mu\rangle$ serć estável na regiäo do diagrama de fases definida por

$$
\frac{k_{B} T}{J} \geq \frac{z(p+1)}{2 \ln 2}
$$

Em temperatueas baixas podemos considerar m $_{2}=1$ para qualquer $i$, e o sistema passa a ser descrito por uma Hamiltoniana etetiva

$$
H_{n+t}=-J(p+1) \sum_{\langle i j\rangle} \nu_{i} \nu_{j}
$$

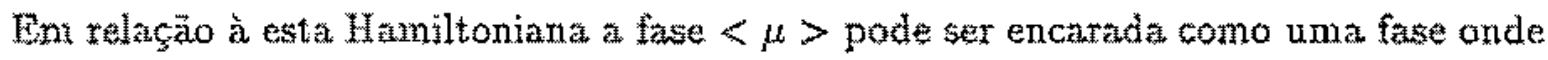
a rede $\nu$ ordena-se paramagneticamente. Como $H_{n f}$ ĕ uma Hamiltoniana tipo Ising a fase H estará presente quando

$$
\frac{k_{z} T}{J} \geq \frac{k_{B} T_{k}}{J}(p+1)
$$

onde $T_{\varepsilon}$ é a temperatura de um Modelo de Ising com interacoes entre spins $J$.

A possibilidade de existênéla da fase de Baxter assimétrica pode ser entendida da seguinte forma: se a regiâo de estabilidade da fase $\langle\mu>$, definita por (3.8), for maior 
que regiăo onde ela estâ efetivamente presente $(3.10)$, isto sigutifica que ela deixa de ser estável em relação à uma outra fase, que a fase de Baxter Assimétríca. Esta condiçäo ocorrerá sempre que

$$
\frac{K_{B} T_{C}}{z^{J}} \geq \frac{1}{2 \ln 2}
$$

o que de fato ocorre em algumas redes cübicas.

Outra questzăo ainda nžo bem entendida no modelo diz respeito à natureza da transiçăo nas proximidades de $p=0$, quando nos aproximamos pelo lado direito. A abordugem via campo métio indica tute a transição que aí ocorre é de segunda ordem. No entanto, a andilise em termos de expansôes em séries efetuada por Ditzian et al. encontrou expoentes que variam continuamente ao longo desta linha. Isto está em desacordo com resultados obtidos através do grupo de renormalizaçäo, que nāo indicam existencia de um operador marginal que explicaria esta variaçāo do expoente. Ditzian propōe entäo que a tranăcăo seju na verdade de $1^{2}$ orden, com os valores obtidos para $\gamma$ näo passando do reflexo de um comportamento pseudo-spinodal.

\subsection{Algoritmo de Cluster para o Modelo de Ashkin- Teller com Interação de Quatro Spins Ferromag- nética.}

Mostramos no capitulo anterior valores para o expoente crítico dinâmico $z$ em alguns modelos, com o objetivo de exemplificar a diminuição deste expoente quando da utilizaçäo de algeritmos de eluster. No entanto, pouco compreendemos do porque deste expoente ser menor do que os obtidos com a algoritmo de Metropolis, on porque ele simplesmente răo se arula. Un dos poncos resultados exatos a este respeito é um linute inferior para o expoente crítico dínâmico do modelo de Swendsen Wang, $z_{5 W} \geq \alpha / \nu$, obtido por Li a Solkal [LS89].

O Modelo de Ashkin-Teler bidimensional é bastante apropriado para o estudo deste 
limite inferior para o expoente dinâmico, já que sabexnos que os expoentes críticos variam continuamente de expoentes tipo Ising no ponto $A$ para expoentes característicos do modelo de Potts de quatro estados no ponto $P$ (ver fig. (3.1)). Foi com este objetivo que Wiseman e Domany [WD93] propuseram un algoritmo de cluster para o modelo de Ashkin-Teller ferromagnético, utilizando o formalismo proposto por Kandel e Domany [KD91] (ver seção 2.5). Mostraremos aqui que o algoritmo encontrado resulta equivalente a um algoritmo de embedding, que foi o algoritmo efetivamente utilizado por Wiseman em suas simulaçōes. Posteriormente, Salas e Sokal [S\$96] efetuaram um estudo do modelo utilizando a versăo completa do algoritmo, onde todos os clusters da rede säo simulados de uma só vez, o que corresponde a um análogo do algoritmo de Swendsen-Wang quando aplicado no Modelo de Ashkin-Teller.

Para obtermos o algoritmo, escrevemos a Hamiltoniana do Modelo de Ashkin-Teller na forma

$$
\beta H=\sum_{i} V_{i}
$$

onde $V_{t}$ é dado por

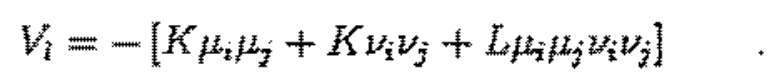

Devemos agora identificar quais sēo as excitaçöes relevantes no modelo, de modo a criar clusters que as representem. Assumiremos aqui que clusters de spins $\mu$ e $\nu$ alinbados representam estas excitaçōes. No entanto, isto poderia nāo refletir toda a fisica do problema, já que por exemplo em uma transiçäo envolvendo a fase $<\mu \nu$ é o comprimento de correlaçăo associado à variável $\mu$ que ế relevante. Para evitar este tipo de problema, estarenos sempre considerando $L<K$. Isto não representa uma limitaçăo do algoritmo, porque se $L>K$ podemos sempre introduzir una mudança de variáveis $\tau=\mu \nu$, de modo a tornar a interaçào entre quatro spins a menor interação.

Como $V_{l}$ depende de quatro spins independentes, ele pode assumir 16 estados, cada 
um deles possuindo um entre quatro valores de energia possiveis, conforme representado na figura (3.2).

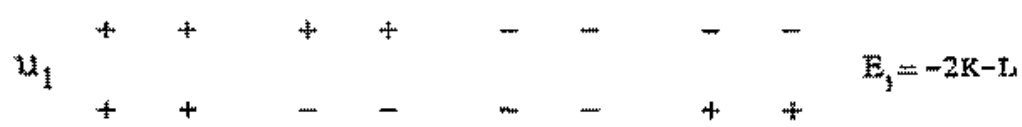

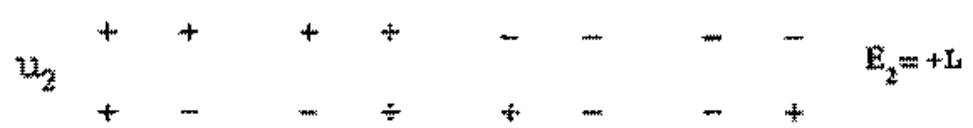

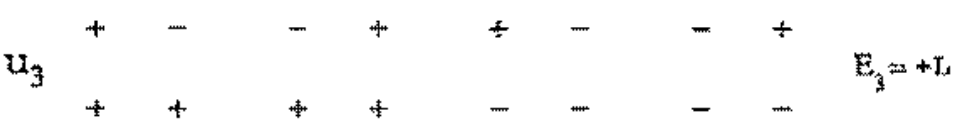

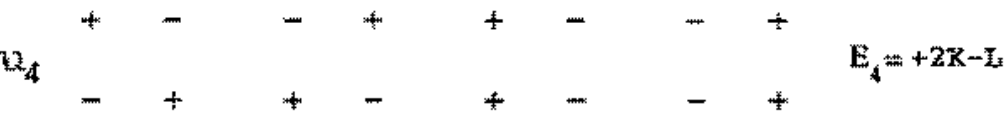

Figura 3.3: Possiveis configuraçōes, com suas respectivas energias. Cada possivel valor de energia é representado por $E_{i}$, e as quatro configuraçôes correspondentes stão representadas por $u_{i}, i=1, \cdots 4$.

Em cada gráfico desta figura representamos uma vizinhança $\langle$ ij $\rangle$ nas duas redes, com a rede $\mu$ por convenção "em cima" da rede $z$. Por exemplo, em $u_{1}$ os valores de spin representados em cada um dos quadrados correspondem a uma vizinhaça

$$
\begin{array}{ll}
\mu_{i} & \mu_{j} \\
\nu_{i} & \nu_{j}
\end{array}
$$

Definimos agora quatro operaçôes que podem ser efetuadas em cada vizinhança $l$, de modo a criar as ligaçōes desejadas. A primeira delas, $P_{1}^{l}$, cria ligaçöes entre spins vizinhos simultaneamente nas redes $\mu$ e $\nu$, se eles forem paralelos en cada uma das redes. Ela é definida como 


$$
P_{1}^{l}(u)= \begin{cases}p_{1} & \text { se } V^{1}(u)=E_{1} \\ 0 & \text { de ontra forma }\end{cases}
$$

A segunda operaçăo cria ligaçốs apenas entre spins paralelos na rede $\mu$, aìtuaçāo que ocorre em configuraçós $u_{1}$ \& $u_{2}$. Na configuraçäo $w_{1}$ ela será denominada $\eta_{2}$ e na configuracia $t_{2}$ de $p_{2}$. Esta operaça é definida por

$$
P_{2}^{\prime}(u)= \begin{cases}e^{V_{1}(u)+C_{2}} & \text { se } V^{\prime}(u)=E_{1} \text { on } V^{\prime}(u)=E_{2} \\ 0 & \text { se } V^{\prime}(u)=E_{3} \text { ou } V^{\prime}(u)=E_{4}\end{cases}
$$

A escolha de $C_{2}$ determinart os valores de $p_{2}$ e $q_{2}$ :

$$
p_{2}=e^{Y_{1}\left(u_{2}\right)+C_{2}}, \quad g_{2}=e^{V_{1}\left(u_{1}\right)+C_{2}}
$$

A terceira operaçăo é similar a segunda, mas agora ligamos spins paralelos na rede $z_{3}$ nas configuraróos $u_{1} \in u_{3}$. Ela é definida por

$$
P_{3}^{l}(u)= \begin{cases}e^{V_{(}(u) C_{3}} & \text { se } V^{\prime}(u)=E_{1} \text { ou } V^{\prime}(u)=E_{3} \\ 0 & \text { set } V^{t}(u)=E_{2} \text { ou } V^{t}(u)=E_{4}\end{cases}
$$

De forma similar,

$$
p_{3}=e^{h_{(}\left(w_{3}\right) \div C_{3}}, \quad a_{3}=e^{y_{3}\left(n_{1}\right) c_{3}}
$$

A quarta operaçẫo elimina ligaçôes em ambas as redes, sendo dada por

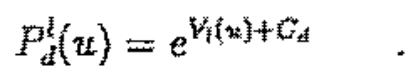

Estats quatro operasöes completan o esquema para a criação do algoritmo de duster. estão representadas na seguinte tabela:

\begin{tabular}{c|c|c|c|l} 
& - & & & \\
& & & & \\
\hline$\left(u_{1}\right)$ & $p_{1}$ & $q_{2}$ & $g_{3}$ & $P_{d}\left(u_{1}\right)$ \\
\hline$\left(u_{2}\right)$ & 0 & $p_{2}$ & 0 & $P_{d}\left(u_{2}\right)$ \\
\hline$\left(u_{3}\right)$ & 0 & 0 & $p_{3}$ & $P_{d}\left(u_{3}\right)$ \\
\hline$\left(u_{4}\right)$ & 0 & 0 & 0 & $P_{d}\left(u_{4}\right)$ \\
\hline
\end{tabular}


Para determinarmos os valores das probabilidades devemos começar analisando o caso u. Näo definimos nenhuma operação de ligação para esta configuraçăo, por ser a de maior energia, año desejarmos congelar configuraçöes referentes a ela. A condiçă亍o de normalizaçăo impöe então que $P_{a}\left(u_{4}\right)=1,0$ que por sua vez determina a constante de deleção $C_{*}^{*}=-E_{4}$. Teremos então todas as constantes de deleçào definidas. Isto nos possibilita calculas $p_{2}$ e pa através da condiçäo de normalização (2.41), ou seja,

$$
\begin{aligned}
& p_{2}=1-P_{d}\left(u_{2}\right) \\
& p_{3}=1-P_{d}\left(u_{3}\right)
\end{aligned}
$$

Conhecendo $p_{2}$ e $p_{3}$, determinarnos $C_{2}$ e $C_{3,}$ e como consequência $q_{2}$ e $q_{3}$. Finalmente,

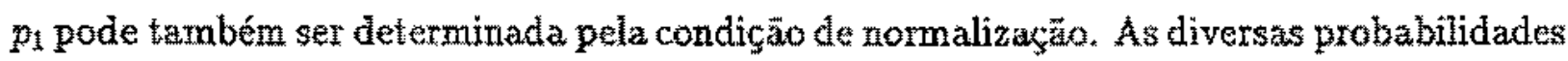
assumem então os seguintes falores:

$$
\begin{aligned}
p_{1} & =1-2 e^{-2 K-2 L}+e^{-4 K} \\
q_{2} & =\left(1-e^{-2 K+2 L}\right) e^{-2 K-2 L} \\
q_{3} & =\left(1-e^{-2 K+2 L}\right) e^{-2 K-2 L} \\
p_{2} & =\left(1-e^{-2 K+2 L}\right) \\
p_{3} & =\left(1-e^{-2 K+2 L}\right) \\
P_{d}\left(u_{1}\right) & =e^{-4 K} \\
P_{A}\left(u_{2}\right) & =e^{-3 K+2 L} \\
P_{d}\left(u_{3}\right) & =e^{-2 K+2 L} \\
P_{A}\left(u_{4}\right) & =1
\end{aligned}
$$

O esquema geral de Kandel e Donany não garante que todas as probabilidades

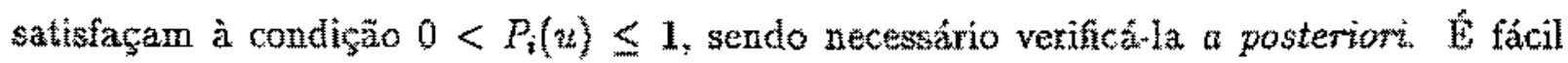
verificar que todas as probabilidades definidas em (3.22) satisfarem a esta condiçäo. 
As operaçôes construidas até aqui definem clusters que mão interagem. Resta ainda definir um procedimento de Monte Carlo que modifique o valor dos spins pertencentes à cada cluster. Um procedimento natural seria o de escolhermos um sinal para os spins pertencentes a cada cluster com probabilidade $p=1 / 2$ entre os dois valores possiveis (11). Este procedimento seria efetuado para cada cluster pertencente a cada uma das redes, $\mu$ e $\nu$, e seria o equivalente ao algoritmo de Swendsen-Wang para o Modelo de Ising.

Embora perfeitamente vălido, este procedimento é de dif́cil implementaçăo em um computador. Umă forma mais simples, e que foi de fato utilizada por Wiseman e Domany em seu trabalho original, consiste na versão onde formamos um so cluster na rede, o que seria o análogo ao algoritmo de Wolff para o Modelo de Ising. Para entendermos este procedimento, basta considerarmos que após termos formado todos os clusters da rede com as probabilidades definidas anteriormente, sorteamos um sítio de uma das redes (que também foi escolhida de forma aleatória) e modificamos o sinal de seus spins com probabilidade $W_{p}=1$.

Esta versão de um cluster é equivalente à versäo de um cluster do algoritmo de embedding, que muito mais simples.

$O$ algoritmo de embedding consiste de, a partir da Hamiltoniana original,

$$
\beta H=-K \sum_{\langle i j\rangle} \mu_{i} \mu_{j}-K \sum_{\langle i j\rangle} \nu_{i} \nu_{j}-L \sum_{\langle i j\rangle} \mu_{i} \mu_{j} \nu_{i} \nu_{j} \quad
$$

fixarmos os valores de spin de uma das redes. Por exemplo, se fixarmos os valores de $\mu$, esta Hamiltoniana pode ser reescrita, a menos de unla constante, como

$$
\beta H=-\sum_{\langle i j\rangle}\left(K+L i \mu_{i} \mu_{j}\right) z_{j} \nu_{j}
$$

Que é equivalente a uma Hamiltoniana de Ising onde a constante de acoplamento é dada por $\left(K+L \mu_{i} \mu_{j}\right)$, podendo variar em cada vizinhança $v_{i} \nu_{j}$, de acordo con $\sigma$ sinal dos spins $\mu_{i} \mu_{j}$. Esta Hamiltoniana pode ser simulada como qualquer dos procedimentos usuais para o Modelo de Ising, como um algoritmo de Swendsen-Wang ou de Wolff. Para 
que este algoritmo seja ergódico, escolhemos do torma aleatória qual das duas rédes será mantida fixa (o procedimento para quando fixamos a rede $y$ é completamente análogo).

Para provarmos que este procedimento é equivalente ao algoritmo completo proposto anteriormente, basta considerarmos que o algoritmo de embedding corresponde a este algoritmo quando configuraçôes modificadas na rede mantida fixa possuem energias infinitas. Se considerarmos uma etapa do algoritmo completo e só modificarmos uma das redes, o que estamos fazendo na prática é considerar que configuraçös modificadas na outra rede têm energia infinita, o que mostra que as duas formulaçōes säo de fato equivalentes. Para nảo restar dúvidas, é sempre possivel calcularmos explicitamente o valor das probabilidades nos dois algoritmos. Por exemplo, a probabilidade de não ligarmos dois spins $w_{z} z_{3}$ em uma configuração do tipo $u_{1}$ é dada, no algoritmo completo, por

$$
P=q_{2}+P_{t}\left(u_{1}\right)=e^{-2 K^{2}-2 t}
$$

que é igual a do algoritmo de embedding para esta configuração, como pode ser visto a partir de (3.24).

Em seu trabalho original, Wiseman e Domany simularam uma versão do tipo Wolff para o algoritmo de embeddiug. Posteriormente, Balıs e Sokal SSS96] efetuaram simulaçoes onde todos os clusters pertencentes a uma das redes săo modificados ao mesmo tempo, o que corresponde à uma versăo de Swendsen-Wartg para o algoritmo de embedding. A vantagem em relação à formulaçăo tipo Wolff é que nesta versāo é possivel provar analiticamente a existência do limite inferior para o expoente crítico dinâmico $z, z \geq \alpha / \nu$. 


\subsection{Mapeamento do Modelo de Ashkin-Teller com Interação de Quatro Spins Ferromagnética em um Modelo de Percolação.}

Ao proporem o seu algoritmo de cluster para simulaçì do Modelo de Ising, o que Swendsen Wang perceberam fo que o mapeamento do Modelo de Ising em um modelo de percolaçäo descoberto por Fortuin e Kastelyn [KF69][FK 72$]$ podia indicar a existencia de uma forma mais eficiente de efetuarmos simulaçōes de Monte Carlo, baseada em clusters (o que aliás ja havia sido observado por Hu [Hu84]).

Com o Modelo de Ashkin. Teller iremos proceder de foma inversa: a existencia de um algonitno de cluster dave indicar que é possivel mapear o modelo em alguma espécie de modelo de percolaçăo. A tormulaçắ de Kandel e Domany, e também a abordagem de Sokal mostram que a simulaçấo através de algoritmos de cluster é um procedimento válido, näo provando que este procedimento equivale a um mapeamento. Mostraremos nesta seçäo que de fato é possivel encontrarmos um mapeamento do modelo em um modelo de percolação, que através deste mapeamento encontramos um algoritmo equivalente ao proposto por Wiseman e Domany.

Para obtermos este mapeamento, vamos notar inicialmente que a operacão 1 do algoritmo deve estar associada a deltas na forma $\delta_{\mu_{i} \mu_{j}} \delta_{\nu_{j} u_{j}}$, a operação 2 a deltas $\delta_{1 \mu_{i} \mu_{j}}$, a operaça 3 a deltas $\delta_{y_{i} y_{j}}$ e a operação 4 a ausência de deltas. Devemos entäo encontras estas estruturas de deltas na funço de partiçōo do modelo, que é dada por

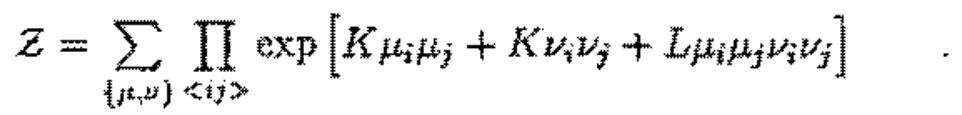

É possivel reescrevermos a função de partição na forma

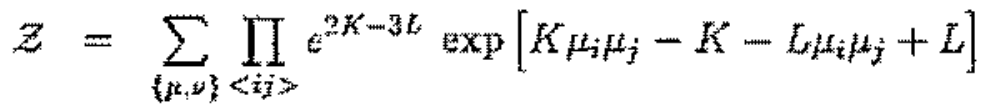

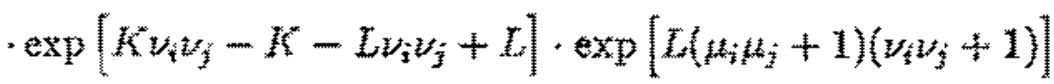


Embora trate-se da mesma funçäo de partiçäo, a expressäo (3.27) é mais conventente, porque o termo de interaçăo entre quatro spinss só contribui agora quando os spins da rede $\mu$ e $\nu$ são iguais entre \&i $\left(\mu_{i}=\mu_{j} ; \nu_{i}=\nu_{j}\right.$, mas näo necssariamente $\left.\omega_{i}=\nu_{i}\right)$. Na expressão (3.26) fica dificil saber entre quais spins devemos criar ligaçoes, no termo wat $_{2} z_{i} \nu_{j}$ podemos crìr ligaçöes entre $\mu_{i}$ e $\nu_{i}$, por exemplo, o que ja não ocorx na expressäo (3.27). Definindo agora

$$
\begin{aligned}
& p_{J_{t}}=1-e^{-2 K+2 L} \\
& p_{t s}=1-e^{-2 K+2 L} \\
& p_{\mu t}=1-e^{-4 L}
\end{aligned}
$$

podemos reescrever a funçäo de partiçäo como

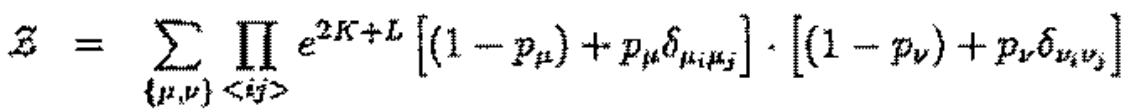

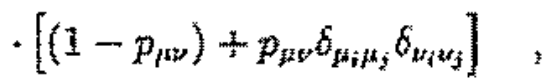

Introduzimos agora três novas variávels, $l, k$ e $m$, que representarāo a existência ou

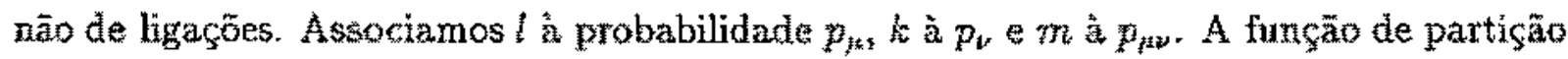
passa a ser escrita agora como

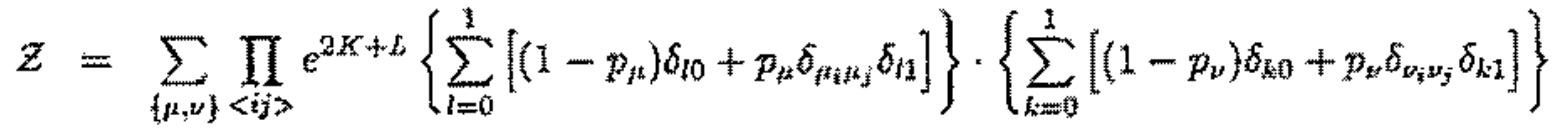

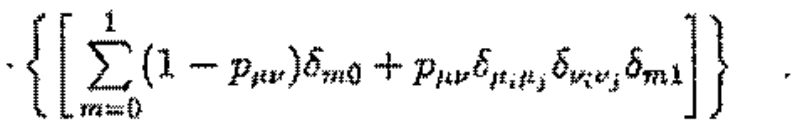

Reescrevendo mais una vez,

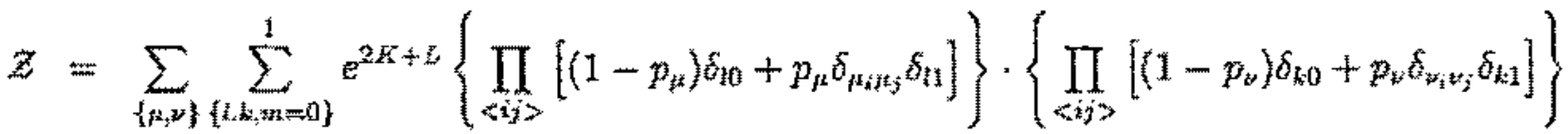

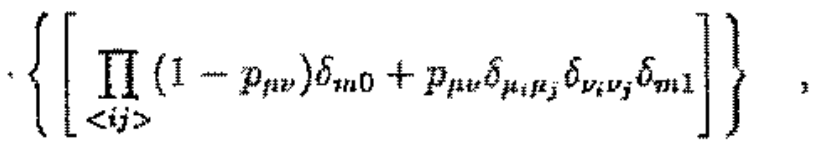


onde a somatória $\sum_{\{t, k, m\}}$ representa uma soma sobre as variáveis de ligaçăo em todas as vizinhanças da rede.

Esta funçäo de partiçâo pode ser interpretada como uma funçäo de partição conjunta entre o Modelo de Ashkin-Teller e um modelo de percolaçäo. Se efetuarmos a soma sobre as variâveis $l, k$ e $m$ (que chamaremos de variáveis de ligaçăo) voltamos ao modelo de Ashkin-Teller. Por outro lado, se somarmos sobre as variápeis $f=\nu$ obtemos um modelo de percolação, onde existem três diferentes tipos de ligação, que săo "colocadas"

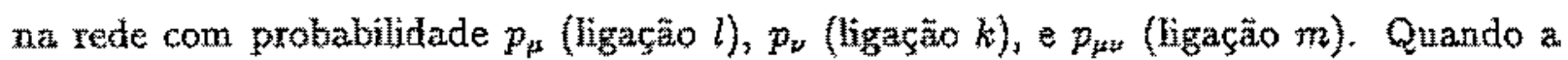
variảvel de ligação assume valor zero, a ligação estâ "ausente", enquanto que quando a variável assume valor um dizemos que ela está "ativada". Para efetuarmos a soma sobre as variáveis de spin, vamos reescrever a função de partição como

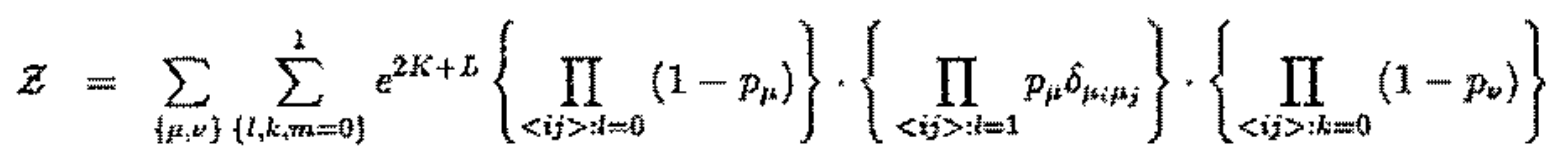

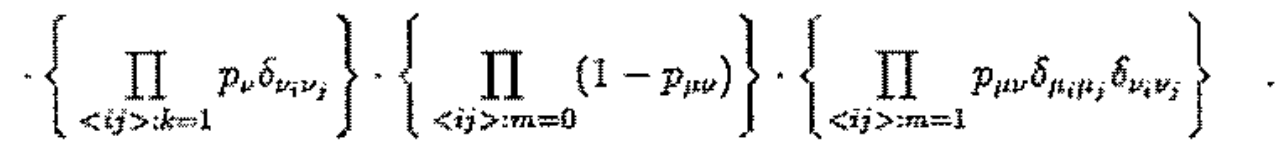

Ao somarmos sobre spins, devemos levar em conta a existência de vínculos representados por differentes $\hat{\delta}^{\prime} s$, já que a existência de ligaçăo sempre implica na existência de um certo tipo de $\delta$, o que por sua vez restringe o número de estados acessíveis ao sistema. Para contarmos o número de estados acessiveis, vamos introduzir o conceito de cluster neste modelo. Vamos inicialmente representar graficamente cada uma das diferentes probabilidades:

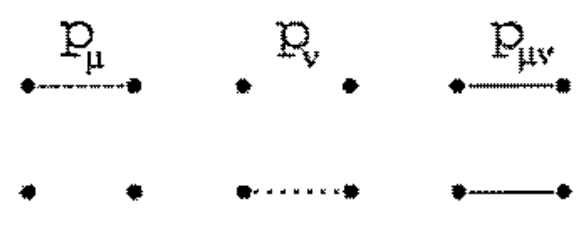

Figura 3.4: Representação gráfica das diferentes probabilidades. 
Como a probabilidade $p_{k}$ está associada a um $\delta_{z_{i} x_{j}}$ a existência de ligaçäo (linha tracejada na figura) implica em os dois sítios possuirem o mesmo sinal de spin. $O$ mesmo é valido em relação probabilidade $p_{p}$, mas agota em relação à rede $u$. Ja a probabilidiade $p_{\mu \nu}$ "carrega" $\delta_{\psi_{k} j_{j} \mu_{j}} \delta_{\nu_{i} \nu_{j}}$, e por isto colocamos ligaçōes nas duas redes. Note ainda que as probabilidades säo independentes, mas todas elas estäo definidas para todas as vizinbanças da rede. possivel então que para um mesmo par de vizinhos $\langle i j\rangle$ dois tipos diferentes de ligação estejam ałivadas, como ocorre entre os sítios i e j ma rede $\mu$ da figura (3.5), onde uma possivel configuração de ligaçōes estă representada.
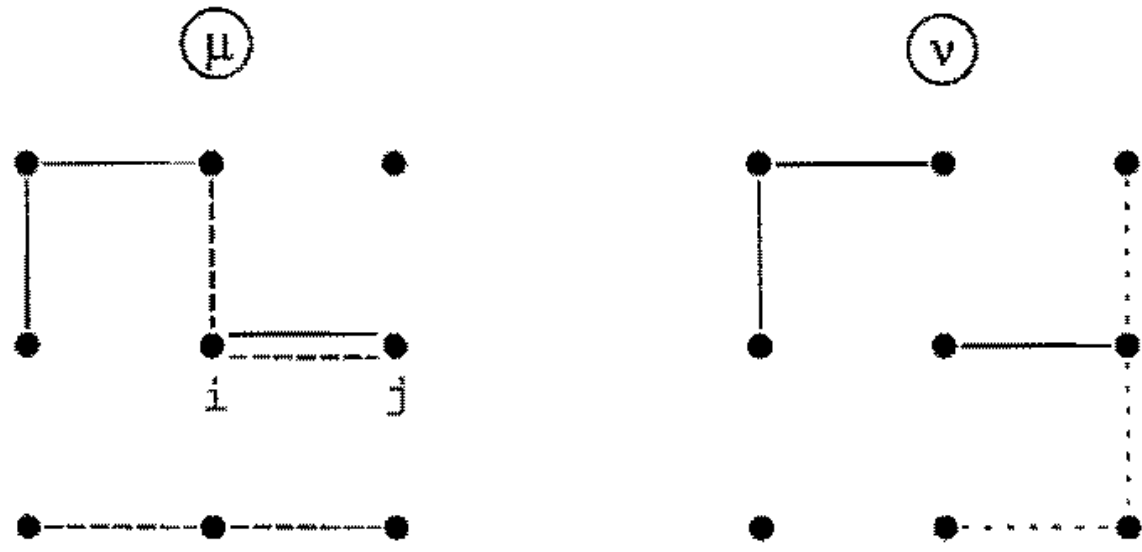

Figura 3.5: Possível configuração de ligaçōes.

Como identificar os clusters? O fator relevante nesta identificaçăo são os termos 6. Lembrando que cada, ligaçầ "carrega" um $\delta_{3}$ vemos que dois sítios pertencentes à mesma rede conectados por um caminho de ligaçoses (não importa de que tipo) terão necessariamente de possuir o mesmo sinal de spin, e portanto dizemos que eles pertencem ao mesmo cluster. $O$ fato de podermos ter dois tipos de ligação para o mesmo par de sítios năo representa problema, porque as duăs contềm a mestna ixformaçầo (o mesmo tipo de 5). Note ainda que, embora ligaçoes do tipo $m$ (probabilidade $p_{* v}$ ) apareçan sempre nas duas redes, isto não implica que os spins das duas redes necessitem possuir o mesmo sinal, 


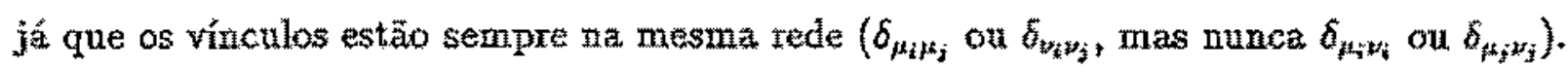
Com estas observaçōes, a identificaçāo de clusters na figura (3.5) seria a seguinte:

(11)

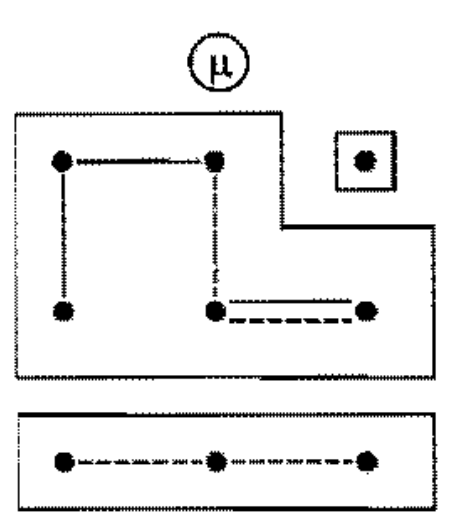

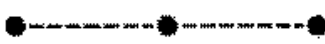

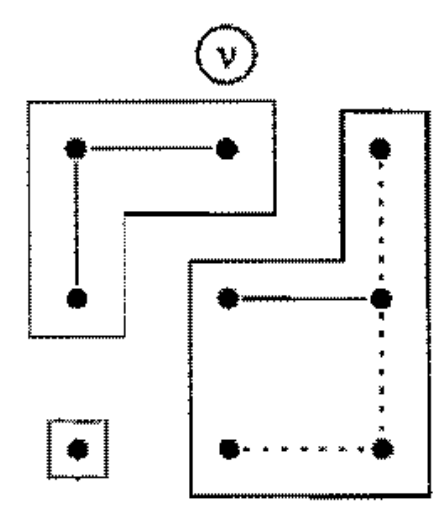

Figura 3.6: Contorno dos clusters formados a partir de uma dada configuraçäo.

Efetuando agora a soma sobre configuraçöes, excontramos

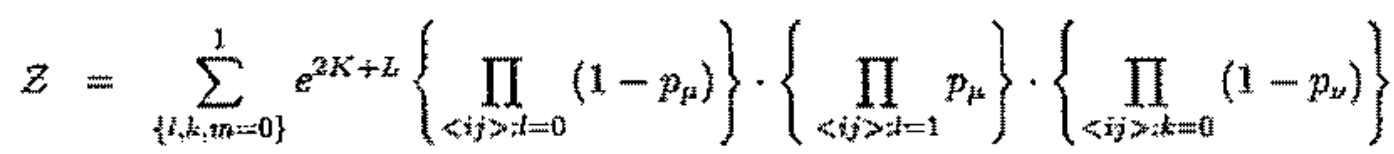

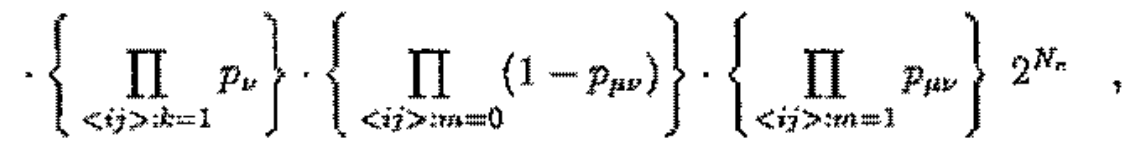

onde $N_{u}=N_{p}+N_{v}$ é a soma do número de clusters nas redes $\mu$ e $\nu$. No exemplo da figura (3.6) temos $N_{\mathrm{r}}=3+3=6$.

Chegamos assim no nosso modelo de percolação para o caso ferromagnético, que consiste en atribuimos os trễs tipos de ligaçấ (com as suas respectivas probabilidades) a cada par $\langle i j\rangle$. Da nesma forma que no mapeamento do Modelo de Ising, o termo $2^{N_{t}}$ introduz correlaçồ nāo locais no modelo.

A generalização para o caso onde a interação ierromagnética em cada uma das redes é diferente (teríamos duas constantes, $K_{1}$ e $K_{2}$, a invés de apenas $K$ ) edireta, basta utilizar o mesmo formalismo.

A primeira vista, o mapeamento encontrado não guarda nenhuma semelhança com o 
algoritmo de cluster proposto por Wiseman e Domany. No entanto, é possivel mostrar que o algoritmo de cluster por nós encontrado atraves do mapeamento é equivalente ao algoritmo de cluster de Wiseman e Domany.

Para ver isto, devemos perceber que as probabilidades encontradas por Wiseman e Domany sāo na realidade o resultado de operações com outras probabilidades, mais básicas, e que säo fornecidas pelo nosso mapeamento. Por exemplo, a probabilidade de ligarmos simultâneamente as duas redes, $p_{1}$, pode ser efetuada no mapeamento de duas formas diferentes, através da ligação $p_{\mu \nu}$ ou então das ligaçōes $p_{\mu}$ e $p_{\nu}$, e será dada por

$$
\begin{aligned}
P= & \left(1-e^{-4 L}\right)\left[\left(1-e^{-2 K+2 L}\right)+e^{-2 K+2 L}\right] \cdot\left[\left(1-e^{-2 K+2 L}\right)+e^{-2 K+2 L}\right]+ \\
& +e^{-4 L}\left(1-e^{-2 K+2 L}\right)^{2} .
\end{aligned}
$$

Os termos entre colchetes correspondem à probabilidade de ativarmos (ou näb) as probabilidades $l$ e $k\left(p_{\mu} e p_{p}\right)$. Somamos sobre todas as possibilidades porque a ligação $m\left(p_{p u}\right)$ já estả ativada, e portanto os spins já estão ligados em ambas as redes. O termo

$$
e^{-4 x}\left(1-e^{-2 K+2 x}\right)^{2}
$$

corresponde à probabilidade de não ativarmos $m\left(p_{k}\right)$, mas ativarmos $l\left(p_{\mu}\right)$ e $k\left(p_{w}\right)$.

Efetuando a soma encontramos

$$
P=1-2 e^{-2 \hbar-2 L}+e^{-4 \pi}
$$

que é igual à probabilidade $p_{\text {g }}$ do algoritno de Wiseman e Domany. Já a probabilidade de ligarmos apenas uma das redes en uma configuração do tipo u userá dada por

$$
Q=e^{-4 L}\left(1-e^{-2 K+2 L}\right) e^{-2 K+2 L}
$$

e vemos que esta probabilidade é igual a probabilidade $q_{2}$ do algoritmo de cluster. Concluimos assim que os dois algoritmos são de fato equivalentes. 


\subsection{Algoritmo de Cluster para o Modelo de Ashkin- Teller com Interação de Quatro Spins Antiferro- magnética}

A Hamiltoniana ê dada agora por

$$
\beta H_{t}=-K \sum_{\langle i j\rangle} H_{i j} \mu_{j}-K \sum_{\langle i j\rangle} \omega_{i} \nu_{j}+L \sum_{\langle i j\rangle} H_{i} \mu_{j} \nu_{i} \nu_{j}
$$

onde $K>0$ e $L>0$. A primeira impressão é que o mesmo algoritmo utilizado no caso ferromagnético deve também ser válido aqui. No entanto, a situaçảo é diferente.

Se considerarmos possiveis as mesmos tipos de ligações e usarmos o mesmo tipo de raciocínio utilizado na criaço do algoritmo ferromagnético, conciuiremos que as probabilidades permanecerão iguais, mas com o sinal dos termos proporcionás a $L$ invertidos (como era de se esperar). Mas o algoritmo resultante não será vallido. Por exemplo, a probabilidade $p_{1}$ será dada por

$$
p_{1}=1-2 e^{-2 R+2 L}+e^{-3 K}
$$

e se tomamos $L=K$, por exemplo, teremos qua $w_{1}=-1+e^{-4 K}$, que tuma probabilidade negativa.

O fato do algoritmo para o caso onde a interaçäo de quatro spin é ferromagnética mäo ser mais apropriado é de certa forma esperado, uma vez que a diagrama de fases 6 completamente diferente. Por exemplo, a existencia da fase $<\mu \nu>A F$ deve torat necessária a existencia de ligacōes antiferromagnêtucas en uma das redes, associada a ligacoes ferromagneticus na outra rede, de modo a conseguirmos prestryar configuraçós tipicas desta fase.

Para compreendernos melhor o porquê deste algoritmo não funcionar, considere a seguinte tabela, análoga a do caso ferromagnético, onde apresentamos as possíveis configuraçōes e suas respectivas energias. 


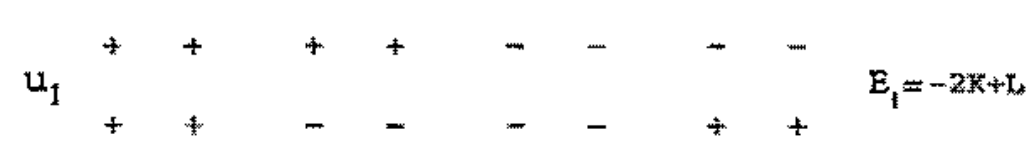

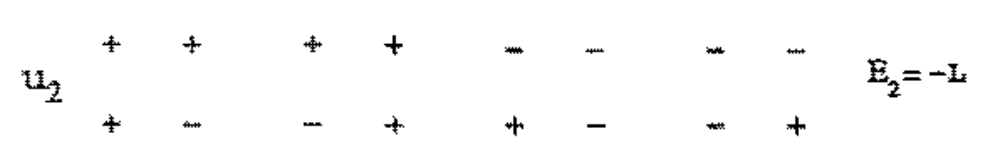

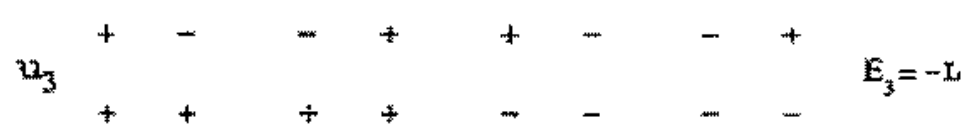

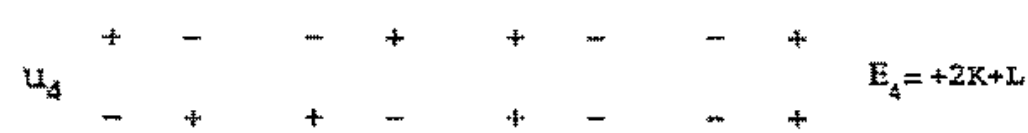

Figura 3.7: Possiveis configuraçoes, com suas respectivas energiat.

A diferença básica em relaçäo ao que ocorre no caso onde a interacăo entre quatro spins é ferromagnética é que aqui, para. $L>K$, são as configuraçōs $u_{2}$ e $u_{3}$ que correspondem ao minimo de energia, e é necessário sermos capazes de preservá-las. Devemos entäo construit um novo algortitmo que inclua operaçōes que congelem estas configuraços, de acordo com a seguinte tabela:

\begin{tabular}{c|c|c|c|c|c|l} 
& & --- & - & & & \\
& & - & - & & &. \\
\hline$\left(u_{1}\right)$ & $p_{1}$ & 0 & 0 & $g_{1}$ & $q_{1}$ & $P_{d}\left(u_{1}\right)$ \\
\hline$\left(u_{2}\right)$ & 0 & $p_{3}$ & 0 & 0 & $q_{2}$ & $P_{d}\left(u_{2}\right)$ \\
\hline$\left(u_{3}\right)$ & 0 & 0 & $p_{2}$ & $q_{2}$ & 0 & $P_{d}\left(u_{3}\right)$ \\
\hline$\left(u_{4}\right)$ & 0 & 0 & 0 & 0 & 0 & $P_{d}\left(u_{1}\right)$ \\
\hline
\end{tabular}

Linhas continuas representam ligaçoes ferromagnéticas, enquanto ligaçōes antiferromagnéticas săo representadas por ligaçôes tracejadas. Note que näo estamos induindo ligacöes simples antiferromagnéticas, uma vez que estas poderiam resultur num congela" 
mento de configurações do tipo $2_{4}$, que são as mais desfavoráveis energeticamente, e que por isto desejamos eliminar. Estamos também utilizando o mesmo valor de probabilidade q1 para duas ligaçôes simples diferentes, o que é justificado por consideraçōes de simetria, jă que a interaçāo entre pares de spins é a mesma nas duas redes. $O$ mesmo argumento é válido para $q_{2}$. Para $p_{2}$ utilizamos o mesmo valor porque configuraçöes $u_{2}$ e $u_{3}$ possuem a mesma energia.

A utilização do método de Wiseman e Domany para determinar as probabilidades do algorítmo representado na tabela anterior năo é possível, já que as linhas referentes à energias $u_{2}$ e $u_{3}$ resultarăo em equaçôes îdênticas, e ficaremos com três incógnitas para duas equações, e sem nenhuma dica de como resolver esta arbitrariedade na escolha de probabilidades.

Uma abordagem alternativa consiste em seguirmos a idéia utilizada para mapearmos o caso ferromagnético, e reescrevermos a Hamiltoniana na forma

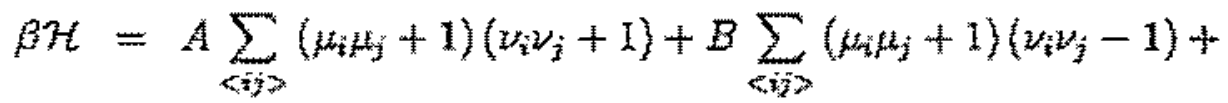

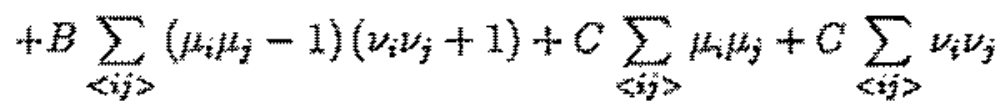

A idéia é que agora cada uma das possiveis operaçôes de ligaçâa corresponde a um respectivo tipo de interação (por exemplo, $p_{1}$ corresponde à interação $A$ ). Reagrupando termos, e impondo que esta Hamiltoniana deve ser igual à Hamiltoniana original, encontramos o seguinte sistema de equações:

$$
\begin{aligned}
& A+2 B=L \\
& A+C=-K
\end{aligned}
$$

Vemos que aqui também temos duas equaçōes para trës incógnitas. No entanto, 
podemos nos orientar aqui por algumas consideraçöes físicas. Vamos considerar dois casos particulares, $K=L$ e $L=0$.

Quando $K=L$, a Hamiltoniana pode ser reescrita como

$$
\beta H=K \sum_{<i j>}\left(\mu_{i} \mu_{j}-1\right)\left(\nu_{i} \nu_{j}-1\right)
$$

que é a Hamiltoniana do Modelo de Potśs Antiferromagnético. As possivieis energias desta Hamiltoniana, em funçăo do estado relativo dos spins em cada uma das subredes, estāo representadas na seguinte tabela:

\begin{tabular}{|l|l|l|}
\hline$\mu_{i} \mu_{j}$ & $\nu_{i} \nu_{j}$ & $\beta \mathcal{U}$ \\
\hline$\neq$ & $=$ & 0 \\
$=$ & $\neq$ & 0 \\
$\neq$ & $=$ & 0 \\
$\neq$ & $\neq$ & $4 \mathrm{~K}$ \\
\hline
\end{tabular}

Onde o sinal de igual significa que os dois spins considerados estäo alinhados, e o sinal de diferente significa que os spins nâo estão alinhados. Vemos que só ocorrerão bonds duplos, todos com probabilidade $p=1-e^{-4 K}$. Neste caso particular devemos ter então que $q_{1}=q_{2}=0$, ou seja, os termos de ligação simples deverão ter interação do tipo $C=x(K-L)$. Vamos considerar alguns valores de $x$ possiveis:

\begin{tabular}{|l|l|l|l|}
\hline$x=-2$ & $x=-1$ & $x=0$ & $x=1$ \\
\hline$C=-2 K+2 L$ & $C=-K+L$ & $C=0$ & $C=K-L$ \\
$A=K-2 L$ & $A=-L$ & $A=-K$ & $A=-2 K+L$ \\
$B=(3 L-K) / 2$ & $B=L$ & $B=(L+K) / 2$ & $B=K$ \\
\hline
\end{tabular}

Por outro lado, sabemos que quando $L=0$ devemos ter um modelo de Ising com duas redes desacopladas, com presença apenas de ligações simples (näo-duplas). A única escolh a de $x$ compatível com essa condição é $x=-1$. Ficamos então com a seguinte Hamiltoniana geral:

$$
\begin{aligned}
\beta H^{\prime}= & -L \sum_{\langle i j\rangle}\left(\mu_{i} \mu_{j}+1\right)\left(\nu_{i} z_{j}+1\right)+L \sum_{\langle i j\rangle}\left(\mu_{i} \mu_{j}+1\right)\left(\nu_{i} \nu_{i}-1\right)+ \\
& +L \sum_{\langle i j\rangle}\left(\mu_{i} \mu_{j}-1\right)\left(\nu_{i} \nu_{j}+1\right)+(-K+L) \sum_{\langle i j\rangle} \mu_{i} \mu_{j}+(-K+L) \sum_{\langle i j\rangle} \nu_{i} \nu_{j}
\end{aligned}
$$


A função de partição é dada por:

$$
\begin{aligned}
Z=\sum \prod_{\left\{\mu_{i}, y\right\}<i j>} & \exp \left[L\left(\mu_{i} \mu_{j}+1\right)\left(\nu_{i} \nu_{j}+1\right)-4 L+4 L\right] \\
& \cdot \exp \left[-L\left(\mu_{i} \mu_{j}+1\right)\left(\nu_{i} \nu_{j}-1\right)-4 L+4 L\right] \\
& \cdot \exp \left[-L\left(\mu_{i} \mu_{j}-1\right)\left(\nu_{i} \nu_{j}+1\right)-4 L+4 L\right] \\
& \cdot \exp \left[(K-L) \mu_{i} \mu_{j}-K+L+K-L\right] \\
& \cdot \exp \left[(K-L) \nu_{i} \nu_{j}-K+L+K-L\right]
\end{aligned}
$$

Para $L<K$, vamos reescrever $\mathcal{Z}$ na forma

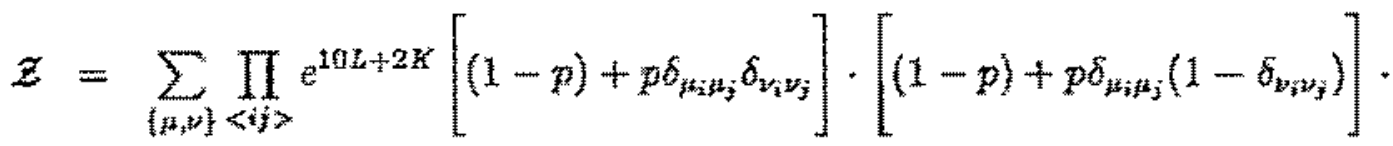

$$
\begin{aligned}
& \cdot\left[(1-p)+p \delta_{v_{i} \nu_{j}}\left(1-\delta_{p_{i} \mu_{j}}\right)\right]\left[\left(1-p_{\mu}\right)+p_{j} \delta_{j i \mu_{j}}\right] \text {. } \\
& {\left[\left(1-p_{\nu}\right)+p_{\nu} \delta_{v_{i} \nu_{j}}\right]}
\end{aligned}
$$

onde

$$
\begin{aligned}
& p=1-e^{-4 L} \\
& p_{\mu}=1-e^{-2 K+2 L} \\
& p_{\nu}=1-e^{-2 K+2 L},
\end{aligned}
$$

Podemos agora calcular as probabilidades correspondentes a cada configuração de ligações possivel, e que correspondem às operaçōes da tabela que define o algoritmo. Por exemplo, a probabilidade de ligarmos spins nas duas redes simultâneamente é dada por

$$
p_{1}=p+(1-p) p_{z} p_{3 x}
$$

Escontramos entäo, seguindo este tipo de raciocínio, 


$$
\begin{aligned}
& p_{1}=1-2 e^{-2 K-2 L}+e^{-4 K} \\
& p_{2}=1-e^{-4 L} \\
& q_{1}=\left(1-e^{-2 K+2 L}\right) e^{-2 K+2 x} \\
& q_{2}=e^{-4 L}\left(1-e^{-2 K-2 L}\right),
\end{aligned}
$$

com o que completamos a formulaçầo do algoritmo. Note que estas probabilidades só sâo válidas quando $L \leq K$. Para $L>K$, constante de interaçăo entre pares de spin representada em (3.39) passa a ser positiva, e devemos então considerar ligacoes simples antiferromagnéticas ao invés de ferromagnéticas. Se procedermos de forma análoga ao cazo anterior, encontraremos uma tunção de partiçăo dada por

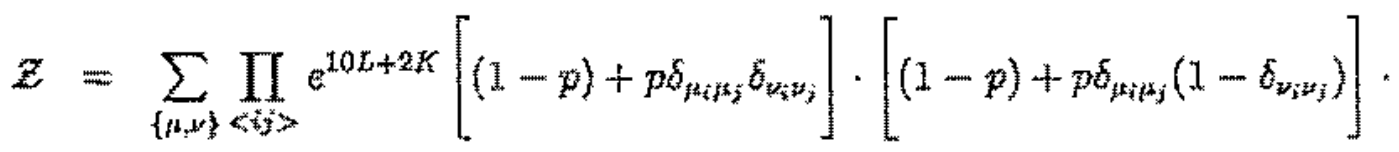

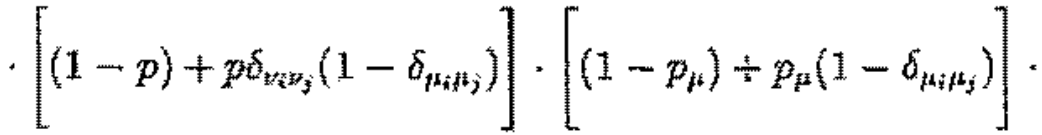

$$
\begin{aligned}
& {\left[\left(1-p_{y}\right)+p_{v}\left(1-z_{z z_{i} z_{j}}\right)\right]}
\end{aligned}
$$

onde

$$
\begin{aligned}
& p=1-e^{-4 L} \\
& p_{\mu}=1-e^{-2 L+2 K} \\
& p_{*}=1-e^{-2 L+2 K} .
\end{aligned}
$$

Embora perfeitamente yailida, estạ escolla não é interessante, porque estarianos entäo thabalhando com uma wabla onde aparecem ligacoes simples antiferronagnéticas, que poden favorecer a manutenção de configuraçöes do tipo $w_{4}$, o que näo interessa. 0 
correto é considerarmos que a partir do ponto onde $L>K$ ligaçôs simples simplesmente deixam de existir, e construir a seguinte tabela para o algoritmo:

\begin{tabular}{c|c|c|c|l} 
& - & -- & - &. \\
& & & $\ldots$ &. \\
\hline$\left(u_{1}\right)$ & $p_{1}$ & 0 & 0 & $P_{d}\left(w_{1}\right)$ \\
\hline$\left(u_{2}\right)$ & 0 & $p_{2}$ & 0 & $P_{d}\left(u_{2}\right)$ \\
\hline$\left(u_{3}\right)$ & 0 & 0 & $p_{3}$ & $P_{d}\left(u_{3}\right)$ \\
\hline$\left(u_{4}\right)$ & 0 & 0 & 0 & $P_{d}\left(u_{4}\right)$ \\
\hline
\end{tabular}

Linhas cheias representam ligaçöes ferromagnêticas, enquanto que linhas tracejadas ligações antiferromagnéticas. Para implementar este esquema, reescrevemos a Hamiltoniana na forma

$$
\begin{gathered}
\beta H=-K \sum_{<i j>}\left(\mu_{i} \mu_{j}+1\right)\left(\nu_{i} \nu_{j}+1\right)+\left(\frac{\alpha+K}{2}\right) \sum_{<i j>}\left(\mu_{i} \mu_{j}+1\right)\left(\nu_{i} \nu_{j}-1\right)+ \\
+\left(\frac{L+K}{2}\right) \sum_{<i j>}\left(\mu_{i} \mu_{j}-1\right)\left(\nu_{i} \nu_{j}+1\right)
\end{gathered}
$$

de forma que cada tipo diferente de interaçäo corresponda a uma das ligações presentes na tabela. A funçăto de partição é dada por

$$
\begin{aligned}
Z= & \sum_{\{i+1\}} \prod_{k j\rangle} \exp \left[K\left(\mu_{i} \mu_{j}+1\right)\left(\nu_{i} \nu_{j}+1\right)-4 K+4 K\right] \\
& \cdot \exp \left[\left(-\frac{L+K}{2}\right)\left(\mu_{i} \mu_{j}+1\right)\left(\nu_{i} \nu_{j}-1\right)-2 L-2 K+2 L+2 K\right] \\
& \cdot \exp \left[\left(-\frac{L+K}{2}\right)\left(\mu_{i} \mu_{j}-1\right)\left(\nu_{i} \nu_{j}+1\right)-2 L-2 K+2 L+2 K\right]
\end{aligned}
$$

Definindo agora as probabilidades

$$
\begin{aligned}
& p_{1}=1-e^{-4 K} \\
& p_{2}=1-e^{-2 K-2 L} \\
& p_{3}=1-e^{-2 K-2 L},
\end{aligned}
$$

é possível reescrever a função de partiçăa na forma 


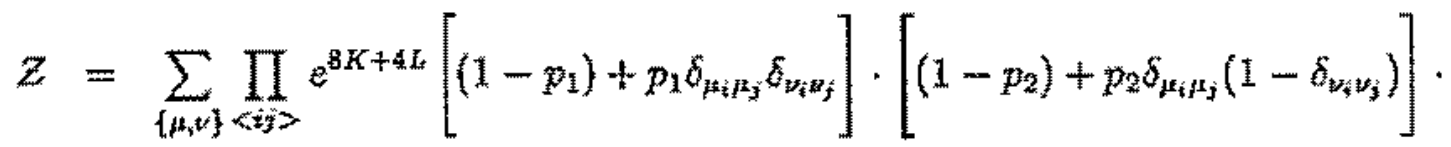

$$
\begin{aligned}
& \cdot\left[\left(1-p_{3}\right)+p_{3} \hat{\delta}_{v_{i} w_{j}}\left(1-\delta_{\mu_{i} z_{j}}\right)\right] \text {. }
\end{aligned}
$$

Completamos assim a definição do algoritmo de cluster para o caso $L>K$.

Finalmente, aqui tambérn é possível definirmos um algonitmo de embedding, o interessante é que ele não será equivalente ao algoritmo encontrado por meio do mapeamento, como ocorria no caso ferromatgnético.

Após fixarmos os valores de spin de uma das redes, por exemplo $\mu$, Hamiltoniana passa a ser dada por

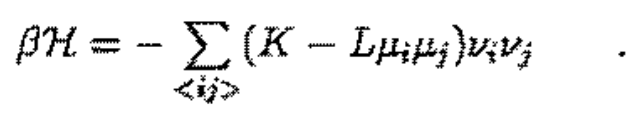

equivalente à uma Hamiltoniana de Ising com constante de acoplamento ferromagnética dada por $\left(K-L t_{i}, \mu_{j}\right)$. Note no entanto que as probabilidades assim obtidas näo são equivalentes as probabilidades obtidas no algoritmo "completo". Por exemplo, a probabilidade de ligarmos spirs $\nu$ em uma configuração do tipo $z_{1} \hat{e}$ dada por

$$
p=p_{1}+q_{1}=1-e^{-2 K-2 I_{i}} \quad
$$

diferente da probabilidade obtida através do algoritmo de enbedding, $p=1-e^{-2 K+2 L}$. Isto acontece porque o algoritmo de "embedding" pode tirar proveito de saber que a configuraçäo da outra rede está fixa na hora de ativar uma dada ligação. Por exemplo, para $p=-1$ e $T=0$ configuraçöes do tipo $u_{1}$, $u_{2}$ e $u_{3}$ possuem a mesma energia, e o algoritmo de embedding "sabe" que se um par de spins da rede fixa estiver paralelo, entäo qualquer configuraçăo da rede môvel possuirả a mesma energia. Já o algoritmo "completo" precisa congelar configuraçöes nas duas redes, para evitar que seja atingida uma configuração do tipo $u_{4}$. 


\subsection{Mapeamento do Modelo de Ashkin-Teller com Interação de Quatro Spins Antiferromagnética em um modelo de percolação.}

Yamos mostrar aqui que o algoritmo de cluster encontrado para o caso antiferromagnético também corresponde a um modelo de percolaçüo.

Na verdade, a forma que utilizamos para encontrar o algoritmo praticamente já define como devemos escrever o mapeamento. No caso $L<K$, escrevemos a funça de partição nia forma

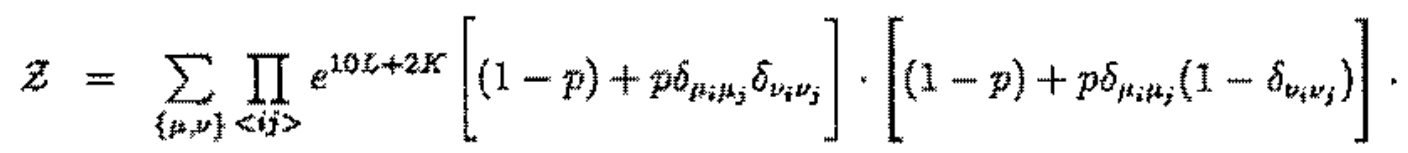

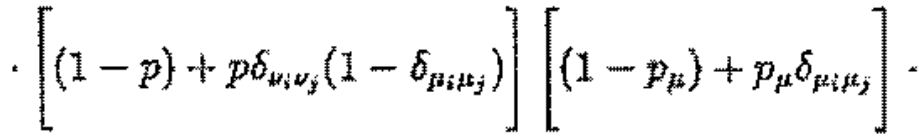

$$
\begin{aligned}
& {\left[\left(1-p_{z}\right)+p_{z} \delta_{w_{\xi} w_{j}}\right] \text {. }}
\end{aligned}
$$

Para completarmos o mapeamento, basta associarmos à cada diferente tipo de ligaça uma nova variável, em seguida somarmos sobre as variáveis de spin reapeíando aos vínculos produzidos pelos $\delta$ 's presentes em cada ligạäo. Vamos começar associando variáveis de ligaçäo da seguing forma:

$$
\begin{aligned}
& \delta_{i^{i} i I_{j}} \delta_{v_{i} t_{j}} \rightarrow l \\
& \delta_{i i_{i j} \mu_{j}}\left(1-\delta_{p_{i} \nu_{j}}\right) \rightarrow k \\
& \delta_{v_{i} \nu_{j}}\left\{1-\delta_{z_{i} z_{j}}\right\} \rightarrow m \\
& \varepsilon_{1 i^{2} 5_{y}} \rightarrow r \\
& \delta_{\text {witis }} \rightarrow s
\end{aligned}
$$

Podemos entāo reescrever a funçäo de partiçäo na forma 


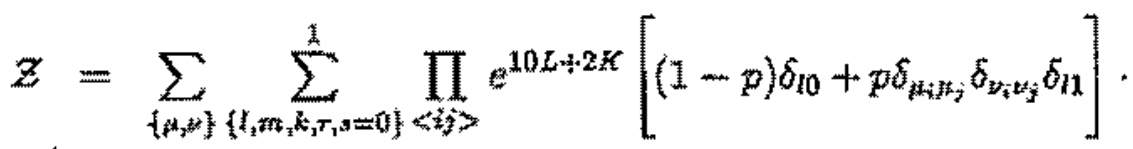

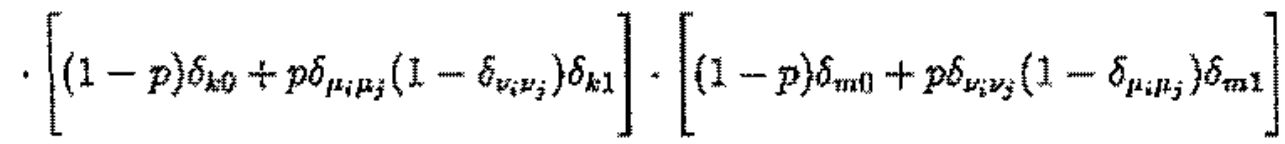

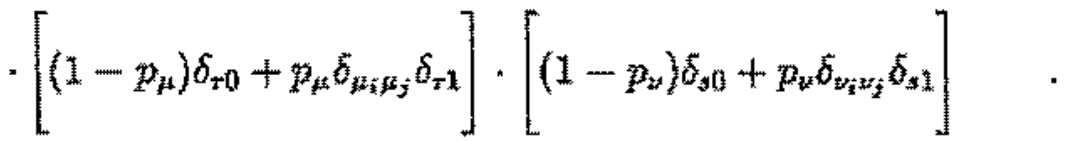

Esta a função de partição conjunta entre o motelo termodinâmico e o modelo de percolação. Para somarmos sobre as variáveis de spins, precisamos definir como identificar os clusters. Dois spins de uma dada rede pertenceräo ao mesmo cluster se existir um caminho continuo de ligacoes entre eles. Note que, diferentemente do caso ferromagnético, os clusters agora sâ̋ formados por dois tipos de ligacöes, ferromagnéticas e anufferromagnéticas, o que faz com que os spins pertencentes ao cluster nấo possuaru necessariamente o mesmo sigal. De qualquer forma, para um dado cluster continuam sendo possiveis apentas duas contugruraçōes de spins, e após somarmos sobre as configurações de spin encontramos

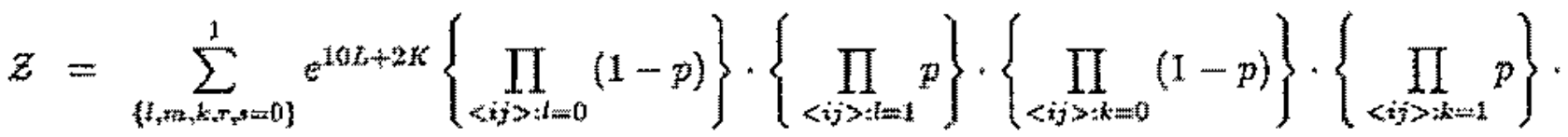

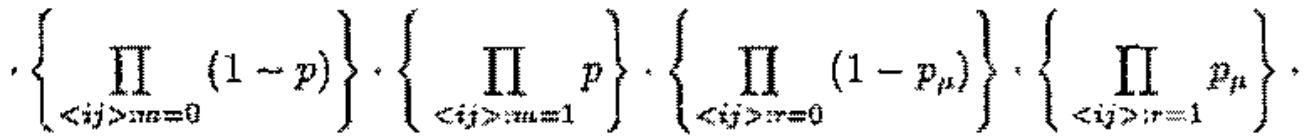

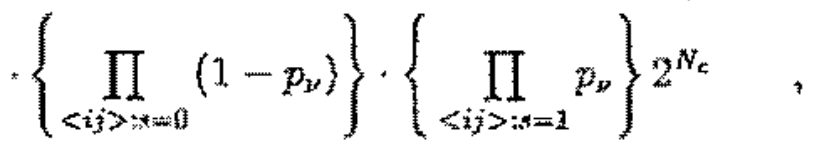

onde $N_{n}$ é o dúmero total de clusters nas duas redtas. A interpretação da funçấo de particäo acima é de que, para cada vizinhanca $\langle\hat{\imath} j>$ de cada una das redes, atriburmos uma variăvel de ligagāo zero ou um para cada um dos cinco típos possiveis de ligaçăo. Correlaçōes năo locais seräo introduridas pelo fator $2^{N_{c}}$. Note ainda que existem configuraçoes de ligaçōes com peso estatístico zero, quando mativarmos por exemplo ligaçäes 
do tipo $l$ e k na mesma vizinhança, devido à ortogonalidade dos zeros presentes em cada uma däs ligagös.

O procedimento para mapeamos o caso $L>K$ é o mesmo, sendo agora necessárias apenas três variaveis de ligação, por sỏ existirem três diferentes tipos de ligação. Após introduzirmoa estas variáveis de ligaçăo e somarmos sobre as variáveis de spin encontraremos a seguinte expressta para a função de partição:

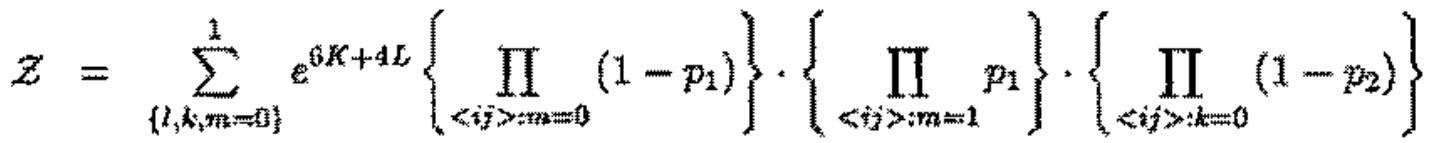

$$
\begin{aligned}
& \left\{\prod_{\langle i j>: k=1} p_{p_{2}}\right\} \cdot\left\{\prod_{\langle i j>: t=0}\left(1-p_{3}\right)\right\} \cdot\left\{\prod_{\langle i j>i t=1} p_{3}\right\} 2^{N_{c}} .
\end{aligned}
$$

Novamente correlaçōes não locaís seräo introduzidas pelo fator $2^{N_{s_{a}}}$ e aqui também

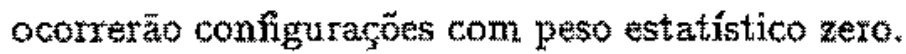

\subsection{Resultados Numéricos}

Dispondo agora de algortmos de cluster capazes de simular todo o diagrama de fases co modelo, é interessante estudar a existência ou nâo da tase de Baxter kssimetrica, conforme sugerido por simulaçóes de Monte Carlo ffetuadas por Ditzian et al. [DBGK80], e posteriormente encontrada através de uma abordagem via árvore de Cayley [COS87].

Se esta fase de fato existir, ela será de difícil deteckäto, por ser bastante estreita, além da diferença entre a magnetizaçäo nas redes ser pequena, podendo acontecer que maguetizacöes diferentes nas duas redes representem apenas um efeito de tamanho finito. A determinaçāo da existência desta fase portanto tarefa computacional bastante dificil, o que justifica a utilização de algorimos de cluster na simulaçäo, através dos quais esperamos obter resultados precisos.

Os resultados computacionais de Ditzian indicam a possibultade de existancia desta fase em uma temperatura $T=4 / 3$, para uma regia compreendida ente $p=-0.78$ e $p=$ 
-0.75. Nesta regiäo, devemos uhilizar o algoritmo proposto para o caso onde interaça de quatro spins é antifetromagnética, ou antāo o algoritmo de embedding. Conforme explicado anteriormente (ver pág. 80), estes dois algonitmos näo săo equivalentes, como ocorre no caso onde a interação de quatro spins é ferromagnetuca, e devemos decidir qual deles utilizar.

A nossa escolha foi pelo algoritmo de embeddiug, pelos motivos explicados anteriormente (pág. 80); acreditamos que o fato de uma das redes estar fixa traz vantagens nata hora de transitarmes entre os diferentes estados possiveis, eliminando possiveis efeitos de histerese permitindo uma descorrelação mais rápida entre as configuraçōes geradas.

A figura $(3.8)$ mostra os resultados obtidos para a magnetizaçäo em uma rede cúbica de dimensão linear $L=10$, quarto varremos o diagrama de fases variando p, em uma temperatura $T=4 / 3$ fixa.

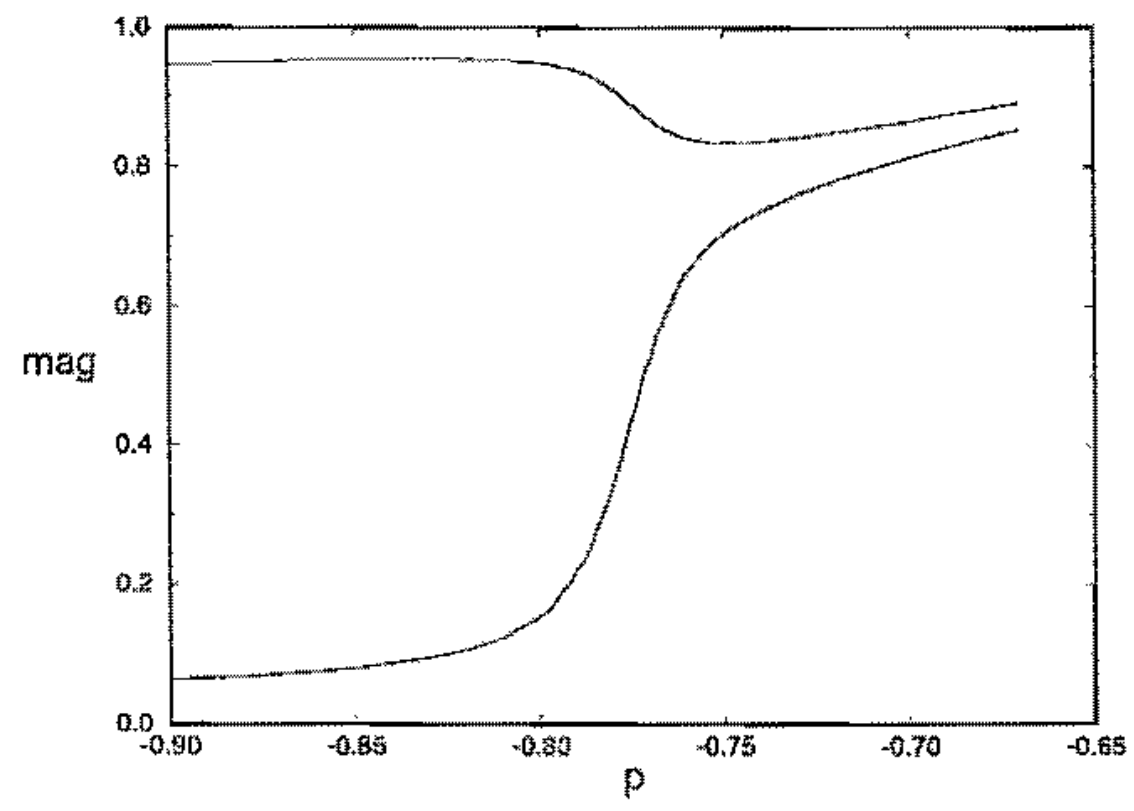

Figura 3.8: Mator e memor magnetiaacäo, en uma rede de dimensäo linear $L=10$.

Devido a feitos de tamanho finito, empre possível uma troca de papel entre az: redes, com a rede que apresentava maior maguetizaçăo assumindo valores de magnetizaçắo 
tipicos da rede de menor magnetizaçăo. Para evitar estes efeitos, estaremos sempre medindo a maior a menor magnetizaçâ, ao invés da magnetizaç̃o ema cada uma das redes. A região entre $p=-0.9$ e $p=-0.8$ corresponde à fase $<\mu$, onde uma rede está magnetizada e autra nä̌o. Em tomo de $p=-0.8$ ocorre uma transição, e as duas fases passam a apresentar magnehizaçă丶 diferente de zero. Note no cutanto que as duat magnetizaçōes näo tornam-se iguais int thatamente, permanecendo diferentes durante uma certa região de variaçäo de $p$. A questäo é saber se este c realmente uma característica de uma nova fase, a fase de Baxter Assimétrica, ou se é apenas um efeito de tamanho finito. Neste úlimo caso, ao ammentarmos o tamanho da rede simulada as duas curvas tenderiam a se encontrat. A figura (3.9) mostra o que acontece com as curvas de magnetizaçäo ao aumentarmos o tamanho da rede.

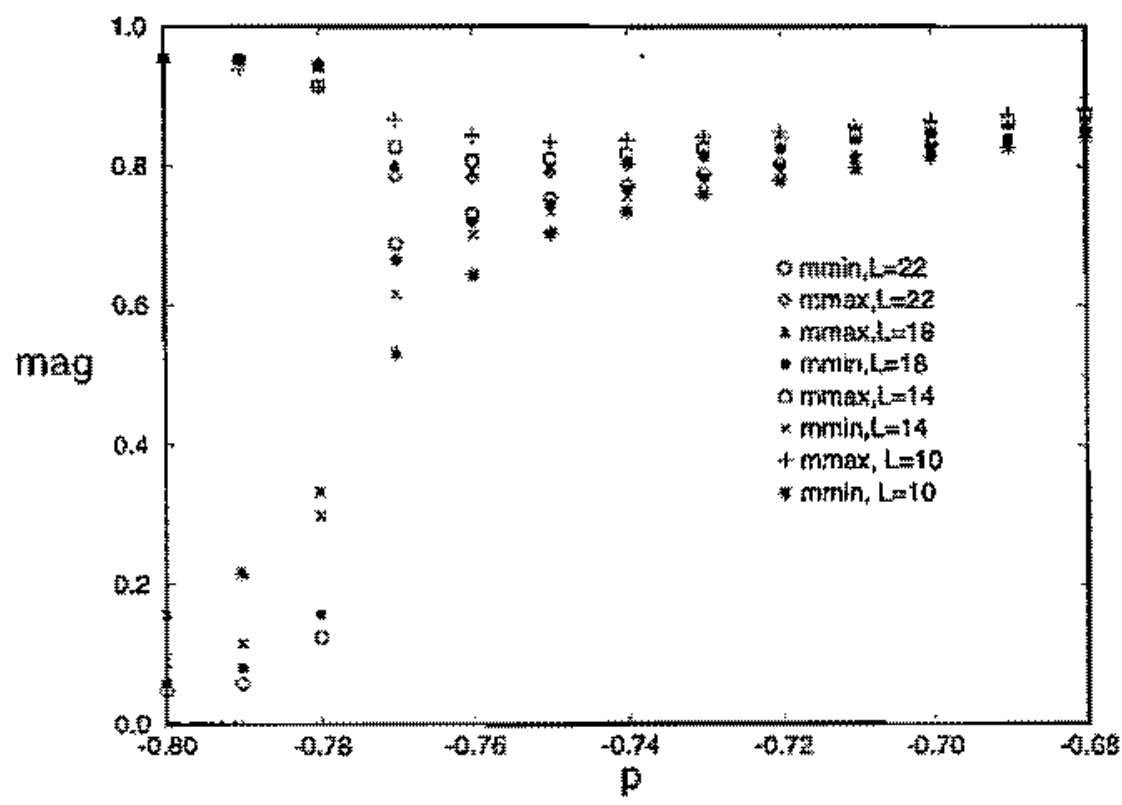

Figura 3.9: Maior e menor magnetizaçăo, para diversos tamanhos de rede.

Vemos que de fato os valores para a magnetizaçäo se aproximam, mas näo é possível contluir se estes valores iräo se encontrar ou näo. Para degarmos a uma conclusăo,

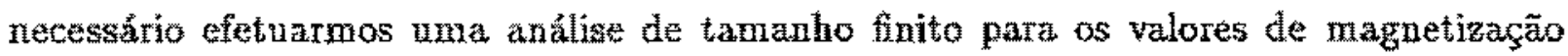


obtidos.

A figura (3.10) representa ajustes de tamanho finito para a rede de menor magnetizaçäo quando $p=-0.7$, considerando-se uma let de escala $m_{E}=m_{\infty}+a L^{+m b}$, e testando diversos valores possíveis para o expoente $b$. Redes de tamanho $L=10$ e $L=12$ näo foram levadas em consideraça no ajuste, que foi efetuado corn redes de tamanho $L=14$ até $L=22$. A estatítica utilizada é de $6 \times 10^{5}$ passos de Monte Carlo, depois de esperarmos 10.000 passos para a termalizaçäo do sistema.
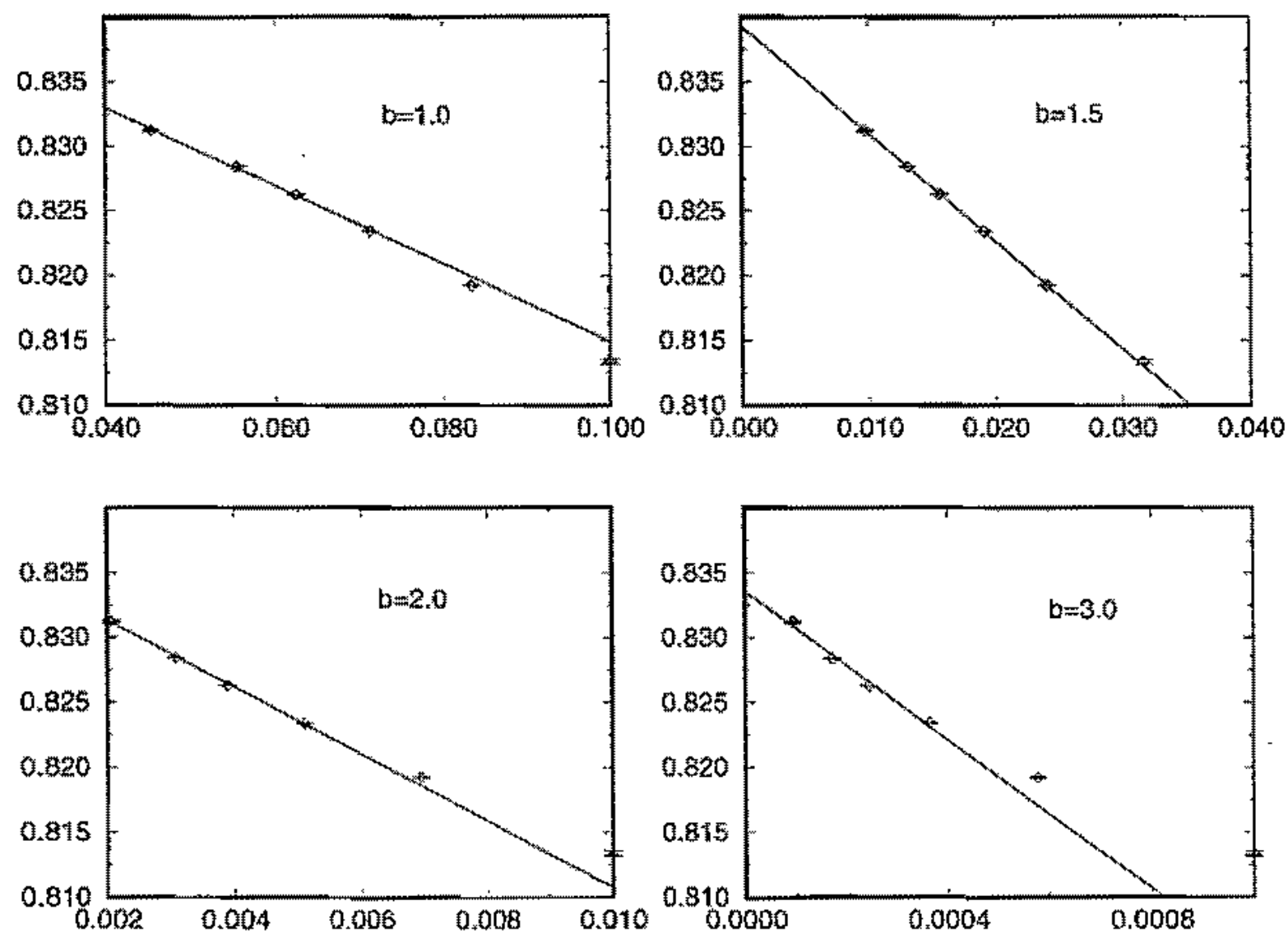

Figura 3.10: Diferentes ajustas para o cálculo de $m_{\infty}$, para a nenor magnetizaça. 0 eixo vertical representa valores de $m_{L \text {; }}$ enquanto que o eixo horizontal $L^{-\frac{t}{t}}$.

Vemos que o mellor ajuste corrasponde a $b=1.5$, sendo que para valores de $b$ menores 
: curva apresenta uma certa concavidade em relaçäo ao ajuste linear, concavidade esta que inverte-se para valores de $b$ malores do que 1.5. A figura (3.11) representa o mesmo tipo de ajuste, agora para a rede de maior magnetizaçăo.
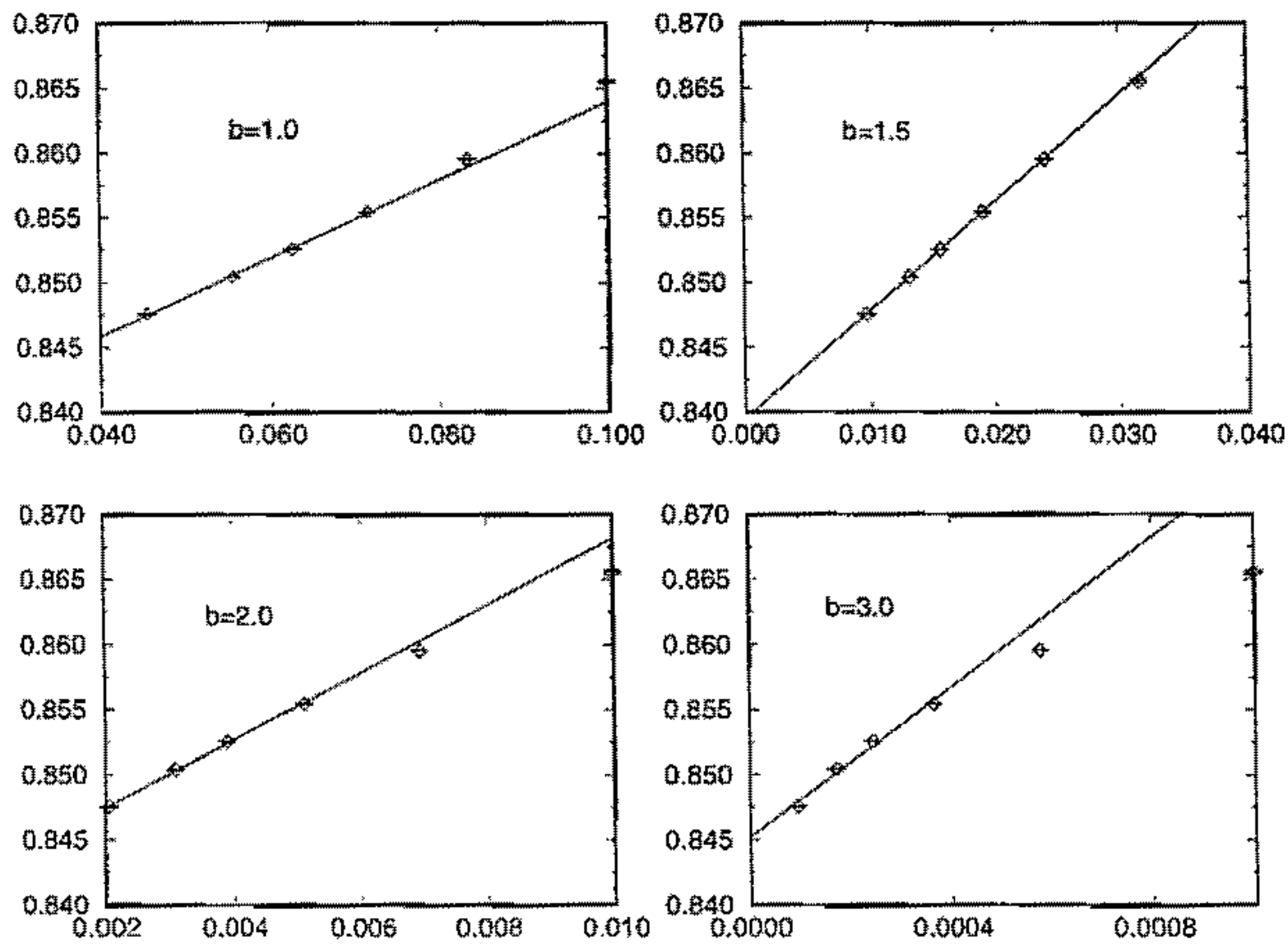

Fignu 3.11: Diferentes ajustes para o cálculo de $m_{\text {se }}$ para a maior magnetização. $O$ eixo vertical representa valores de $m_{L}$ : enquanto que o eixo horizontal $\mathrm{L}^{-t^{*}}$.

Do mesmo modo que ocorria para a menor magnetizaç⿰彳口⿻, $b=1.5$ nitidamente corresponde a melhor ajuste. O mesmo tipo de análise foi efecuado para diferentes valores de $p$, a fim de determünarmos a mugnetização da rede infnita, e deterninarmos se a major e menor magnetizază coincidem neste limita. Para todos os valores de $p$ analisados 0 melhor ajuste foi obtido com $b=1.5$. Os resultados estato na tabela a seguir, que mostra 
valores da maior e menor magnetizaçāo obtidos através de um ajuste de tamanto finito, bem como o coeficiente angular da reta obtida.

\begin{tabular}{|c|l|l|l|l|}
\hline$p$ & \multicolumn{2}{|c|}{ mmax } & \multicolumn{2}{c|}{ mmin } \\
\hline & $\mathrm{mg}$ & $\mathrm{tg}$ & $\mathrm{mg}$ & $\mathrm{tg}$ \\
\hline-0.71 & $0.8271(3)$ & $-0.956(2)$ & $0.8272(1)$ & $0.957(8)$ \\
\hline-0.72 & $0.8146(1)$ & $-1.122(9)$ & $0.8143(2)$ & $1.125(11)$ \\
\hline-0.73 & $0.80100(5)$ & $-1.308(4)$ & $0.80100(10)$ & $1.322(9)$ \\
\hline-0.74 & $0.7876(2)$ & $-1.62(1)$ & $0.7872(2)$ & $1.601(9)$ \\
\hline-0.75 & $0.7728(3)$ & $-2.05(3)$ & $0.7730(8)$ & $1.98(2)$ \\
\hline-0.76 & $0.7594(7)$ & $-3.03(5)$ & $0.7577(1)$ & $2.692(7)$ \\
\hline-0.77 & $0.755(2)$ & $-6.8(2)$ & $0.7402(3)$ & $4.68(2)$ \\
\hline
\end{tabular}

Exarninando a tabela, concluimos que existem valores de $p(p=-0.76$ e $p=-0.77)$ para os quais a magnetizaçä́n nas duas redes pode de fato näo coincidir, mesmo quando tomamos o limite de uma rede inñnita. A fase de Baxter Assimêtrica estaria presente entáo até o valor $p=-0.76$. Se a fase de fato existir, o outro limite da região de existência desta fase será dado pela iransiçäo entre esta fase e a fase $\langle\mu\rangle$, onde apenas uma rede estúx maxnetizada.

Determinarmos a temperatura de transiçâo entre estas c̀uas fases através da divergência que ocorre na susceptibilidade magnética das redes de maior e menor magnelização, representadas ras figuras (3.12) e (3.13). A estatística utilizado é a nesma que a utilizada para a determinaçāo da magnetizaçăo. exceto inas regioes de máximo da susceptibilidade, onde estatísticas de ate $10^{7}$ passos de Monte Carlo foram utilizadas para uma determinaçāo precisa de $p_{L}^{*}$; valor de $p$ que corresponde ao máximo da susceptibilidade, en uma rede de dimensäo linear $L$. 


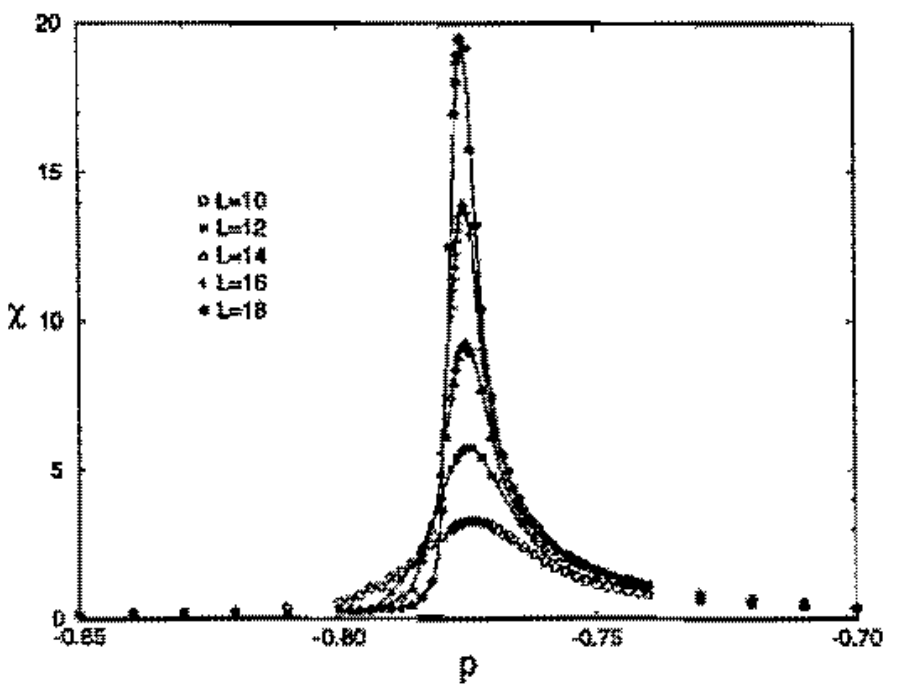

Figura 3.12: Curvas de susceptibilidade para a rede de maior magnetizaçäo.

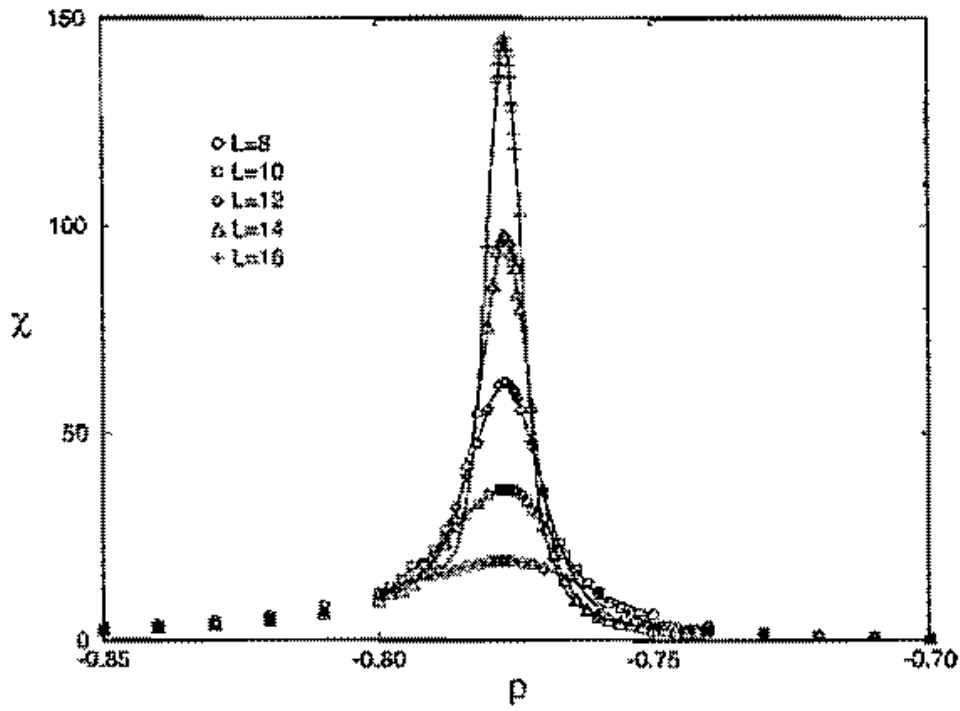

Figura 3.13: Curvas de susceptibilidade para a rede de menor magnetizaçăa. 
Para deterniniarmos a temperatura de transiçă̄o de uma rede infinita precisamos supor aqui também um comportamento de escala na forma $p_{L}^{*}=p_{\infty}^{*}+x L^{-y}$, onde $p_{L}^{*}$ é valor de $p$ que corresponde ao mâximo da susceptibilidade em uma rede de dimersäo linear $L_{2}$ e o expoente $y$ depende da nătureza da transiçăo. Efetuando uma anălise análoga a utilizada para a magnetização, encontramos que aquỉ também o expoente que produz um melhor ajuste é dado por $y=1.5$. Os valores de $p_{\infty}^{*}$ são dados entäo por $p_{\infty}^{*}=-0.7769(1)$, para a rede de maior magnetizaçâ, e $p_{\infty}^{*}=-0.7763(1)$, para a rede de menor magnetizaçäo.

Os ajustes obtidos estăo representados nas figuras (3.14) e (3.15).

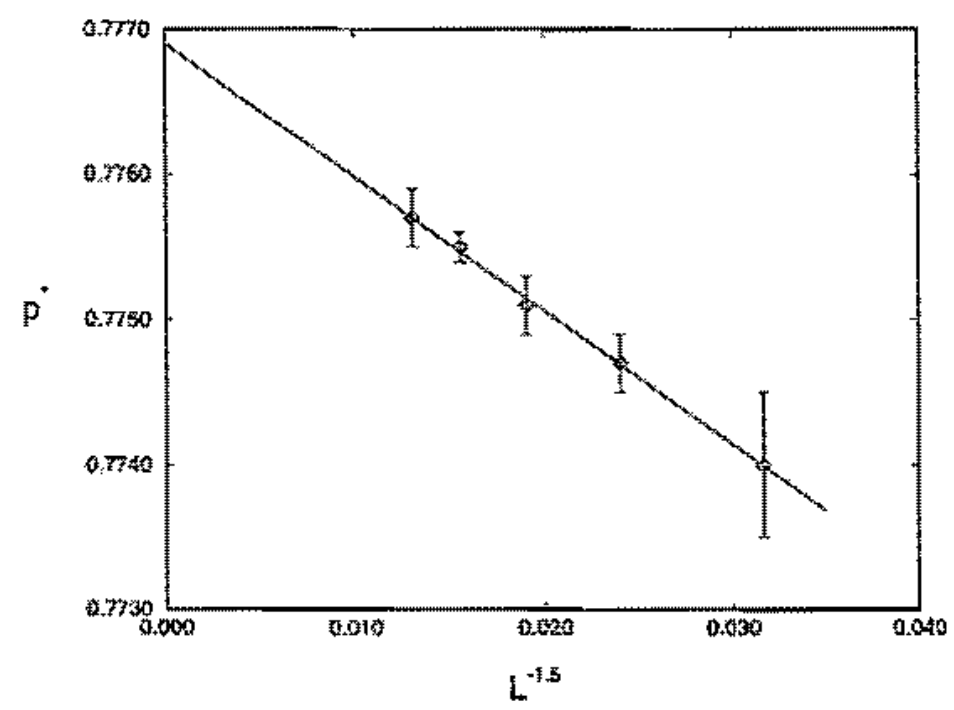

Figura 3.14: Ajuste para determinação de $p_{\infty}^{*}$ para a tede de maior magnetizacăon. 


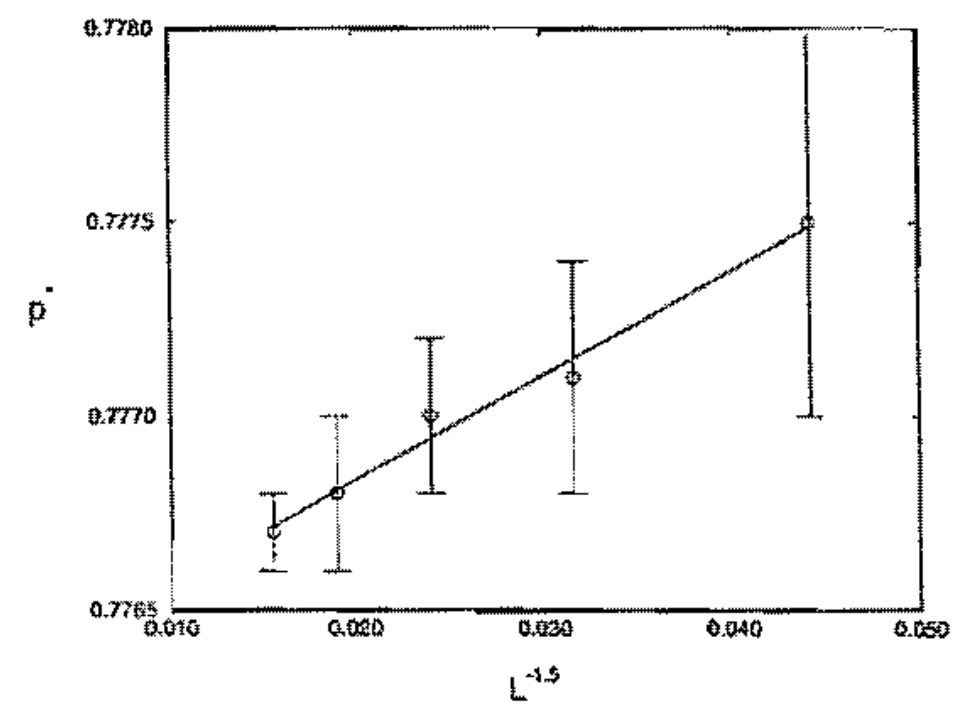

Figura 3.I5; Ajuste para determinaçäo de $p_{\text {to }}^{*}$ para a rede de menor magnetizaça

Qual é a ordem da transiçāo? Todos os ajustes de apresentaram comportamento proporcional a $L^{-1.5}$. Este expoente näo corresponde a nenhuma combinaçấo obvia de expoentes de modelos tridimensionais, sendo por outo lado igual a $\sqrt{\mathrm{V}}$. Se esta for a origen deste expoente, entầo esta é uma transiçäo de 1 arden. onde o deslocamento do parâmetro que controla a transiçāo é dado agora por $\sqrt{V}$ : em contraste com a dependência com volume da rede prevista para o Modelo de

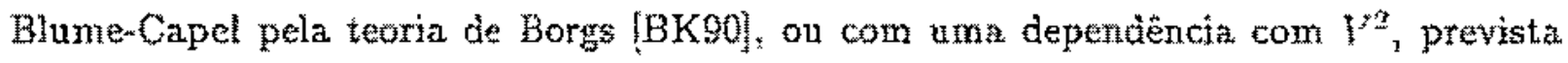
para trartisoes ale primetra ordem assimétricas.

A caracterizaçäo da transica como sendo de 1 a ordem pode ser ainda confimada de outras maneizas. Por exemplo. o máximo da susceptibilidade om funçäo do tamanho de rede ten un comportamento que depende claramente com o volume dá rede. conforme mostra as figuras $(3.16)$ e $\left(\begin{array}{c}3 \\ y^{2}\end{array} .7\right)$. 


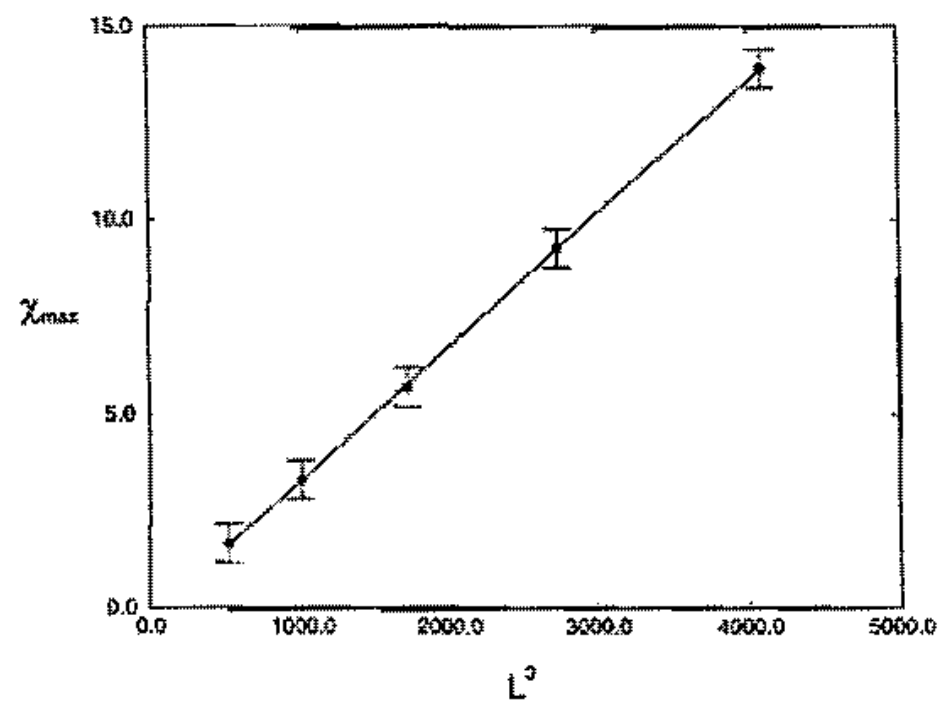

Figara 3.16: Mäxino da susceptibilidade em funç艹o do tananho da rede, para a rede de maior maguetizaçẵo.

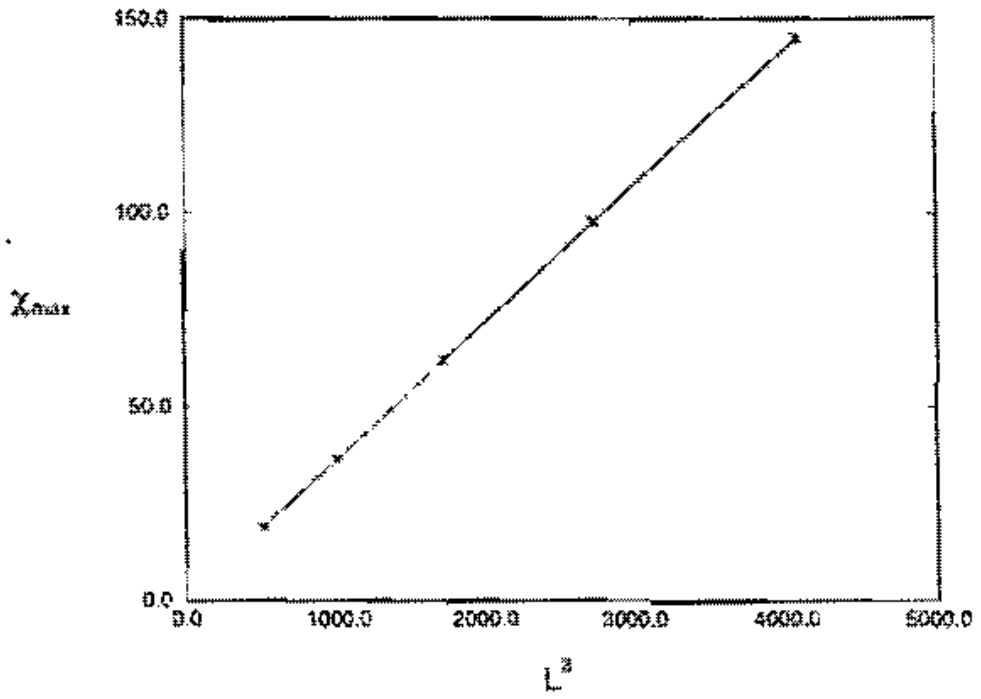

Figuta 3.I7: Máximo da susceptibitidade em funçăo do tamanho da rede, para a tede de menor magnetiação. 
As figuras (3.18) (3.19) mostram o colapso de dados obtido a partir das curvas de susceptibilidade, considerando-se que a transiçào é de $1^{\mathrm{a}}$ ordem.

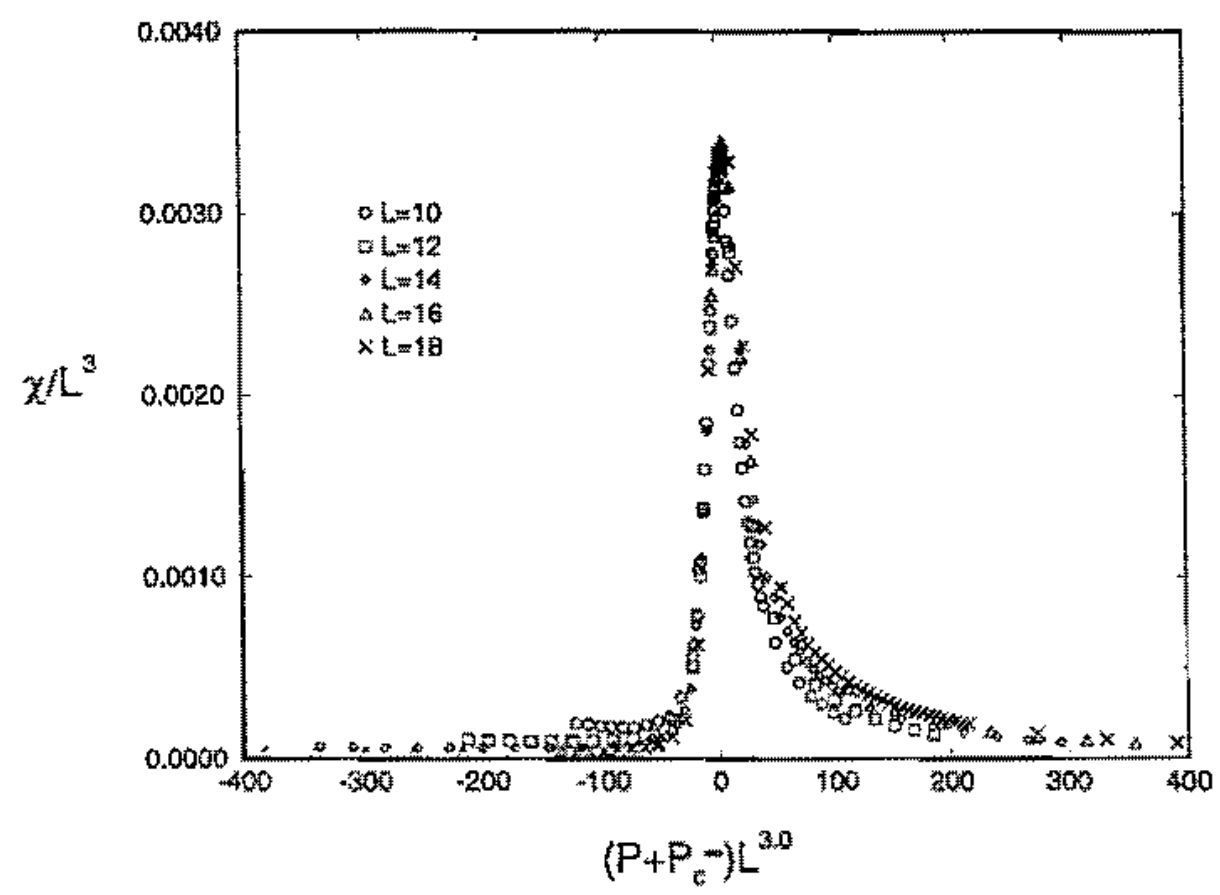

Figura 3.18: Colapso de dados para a susceptibilidade, rede de maior magnetizaçăo.

Baseados nas análises apresentadas ata aqui, nossa conclusăo é a de que a faze de Baxter Assimétrica năo existe em uma rede cúbica, no menos para a temperatura para a qual antes se acreditava que da pudesse existir. A fase $\langle\mu\rangle$ transita diretamente para a. ase de Baxter Simétrica através de uma transiçấo de $1^{\text {a }}$ orden, conforme previsto pela abordagem de campo médio.

Embora a antise de dados para a magneh̉zacăo (pág. 88) pareça indicar que a fase pode existir para valores de $p=-0.76$ e $p=-0,7$, as outras analises efetuadas aqui näo estāo de acordo com esta possibilidade. Por exemplo, os valores de p p fo valor de 


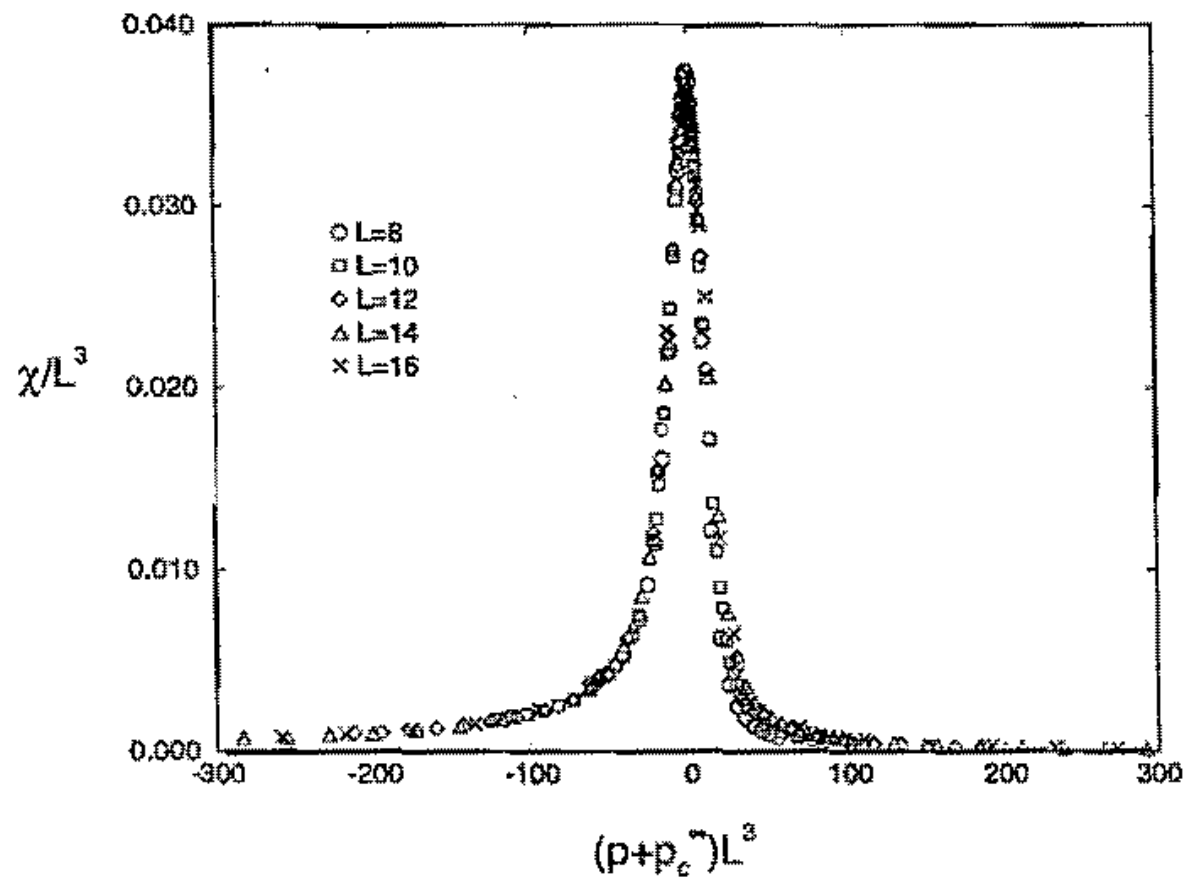

Figura 3.19: Colapso de dados para a susceptibilidade, rede de menor magnetizaçââ.

p para o qual a susceptibilidade de uma rede infinita diverge) para as redes de maior e menor magnetizaçă näo coincidem, o que inđica que nossa análise está subestimando os erros estatisticos envolvidos, o que explica porque os valores da magnetizaçäo resultam diferentes para $p=-0.76$ e $p=-0.77$. A provăvel fonte destes erros está no fato de năo considerarmos um erro intrínsico ao expoente $b$ (ou $y$ ). Com isto, estamos assumiado que este vaior ê conhecido com exatidäo, de acordo com nossa hipótese de que o sistema tem um conportamento de escain que depende de $\sqrt{V}$, mas o oue pode estar ocorrendo é que correçós devido ao tamanho finito do sistema estejam modiñcando este valor. Se supormas por exenuplo que $y=2.0$ encontraremos valores iguais para o máximo das susceptibilidades dados por $p=-0.7765(1)$, o que mostra que tealmente os valores distintos encontrados anteriormente para $p^{*}$ săo uma consequência da análise de erros 
efetuada não levar em consideraçăo todata as fontes de arro envolvidas.

Outra confirmaçầ deste argumento é o fato do colapso de dados para magnetizaça não estar täo preciso quanto o colapso de dados para a rede ds menor magnetizaçăo, o que indica que o valor de $z_{\infty}^{*}$ nầo estâ preciso o suficiente.

Ax curvas de susceptibilidada obtidas apresentam tambem apenas um mâtino, que está em desacordo com a existência da fase de Baxtez Assimétrica, porque tutäo devexianos encontrar dois máximos, quando entramos na fase e quando saímos dela. 


\section{Capítulo 4}

\section{Mapeamento do Modelo de Blume-Capel em um Modelo de Percolação}

Nos mapeanentos estudados até aqui, estivemos lidando sempre com variáveis tipo Ising $( \pm 1)$, onde as transiçöes que ocorrem são constituídas por mudanças no ordenamento do sinal dos spins. Desta forma, as clusters que representam as excitaçôes do modelo são clusters de sinal, o que explica porque algoritmos de embedding são tão eficientes nestes casos.

No modelo de Blume-Capel a situação ê diferente, porque além dos estados de Ising \pm 1 temos tambén um terceiro estado de spin, $S=0$, que torna o modelo assimétrico. Além de uma linha critica de transição tipo Ising, existirá tambén uma linha de transiçäo de $1^{\text {t }}$ ordem: orde ocorrem transigöes entre spins $11 \rightarrow 0$, encontrando-se as duas curvas em um ponto tricrítico.

Descreveremos aq̣ui um algoritmo de cluster desenvolvido por nós que é capaz de simular o modela, e que resulta na formaçăo de clusters constituídos também por spins zero, por paradoxal que isto possa parecer, já que spins zero năo interagem com os seus vizinhos. A inclusāo deste novo tipo de spin modifica completamente o cenário dos clusters formados: ao contrário cie algoritmos anteriores, encontraremos aqui dois tipos diferentes 
de clusters, que podem assumix diferentes estados de spin. Veremos que um deles está ligado a transiçoes críticas tipo Ising no modelo, enquanto que o outro é fesponsável pelas transiģöes que ocorrem ao longo da linha de $1^{\text {a }}$ ordem. Esperamos entâo no ponto tricritico uma transiçāo entre os tipos de cluster característicos de cada uma das transiçöes, o que abre a possibilidade de caracterizarmos propriedades fisicas tricriticas em termos das propriedades dos clusters formados.

Por tado isto, o mapeamento do modelo em um modelo de percolação que resulte na formação de clusters eqquivalentes ao do algoritmo desenvolvido desempenha aqui um papel fundamental, porque teremos mostrado entäo que a construçăo dos clusters nầo é apenas um recurso computacional para efetuarmos a simulação, e sim uma construção que reflete diretamente propriedades da função de partiçäo.

Mostramos neste capitulo que, embora bastante complexo, este mapeamento de fato existe, e nos conduz ao algoritmo de cluster destnvolvido anteriormente. Podemos entāo relacionar propriedades de clusters formados na simulaçäo com propriedades físicas do modelo.

\subsection{O Modelo de Blume-Capel}

A Hamiltoniara do modelo é definida como

$$
H=-K \sum_{\langle i j\rangle} S_{i} S_{j}+\Delta \sum_{i} g_{i}^{2} \sim H \sum_{i} S_{i}, \quad S_{i}= \pm 1,0
$$

onde a primeira somatória é sobre spins printeiro viainhos na rede, $\Delta$ representa um campo cristalino ou um potencial químico (dependendo da interpretaçäo que damos h̀s variáveis de spin], e $H$ t um campo magnético. O modelo foi proposto por Biume [Blu66] e Capel [Cap66] para explicar transiçoes de 1 a orden que ocorrem em dióxido de Urânio, e que săo controladas por efeitos magneto-mecânicos.

Um dos aspectos mais interessantes do modelo é a ocorrência de um ponto tricrítico, 
onde três fases que coexistem ao longo de uma linha tripla tornam-se indistinguíveis. 0 diagrama de fases do modelo \&́ representado esquematicamente na figura (4.1),

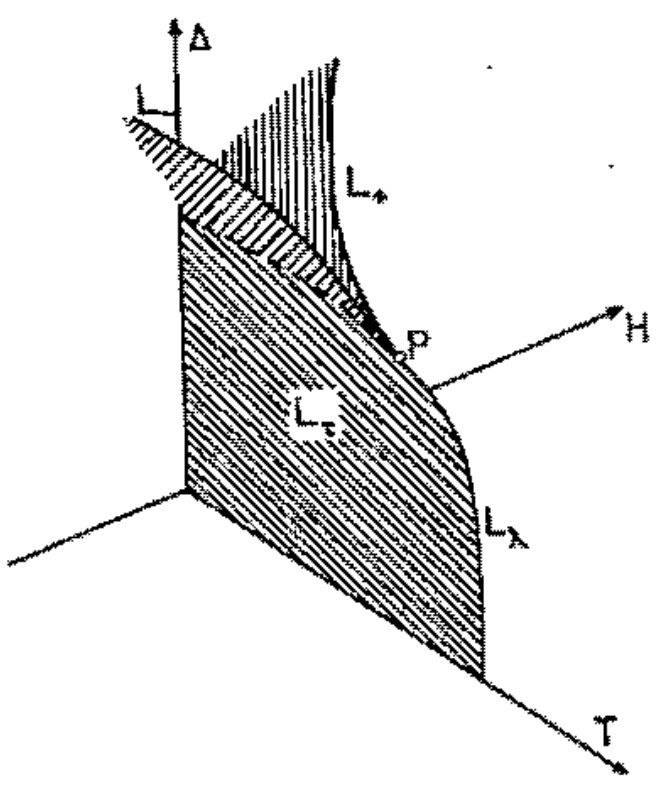

Figura 4.1: Representação esquemática do Modelo de Blume-Capel.

Na superfície $L_{\tau}$ duas fases ferromagnéticas coexistem, com orientaçäo de spin opostas. Esta superficie é delimitada por uma linha de pontos críticos tipo Ising $L_{\lambda}$ e uma linha tripla (tracejada na figura) de $1^{\text {a }}$ ordem, onde estas duas fases ferromagnëticas e mais una fase paramagnética coexisten. Estas duas curvas. assim cono as linbas criticas $L_{7}$ e L... encontram-se no ponto $P$, que é o ponto tricrítico.

A localização do ponto iricritico foi alvo de estudos em diversos trabalhos. Podemos citar como os mais precisos os resultados de Landau e Swendsen [LS86], que utilizaram uma técnica de grupo de renormalizą̧ăo via Monte Caylo, e os resultados de Beale [Be286], atraves de uma andilise de tamanho finito a partir da matriz de transferência do modelo. 
Mais recentemente, Wilding e Nielaba [WN96] efetuaram uma análise do ponto tricrítico utilizando-se de urn ansatz para a forma de escala da distribuiçăo de probabilidades no ponto tricrítico. Na tabela abaixo apresentamos os valores encontrados por estes autores. Por simetria, sabemos que o ponto tricrítico estará no plano $H=0$.

\begin{tabular}{|c|c|c|}
\hline & $\Delta_{t}$ & $T_{t}$ \\
\hline Landau e Swendsen & $1.965(15)$ & $0.609(3)$ \\
\hline Beale & $1.965(5)$ & $0.610(5)$ \\
\hline Wilảing e Nielaba & $1.9665(3)$ & $0.608(1)$ \\
\hline
\end{tabular}

Beale nos fornece também a localizaçāo de diversos pontos de transição:

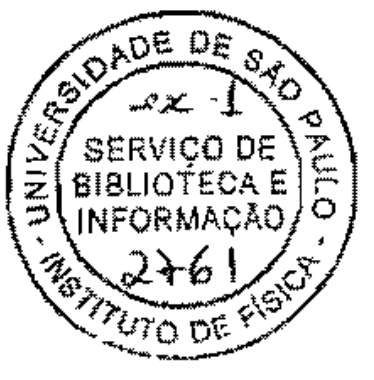

\begin{tabular}{lcc}
\hline \hline$\Delta$ & $T$ & transiçá \\
\hline 0.00 & 1.695 & $2^{\mathrm{a}}$ \\
0.50 & 1.567 & $2^{\mathrm{a}}$ \\
1.00 & 1.398 & $2^{\mathrm{a}}$ \\
1.50 & 1.150 & $2^{\mathrm{a}}$ \\
1.87 & 0.800 & $2^{\mathrm{a}}$ \\
1.92 & 0.700 & $2^{\mathrm{a}}$ \\
1.95 & 0.650 & $2^{\mathrm{a}}$ \\
1.962 & 0.620 & $2^{\mathrm{a}}$ \\
1.965 & 0.610 & tricr. \\
1.969 & 0.600 & $1^{\mathrm{a}}$ \\
1.900 & 0.500 & $1^{\mathrm{a}}$ \\
1.992 & 0.500 & $1^{\mathrm{a}}$ \\
2.000 & 0.000 & $1^{\mathrm{a}}$ \\
\hline \hline
\end{tabular}

Ao longo da linha $L_{\lambda}$ sabenos que os expoentes críticos seräo do tipo Ising. Já no ponto tricrítico o caráter da transiç̆ho se modifica, devido a interferências entre flututçōes de densidade e magnéticas, e devenos esperar expoentes distintos, conhecidos como expoentes tricriticos. Sabemos também que en três timensôtes os valores destes expoentes setāo clássicos, a menos de correçöes logarítinicas. 
Na seçäo (1.4) introduzimos os campos de escala $h, \lambda$ eg, atraves dos quais podemos apreciar o comportamento de escala do sistema nas vizirhanças do ponto tricritico, e os expoentes dos autovalores associados a eles ${ }^{*}, y_{1}, y_{2}$ e $y_{n_{1}}$ cujos valores são conhecidos através de uma conjectura devida a Neinhuis et al. [NBRS79], que relaciona um modelo de gás de rede tipo Potts (do qual o Modelo de Blume-Capel é um caso particular) com expoentes do modelo de 8 vértices, conhecidos exatamente. Em duas dimensōes, estes expoentes assumem os seguntes valores:

$$
\begin{aligned}
& y_{1}=\frac{77}{40}=1.925 \\
& y_{2}=\frac{9}{5}=1.80 \\
& y_{3}=\frac{4}{5}=0.8
\end{aligned}
$$

Os expoentes tricriticos associados a estes expoentes podem ser obtídos atraves da forma de escala para a distribuiçẫo de probabilidades [WN96], são dados por (o subscrito $t$ refere-se à expoentes tricriticos):

$$
\begin{aligned}
\alpha_{t} & =2-d / y_{2} \\
\beta_{t} & =\left(a-y_{1}\right) / y_{2} \\
\gamma_{t} & =\left(2 y_{1}-d\right) / y_{2} \\
y_{t} & =1 / y_{2} \\
\eta_{t} & =2-2 y_{1}+a \\
\phi_{3} & =y_{3} / y_{2}
\end{aligned}
$$

onde T é o exponte de crossover, que controla a mudança entre os regimes cxítico of tricritico.

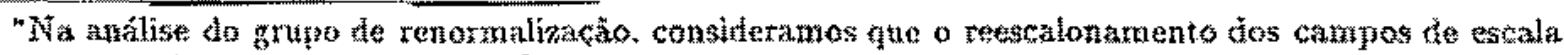

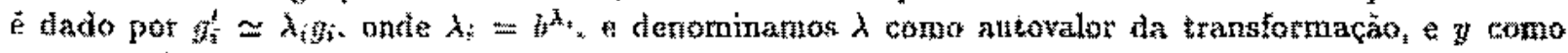
expoente do antovalor. 


\subsection{Algoritmo de Cluster para o Modelo de Blume- Capel}

Vamos reescrever inicialmente a Hamil toniana do modelo em unidades de temperatura, e na ausência de campo magnético:

$$
f K=-K \sum_{<i j\rangle} S_{i} S_{i}+\Delta \sum_{i} S_{i}^{2}, \quad S_{i}= \pm 1,0
$$

onde asora cada constante de interaçäo é medida em unidades de temperaturat.

A forma mais simples de efetuarmos uma simulação de ciuster para esta Haniltoniana é através de um algoritmo de enbedding Decompomos a variável $\$$ em mớdulo e sinal, da seguinte forma:

$$
s_{i}=p_{i} \sigma_{i}, \quad \sigma_{i}= \pm 1, p_{i}=1,0
$$

A Hamiltoniana passa a ser dada entĩo por

$$
\beta H=\left[-\sum_{\langle i j\rangle} K p_{i} p_{j} \sigma_{i} \sigma_{j}\right]+\left[\sum_{i} \Delta p_{i}\right]=\left[-\sum_{\langle i j\rangle} K_{i j} \sigma_{i} \sigma_{j}\right]+\left[\sum_{i} \Delta p_{i}\right] \text { : }
$$

onde

$$
K_{i j}=K p_{i} p_{j}= \begin{cases}K & \text { se } S_{\text {i }} \text { e } S_{j} \text { são diferentes de zero. } \\ 0 & \text { eni outro caso }\end{cases}
$$

Esta nova Hamiltoniana pode se: simulada através de un algoritmo de cluster que cria clusters de sinal na variavel $\sigma$. ta mesma forma que na Hamilioniana de Ising usual. O termo propotcional a $\Delta$ permanecté constante, pois a etapa de criaçăo de clusters näo alterará os valores da rariável $a$. Para que a simulaçäo seja ergódica, após cada etapa de criagå de clusters efetuamos una elapa de Metropolis para ser possivel modificamos $p$.

Este algoritmo de embedding é bastante eficiente na simulaçăo da linha critica do modelo, uma vez gue constrói clusters do tipo Ising, e boda a linha critica pertence a classe de universalidade deste modelo. Mas isto nä́ é suficiente, porque como mencionamos anteriormente a linh de transiçäo de la orden é formada por transiçōes que nodificarn 
o módulo do spin, que correspondente a variźzel $\rho$, que permanece intocada na etapa de formaçăo de clusters. Além disto, o ponto tricrítico é caracterizado por flutuaçoes de densidade e magnetizaçăo, e clusters que representen excitaçöes apenas de magnetizaçäo näo conterẩo toda a física do problema.

A questäo entầ é formular um algorizmo capaz de modifícar tambếm o módulo dos spins pertencentes ao cluster. Este algonimo foi desenvolvido por nós [BC96], e pode ser descrito da seguinte forma:

- Sorteamos o spin inicial do cluster, chamado de spin "semente?

- Sorteamos entre os dois valores de spin diferentes do valor da semente, $\operatorname{com} p=1 / 2$ para cada um deles, o valor para o qual vamos tentar mudar a semente (por exemplo, se o spin da semente tiver valor +1 , sorteamos entre -1 e 0 ).

- Se a transiçäo sorteada for do tipo $\pm 1 \rightarrow \mp 1$, utilimamos o algoritmo de Wolf para - Modelo de Ising. Spins primeiros vizinhos da semente e que possuern o mesmo valor da semente säo ligados com probabilidade $z_{w}=1-\exp (-2 K)$. Cada novo spin adicionado ao cluster tem seus vizinhos de mesmo sinal ligados com $p_{w}$, seguimos com este processo ate que näo existam mais novos spins a serem ligados. Os spins pertencentes ao clustar inverten de sinal, com probabilidade 1 .

- Se a transicto é do ipo $\pm 1+0$, chamamos de 'spin proibido' o spin que não aparece ua transiç̧o. Por exenplo, numa transição $+1 \rightarrow 0$ o spin proibido é -1 . Ligamos então spins primeiros vizinhos da semente que näo sejum proibidos con probaillidade $p=1-\exp (-K)$. Este procedimento continua até que nà̃o existam mais novos spins a serem considerados.

Spins ligados tormam o cluster, que é iransformado adicionando-se o valor do spin proibido aos spins pertencentes a ele. Assim, um cluster constituido de spins $+1,0$ 
transforma-se da seguinte forma: $+1 \rightarrow 0,0 \rightarrow-1$. A probabilitade de aceitarmos esta transformaça 2 igual a 1, se a energia interna do cluster (näo consideramos interacoses com sua vizinhanca) diminuir. Se a energia interna do cluster aumentar, a probabilidade de aceitarmos a nova configuraçă é exp $(-\beta \Delta H)$, onde $\Delta H$ ê a diferença de energía interna ao duster.

A figura (4.2) mostra uma possivel transiçäo entre clusters.

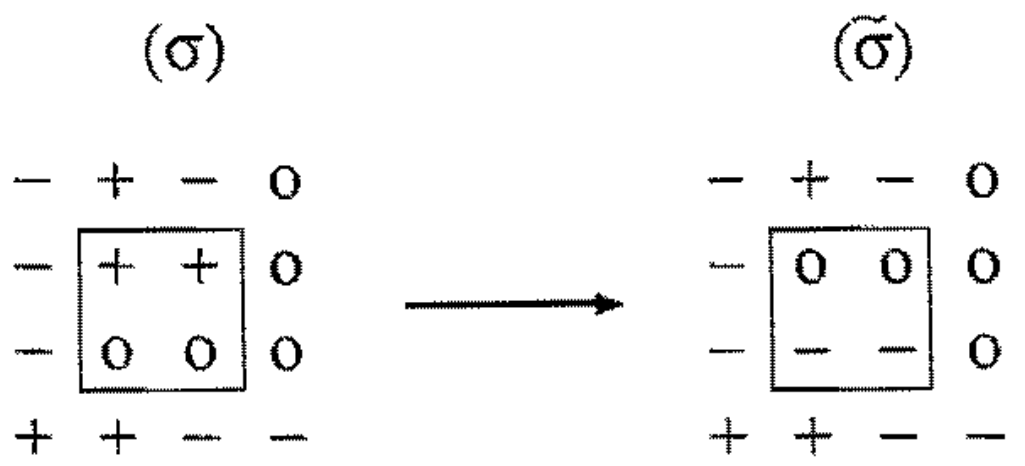

Figura 4.2: Transição passivel entre clusters.

Observe que este e um algoritmo do tipo Wolf, onde en cada etapa formanos apenas un cluster. Para que a algoritmo seju válido, devemos provar que ele obedece a condição de balanço detalnado:

$$
\frac{W\left(\sigma-\sigma^{*}\right)}{W\left(\sigma^{2}-\sigma\right)}=e^{-a \Delta x}
$$

Transiçỏes $\pm 1 \longrightarrow$ - 1 săo completamentes equivalentes a transiços que ocorrem no modelo de lsing, já que neste caso spins zero não desempenham nenhum papel especial. A prova de balanço detalhado pode entäo ser realizada da mesma forma. Esta etapa do algoritmo é equivalente tambén ao algorimo de embedaing.

Mais complicada é a prova de balanço detalhado para transiçós onde dois tipos de spins diferentes pertencem ao cluster. Para efetuá-là vamos seguir a mesma estratégia 
utilizada para o algoritmo de Wolff quando aplicado ao Modelo de Ising, reescrever a probabilidade de transiçäo entre duas configuraços na forma

$$
W\left(\sigma-\sigma^{\prime}\right)=W_{C} W_{\text {ac }} W_{w}
$$

onde Wo è a probabilidade de ligarmos spins do cluster, Woe é a probabilidade de näo lifarmos o cluster com a sua vizinilanca, e $W_{0}$ é a probabilidade de modificarmos o valor dos spins pertencentes ao cluster.

Vamos analisar agora a condiçăo de balanço detalhado (4.8). A probabilidade $W_{C}$ de ligarmos o cluster será igual nas transifós direta e inversa, porque a probabilidaje de ligarmos spins será sempre a mesma, e existe o mesmo numero de ligaçoes nas configuraçöes $t \propto \sigma^{r}$.

Para fxar a notaçăo, varuos constderar que na transiçào direta o spin proibido é um spin -. A razăo entre as probabilidades de nầo ligarmos o cluster com a sua vizinhança nas transicōes direta e inversa seráa dada por

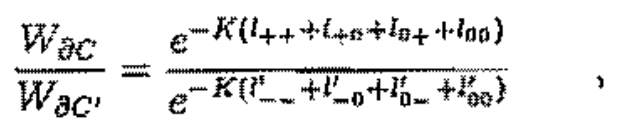

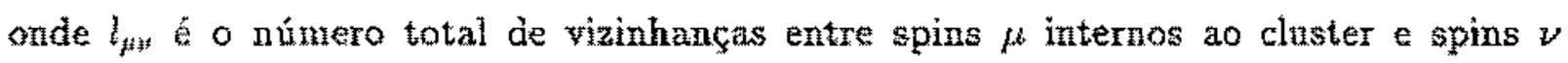
prinxeiros vizimhos extemos ao chuster na trajsiçäo direta, e $l_{y \mu}^{\prime}$ tem o mesmo significado na transiç̆o inversa. Utilizando agora que

$$
\begin{aligned}
& l_{+0}=\mathrm{c}_{\mathrm{t}} \\
& l_{00}=l_{\mathrm{mo}}^{\prime} \\
& l_{6+}=t_{-+}^{t} \\
& l_{t+\ldots}=l_{0, \ldots}^{z},
\end{aligned}
$$

encomtramos

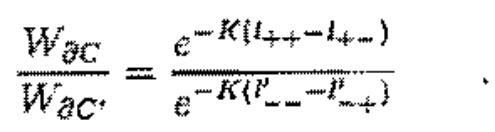


Se considerarmos agora a diferença de energia entre as configuraçōes inicial e final, veremos que a differença de ezergia entre o cluster e a sua vizinhança é dada exatamente pela expressão acima. Já a điferença de energia interna é levada em consideração pela razão entre as probabilidades de transformarmos os valores dos spins pertencentes ao cluster, $W_{v} / W_{w}^{\prime}$ Concluimos assim que esta etapa do algoritmo realmente satisfaz a condiçāo de balarıço detalhado.

Note que esta prova näo pode ser estendida para um algoritmo do tipo SwendsenWang, da forma realizada na seçāo (2.1). Isto porque podemos ter agora dois clusters vizinhos de diferentes tipos (um cluster de Wolff e um cluster que contenha spins zero) que se transformem simultaneamente, e a configuraçäo obtìda desta forma näo será simétrica em relaçāo à configuraçäo inicial, e desta forma o algoritmo näo obedece à condiçăo de balanço detalhado. Isțo parece ser uma restriçấo séria, porque se näo podemos criar um algoritmo tipo Swendsen-Wang entäo o mapeamento em um modelo de percolaçäo não deve existir. Mostraremos na próxima seçãa que este não é o caso, näo só é possivel encontrarmos um algoritmo tipo Swendsen-Wang, como também um mapeamento. O que acontece é que o algoritmo que resulta do mapeamento é un pouco mais geral que o proposto aqui, que corresponde a uma particular escolha de sua dinảmicat.

O algoritmo tambëm é ergódico, porque é sempre possivel construirmos um cluster com um só spin, o que nos possibilitará alkançar todas as configuraçōes possiveis. Näo é necessắrio entäo acrescentarmos uma etapa com o algorituo de Metropolis, como ocortia com o algorimo de embedding.

\subsection{Mapeamento em um Modelo de Percolação}

O algoritmo encontrado na seçâo anterior possui todas as propriedades desejadas: é capaz de criar cluster relevantes tanto para transiç̧ōes de segunda ordem quanto para de primeira, e como consequência deve reffetir de forma apropriada as propriedades do ponto 
tricritico.

Mas ele possul algumas peculariedades, que podem nos levar a acreditar que ele näo passa de um recurso computacional curioso. Para começar, spins + e - não são equizalentes em chusters que incluem spins zero, é dificil entender porque é necessáxio excluirmos um dos sinais de spin do duster formado. Pior do que isto, como explicar que spins zero formem ligaçöes, se eles näo interagem com os seus vizinhos? E como explicar a existência de duas probabilidades de lìgaçă̊ diferentes, quando a Hamiltoniana sô possue um termo de interaçãâ?

A resposta para todas estas questöes devem estar contidas em um mapeamento do modelo em um modelo de percolaçäo que resulte nos clusters formados pelo algoritmo. No entanto, encontrar este mapeamento tumbém uma questäo delicada, porque a Hamiltoniana do modelo parece bastante intratavel para ser representada em termos de expansöes ern grafos, como aa abordagem de Hu (ver seçäo 2.3), o que resultaría em um mapeamento

Para procuramos solucionar estes problemas, vamos reescrever a Hamiltoniana em

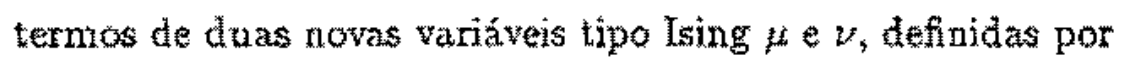

$$
\begin{aligned}
& \mu_{i}=+s_{i}^{2}+S_{i}-1 \\
& \nu_{i}=-S_{i}^{2}+S_{i}+1
\end{aligned}
$$

\begin{tabular}{|c|c|c|}
\hline$\mu$ & $\nu$ & $S$ \\
\hline+ & + & + \\
\hline- & $+\frac{7}{7}$ & 0 \\
\hline$m$ & - & - \\
\hline
\end{tabular}

Temos então a seguinte labela:

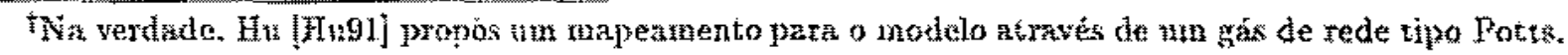

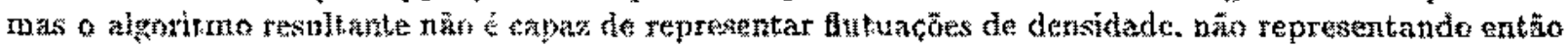

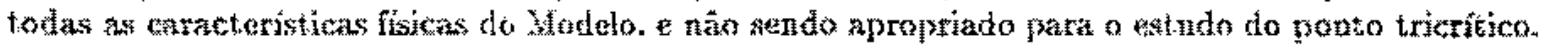


Note que o estado $\mu=+, y=-$ näo existe. Ao escrevermos a funçăo de partiçäo para o modelo teremos de levar em conta este vinculo para o número de estados possiveis, e as probabilidades de ligaçăo do algoritmo deverão ser definidas de forma tal a ser possível obedecermos a esta condiçào.

A motivaçẵo de termos introduæido estas variáveis é que um cluster constituido oriv ginalmente por spins $S=+$ e $S=0$ é constituido agora por um cluster de spins + na variável $\nu$, enquanto um cluster de spins $S=-$ e $S=0$ constitui-se agora de um cluster de spins - na variável $\nu$. Da definiçăo de esta substituiçāo na Hamiltoniana encontramos

$$
\beta \mathcal{H}=-\frac{K}{4} \sum_{\langle i j\rangle}\left(\mu_{i} \mu_{j}+\nu_{i} \nu_{j}+\mu_{i} \nu_{j}+\mu_{j} \nu_{i}\right)+\frac{\Delta}{4} \sum_{i}\left(\mu_{i}+\nu_{i}\right)^{2}
$$

Vamos considerar por enquanto a Hamiltoniana na ausência de campo cristalino $\Delta$. Temos as seguintes configuraçōes de exnergia possíveis:

$$
\begin{aligned}
& \mathrm{u}_{*++}^{+}+-\mathrm{E}_{1}=-\mathrm{k} \\
& "+++\quad E_{i} \neq 0 \\
& 4_{3}+\ldots+\infty \mathrm{y}_{3}=0 \\
& u_{+}+-++E_{4}=0 \\
& u_{s}+-\ldots+\ldots \quad E_{3}=R
\end{aligned}
$$

Figura 4.3: Possiveis configuraçōes, com as suas respectivas energias. 
Como de hábito, em cada grä́fico representamos uma vizinhança $<i j>$ nas duas redes, com a rede $\mu$ por convenção "em cima" da rede $\psi$. For exemplo, em $u_{2}$ os valores de spin representados correspondem a uma vizinhaga

$$
\begin{array}{ll}
\mu_{i} & \mu_{j} \\
\nu_{i} & \nu_{j}
\end{array}
$$

Nossa esperança é a de que seja possivel napearmos o modelo de Blume-Capel utalizan* do estas novas variáveis. Mas o primeiro passo é mostrar como encontrar um algoritmo de cluster em relaçăo a estas variazveis, e veriffear se este algoritmo corresponde ao encontrado para a Hamiltoniana de Blume-Capel original. Visando a estes objetivos, vamos definir as seguintes probabilidades de estabelecermos ligaçōes:

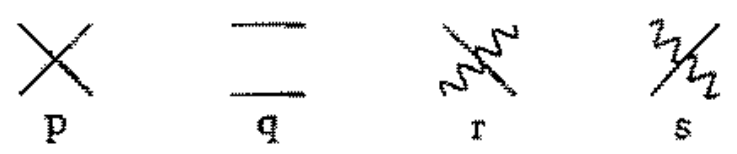

Linha ondulada corresponde a ligação entre spins diferentes, enquanto que linha cha corresponde a ligaçäo entre spins iguais. Cada gráfico representa uma vizinhanç $<>$ nas redes $\mu$ $v$. Por exemplo:

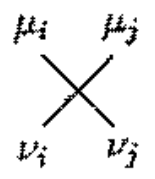

A escolla destas operaföen de ligação é arbitzária, poderiamos ver escolhido outras, mas nada garante que estas resultariam em um alyoritmo válido para o Modelo de Blume-Capel. Por exemplo. a escolha mais direta teria sido escolhermos ligacoóes simples associadas à cada un dos temos de interação. Mas esta escolha fracassaria, porque poderímos entāo gerar configuraçōes de ligaçōs onde a escolha de configuraçöes de spins que satisfaçam \& condiçăo de vinculo näo seria possivel. A escolha apresentada foi efetuada de forma tal a sempre ser possível obedecer a condiça de vínculo presente nestas 
novas variáveis, e de forma a obternos o algoritmo de cluster proposto anteriormente. $\mathrm{Na}$ verdade, sabemos onde devemos chegar, estamos utilizando o algonitmo de cluster proposto anteriormente como referência.

Vamos encontrar agora o valor destas diversas probabilidades, utilizando o método de Kandel e Domany [KD91]. Com este fim, construímos a seguinte tabela, corn as possiveis ligaçōes em cada configuração:

\begin{tabular}{c|c|c|c|c|c|l} 
& $X$ & $X$ & - & 5 & $z_{2}$ &. \\
\hline$\left(u_{1}\right)$ & $p(1-q)$ & $q(1-p)$ & 0 & 0 & $P_{d\left(u_{2}\right)}$ \\
\hline$\left(u_{2}\right)$ & 0 & 0 & $q$ & 0 & 0 & $P_{d}\left(u_{2}\right)$ \\
\hline$\left(u_{3}\right)$ & 0 & 0 & 0 & $r$ & 0 & $P_{d}\left(u_{3}\right)$ \\
\hline$\left(u_{4}\right)$ & 0 & 0 & 0 & 0 & $s$ & $P_{d}\left(u_{4}\right)$ \\
\hline$\left(u_{5}\right)$ & 0 & 0 & 0 & 0 & 0 & $P_{d}\left(u_{5}\right)=1$ \\
\hline
\end{tabular}

Por $P_{d}\left(u_{i}\right)$ representamos a probabilidade de nāo fetuarmos nenhurna operaçấo de ligaçăo em uma dada configuraçăo $u_{i}$. Escolhemos $P_{d}\left(u_{5}\right)=1$ porque nāo quetemos congelar este tipo de configuração, que é a de maior energia.

As probabilidades de eliminação $P_{d}\left(u_{i}\right)$ obedecerāo à condiçăo

$$
P_{d}\left(u_{i}\right)=e^{B_{i}-G_{i}}
$$

onde $E_{i}$ é a energia da particular configuraçăo $u_{i}, \approx \mathcal{C}_{d}$ ê uma consiante independente da particular configuracano $z_{i}$. Como já estolhemos $P_{d}(u g)=1$. temos que $C_{d}=K_{\text {: }}$ e todas as outras probabilidades de eliminação já estão definidas. Tenos ạue

$$
\begin{aligned}
& P_{d}\left(u_{1}\right)=e^{-\dot{z} K} \\
& P_{d}\left(u_{2}\right)=e^{-K} \\
& P_{d}\left(u_{3}\right)=e^{-K} \\
& P_{d}\left(u_{u_{3}}\right)=e^{-K}
\end{aligned}
$$


0 yalor das demais probabilidades resultam da condiçăo de normalizaçäo. Desta Sorma,

$$
\begin{aligned}
& p=1-e^{-K} \\
& q=1-e^{-K} \\
& r=1-e^{-K} \\
& s=1-e^{-K}
\end{aligned}
$$

Encontramos assim um algoritmo que obedece condiçäo de balanço detalhado nas novas variáveis, $\mu \mathrm{e}$. Resta verificarmos se este algoritmo é equivalente wo algontmo desenvolvido anteriormente para variavel $S$, se possivel obedecermos a condição de vinculo destas variáveis.

À primeir a vista isto parece näo acontecar, porque no algoxitmo original existiam duas probabilidades diferentes de criarnos clusters: $y=1-e^{-2 K}$ para clusters tipo Wolf, que são constituidos de apenas un sinal de spin que será invertido após a transitōo; $p=1-e^{-k}$, para clusters mistos, formados por dois tipos tiferentes de spins, sendo que o terceiro tipo possível probido de fazer parte do cluster. Estas duas características do algoritmo parecem nă ocorrer aqui, porque nâa há sinal de spins proibidos tambén só temos uma probabilidade de ligaçă丶万

O que atoniece é que a probabilidade de ligação que cria clusters tipo Wolti resulta de uma combinaço das possiveis formas de ligarmos o cluster. Para ver isto, vanos considerar a seguinte transigäo tipo Wolf:

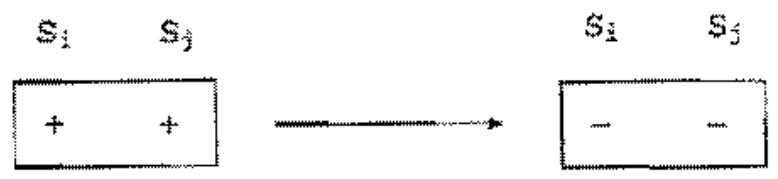

Figura 4.4: Transiçäa tipo Wolf na variavel $S$. 
Nas novas variáveis $\mu$ e $\nu$ esta transiçäo é representada por

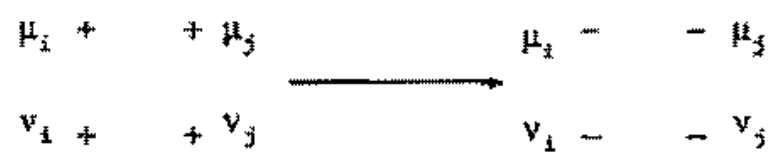

Figura 4.5: Transiçāo tipo Wolff nas variáveis $\mu$ e $\nu$.

Podemos efetuar sta transiçăo ligando de três formas possiveis,

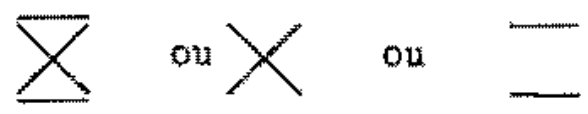

A probabilidade de efetuarmos esta transição é dada entäo por

$$
P=p q+p(1-q)+q(1-p)=1-e^{-2 K} \quad
$$

que é a probabilidade de ligaçäo para criarmos spins tipo Wolff no algoritmo original.

Vamos considerar agora uma transiçẫo que mude o módulo dos spins, por exemplo:

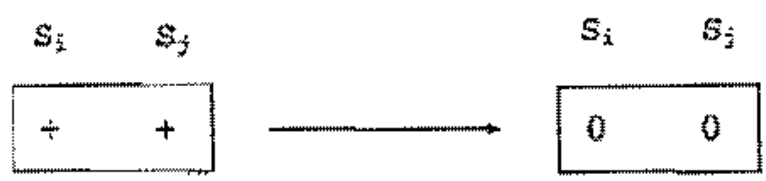

Figura 4.6: Transição que muda módulo dos spins na variável $S$.

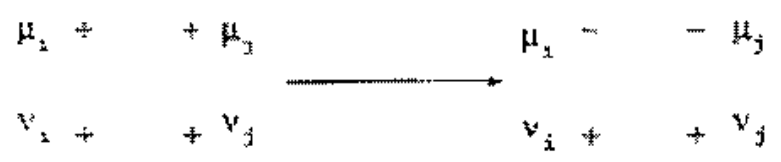

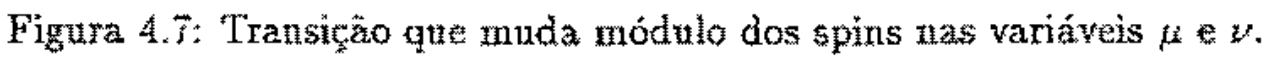


A forma de efetuarmos transiçōes entre estas configuraçöes ể através de ligaçōes tipo

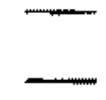

Em $u_{1}$ esta probabilidade é dada por $P\left(u_{1}\right)=\left(1-e^{-K}\right) e^{-K}$, enquanto que em $u_{2}$ ela é dada por $P\left(u_{2}\right)=\left(1-e^{-K}\right)$. Note a presença do termo adicional $e^{-K}$ na probabilidade de ligaçäo em $u_{1}$, em relaçäo a probabilidade utilizada no algoritmo para a variảvel $S$. Ele está presente aqui de forma a compensarmos a diferença de energia entre um cluster de spins com módulo 1 e um cluster de spin 0 . No algoritmo na variável original $S$ esta diferença de energia e levada em consideraçäo quando consideramos a probabilidade do cluster ter seus spins modificados (probabilidade de transiçăo $W_{v}$ ). No algoritmo nas novas variáveis esta diferença de energia é considerada em cada ligação, mas o efeito global e o mesmo. Se uma ligaçäo do tipo $p$ for ativada os spins do cluster não poderão mudar de módulo, o que corresponderia ao caso em que a probabilidade de transiçâo para - cluster na variável $S$ impede que ele se modifique.

Una ullima questão que falta ser esclarecida é a que diz respeito aos spins proibidos. Na formulaçăo nas novas variáveis este conceito näo existe, mas acaba ocorrendo de forma indireta. $O$ que acontece por exemplo se criarmos o seguinte tipo de cluster, que na formulaçăo oxiginal era impossivel, devido a presença de sp̧ins proibidos? Este cluster só

\begin{tabular}{rrr}
$s_{i}$ & $s_{j}$ & $s_{k}$ \\
\hline- & 0 & -
\end{tabular}

Figura 4.8: Cluster possivel na nova formulaçào.

pode ter sido ligado da seguinte forma. nas variáveis $f$ e $y$.

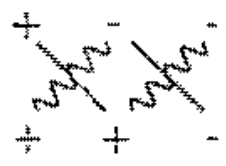


O que está acontecendo é que devido ao vínculo só existe uma configuração de spins compativel com esta configuração de liggaços: ela mesma. Concluinos entāo que ao incluimos três tipos diferentes de spins no mesmo cluster o cluster necessariamente não se modifica. On seja, este cluster năo vai ser responsável pelas transiçòes que vierem a ocorrer. A introdução de spins proibidos na formulaçäo original é na verdade uma maneira de evitar-se este tipo de situação, já que a criaçäo de um cluster que năo se rnodifica é ineficiente em termos computacionais. Mas o importante é que os spins pertencentes a clusters responsáveis por transiçồs na rede terão sido ligados com a mesma probabilidade, estes clusters serão idênticos nas duas formulaçoes do algoritmo. Com relaçăo ao vínculo, esta é também a pior situaçāo que pode ocorrer, uma onde sỏ existe uma configuraçầ de spins compativel com a de ligaçōes.

Conseguimos então formular um algoritmo do tipo Swendsen-Wang para a o modelo, algo que em termo das variaveis $S$ parecia impossivel. A diferença entre este algoritmo o formulado anteriormente na variável $S$ é a possibilidade de incluirmos spins antes proibidos, sendo que para isto pagamos o preço de termos apenas uma configuração de spins compatível com esta configuraçăo de ligações.

Qual o efeito de incluirmos o campo cristalino $\Delta$ ? Teremos entăo que a energia de um spin irá se modificar ao efetuarmos transiçōes $11 \leftrightarrow 0$. Isto é provocado por um termo adicional na Hamiltoniana,

$$
\frac{\Delta}{2}\left(\frac{\mu_{i}^{2}}{2}+\frac{\nu_{i}^{2}}{2}+\mu_{i} \nu_{2}\right)
$$

Como fa e $\nu$ săo variáveís de Ising os dois primeiros temos são constantes e não precisamos nos preocupar com eles. O último termo corresponde a interaçós antíferromagnéticas entze spins $\mu_{i}$ e $\nu_{i}$, de forma tal que quando estes dois spins tiverem simais opostos (spin 0 na variável S) podemos ligá-los com probabilidade $p=1-\epsilon^{-A}$. Para que uma transição entre módulo de spins seja possivel, é necesstírio entäo que nenhum spin zero pertencente ao cluster seja ligado, e a probabilidade disto ocorrer $e e^{-\triangle N_{\text {in }}}$, onde 
$N_{0}$ o rúmero de spins zero no cluster. No algoritmo original, este termo era levado em consideraça na probabilidade de aceitarmos uma modificaçăo no valor dos spins pertencentes ao cluster, $W$, o que é completamente equivalente.

Tendo encontrado um algorifmo tipo Swendsen-Wang para o modelo, tado indica que um mapeamento a partir da funçäo de partição deve também ser possível. Na ausência de campo crístalino, a funçäo de partiçăo tada por

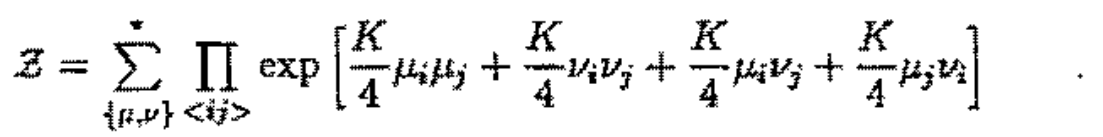

O asterisco sobre a somatória indica a restriçắo calsada pelo vínculo: apenas configuraç̧es que obediecem ao vinculo serào consideradas na somatónia. Podemos reescrever esta expressão como

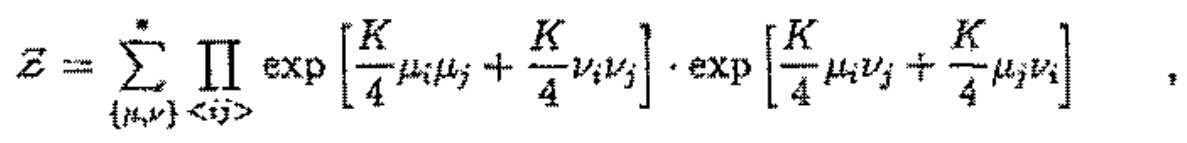

ou ainda

$$
z=\sum_{\{t, v\}}^{*} A B
$$

onde

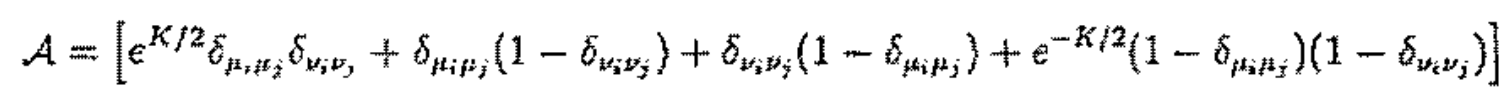

e

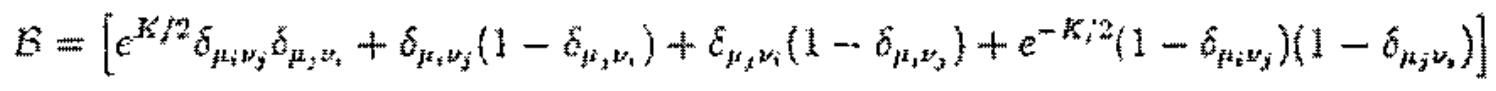

Após algumas manipulacöes das funçōes delta, podenos rescrever $A$ a $B$ da seguinte forma:

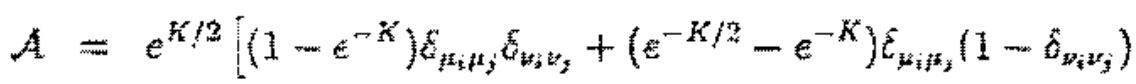

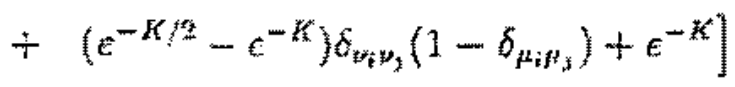




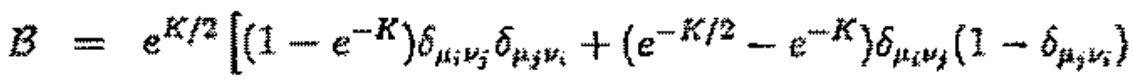

$$
\begin{aligned}
& \left.+\left(e^{-K / 2}-e^{-k_{j}}\right) \delta_{p_{j} \nu_{i}}\left(1-\delta_{\mu_{i} \nu_{j}}\right)+e^{-K}\right]
\end{aligned}
$$

Vamos introduzir agora a seguinte notaçäo simbólica para os deltas de kroenecker:

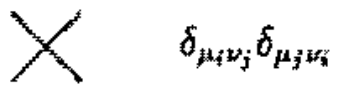

$$
\begin{aligned}
& =\delta_{\mu_{i} \mu_{j}} \delta_{v_{i} w_{j}}
\end{aligned}
$$

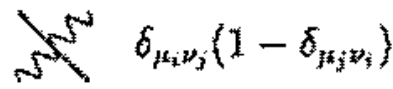

$$
\begin{aligned}
& \gamma_{z_{2}} \delta_{\mu_{j} \nu_{i}}\left(1-\delta_{\mu_{i} \nu_{i}}\right) \\
& \text { WN } \delta_{\nu_{i} \nu_{j}}\left(1-\delta_{i i_{i} y_{j}}\right)
\end{aligned}
$$

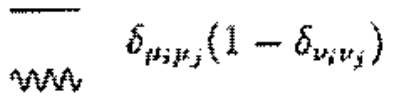

Podemos então reescrever A na torma simbólica

$$
A=e^{K / 2}\left[\left(1-e^{-K}\right)-+e^{-K}+e^{-K / 2}\left(1-e^{-K / 2}\right) \mathrm{Mm}^{+}+t^{-K / 2}\left(1-e^{-K / 2}\right)-M\right.
$$


ou

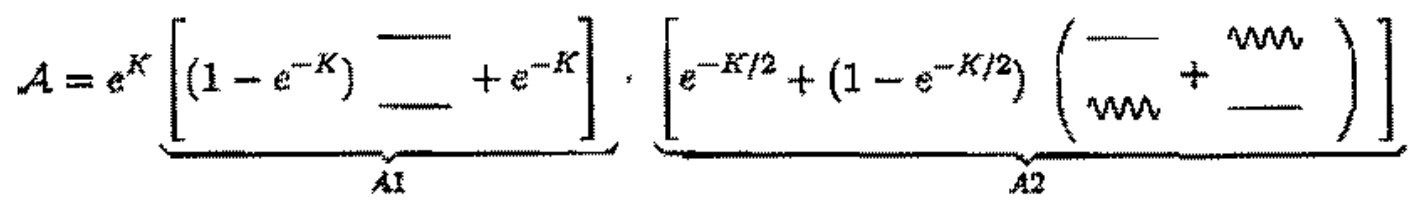

De forma análoga, podemos reescrever $B$ na seguinte forma:

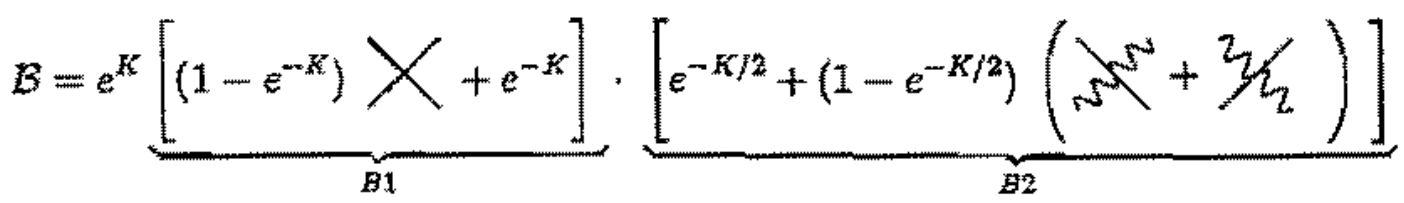

Os termos $A 1$ e $B I$ ji estäo em forma conveniente. Utilizando as relaçōes (4.32) notamos que, devido a presença do vínculo,

$$
m^{+}+w^{2}=\sqrt{5}+\frac{2}{2} / 2
$$

e portanto $A 2=B 2$. Vamos reescrevê-lo de forma conveniente:

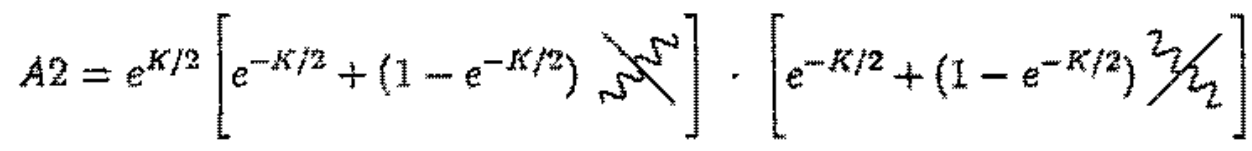

Juntando todos os termos, a função de partiçäo é àala por

$$
\begin{aligned}
& \mathcal{Z}=\sum_{\{\ldots, z\}}^{*} \prod_{\langle i j\rangle} e^{3 K}\left[\left(1-E^{-K}\right)^{-}+e^{-K}\right] \cdot\left[\left(1-e^{-K}\right)\right\rangle\left\langle+e^{-K}\right] \\
& \cdot\left[\left(1-e^{-k / 2}\right)+v^{m}+e^{-k / 2}\right]^{2} \cdot\left[\left(1-e^{-k / 2}\right)^{2} / z_{2}+e^{-k / 2}\right]^{2}
\end{aligned}
$$

Expandinăo os termos quadráticos, encontramos

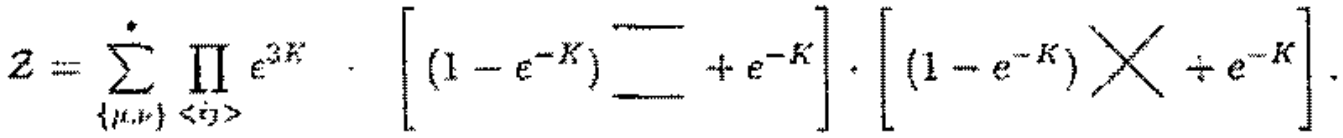

$$
\begin{aligned}
& {\left[\left(1-e^{-k}\right) s^{-3}+e^{-K}\right] \cdot\left[\left(1-e^{-k}\right)^{2} / 2 / 2+e^{-k}\right]}
\end{aligned}
$$


Vamos introduzir agora o campo cristalino. A funçäo de partì̧äo será multiplicada entäo por um termo na forma

$$
e^{-\frac{A}{i} \sum_{i}\left(\mu_{i}+z_{i}\right)^{2}}=\prod_{i} \exp \left[\frac{-\Delta}{4}\left(\mu_{i}^{2}+\nu_{i}^{2}+2 k_{i} \nu_{i}\right)\right]=e^{\frac{-\Delta N}{2}} \prod_{i} \exp \left[\frac{-\Delta}{2} \mu_{i} \nu_{i}\right]
$$

onde $N$ é o múmero de sítios da rede. Podemos reescrever esta expressão como

$$
e^{-\frac{i N-B) \Delta}{2}} \prod_{i}\left[\left(1-e^{-\Delta}\right)\left(1-\delta_{z_{i} \nu_{i}}\right)+e^{-\Delta}\right]
$$

ou

$$
e^{-\frac{i N-1 \mu \Delta}{2}} \prod_{i}\left[\left(1-e^{-\Delta}\right) \sum_{i}^{*}+e^{-\Delta}\right]
$$

onde introduzimos a notaçâo $\xi=\left(1-\delta_{z_{i} \nu_{i}}\right)$ para representar ligaçăo entre spins $\mu_{i}$ e $v_{i}$ de sinais opostos.

A funçāo de partiçăo completa, desprezando-se constantes, é dada então por

$$
\begin{aligned}
& Z=\sum_{\{\{, \nu\}<i j\rangle}\left[\left(1-e^{-n}\right)+e^{-K}\right] \cdot\left[\left(1-e^{-k}\right)<<+e^{-K}\right] . \\
& {\left[\left(1-e^{-x}\right) x^{5}+e^{-k}\right] \cdot\left[\left(1-e^{-k}\right)^{2} / h_{2}+e^{-k}\right]} \\
& \prod_{i}\left[\left(1-t^{-\dot{\Delta}}\right) \xi+e^{-\Delta}\right] \text {. }
\end{aligned}
$$

Introduzindo agora variáveis de ligą̧ăo, utilizando a convençāo 


\section{_. variatuel $q$ \\ $X$ variăvel p}

vatriátel

$y_{2}$ variável $s$

$\sum$ variavel

e considerando que cada uma destas variaveis pode assumir os valores 0 (ligacäo ausente) ou 1 (ligaçäo ativada), e estäo defnidas para cada vizinhança $<j j>$ da redac escrevemos a funçăo de parlição na forma

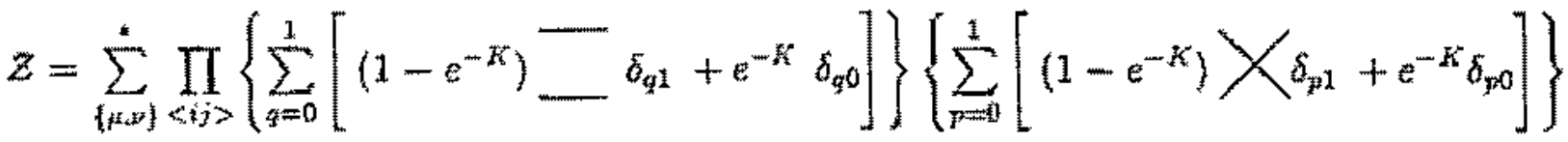

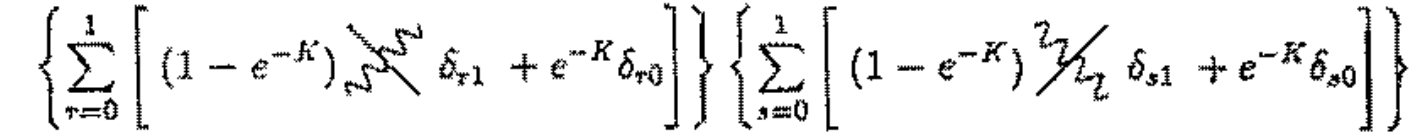

$$
\begin{aligned}
& -\left\{\prod_{i} \sum_{t=0}^{1}\left[\left(1-e^{-\Delta}\right) \sum_{\xi}^{3} t_{t 1}+e^{-\Delta s_{t 0}}\right]\right\}
\end{aligned}
$$

que pode set reescrita como

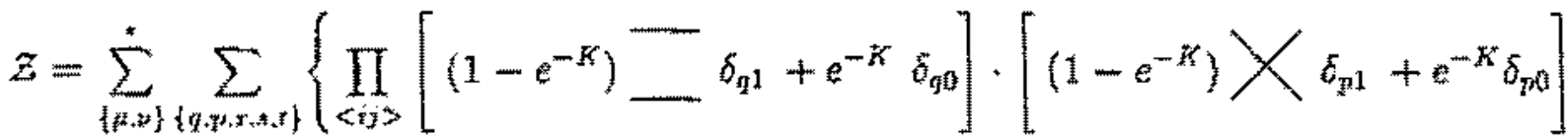

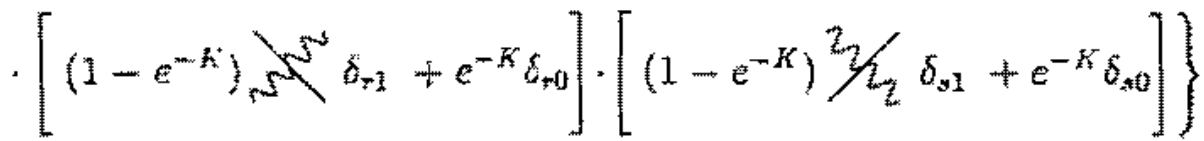

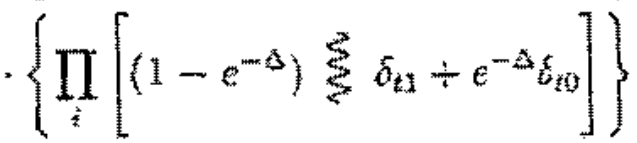




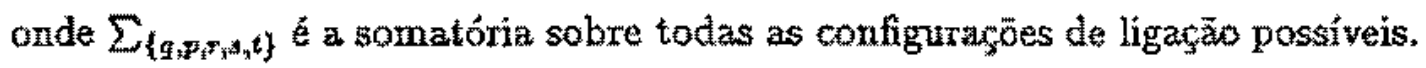

Vamos considerar agora que cada possivel configuraçāo de lighaçôs da rede constitui um grafo $G^{\prime}$. Podemos entầ representar a expressăo acima na forma

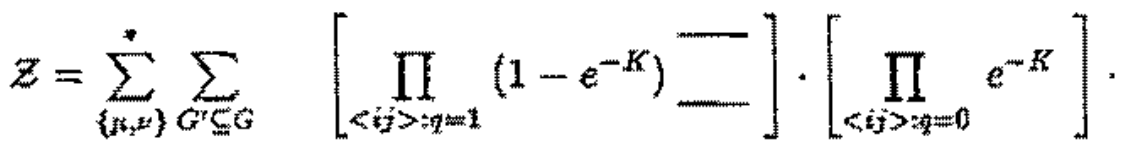

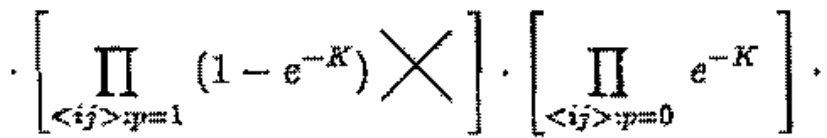

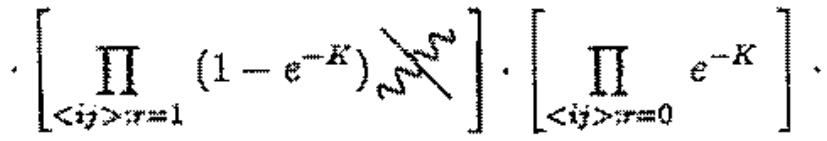

$$
\begin{aligned}
& {\left[\prod_{\langle i j\rangle: s=1}\left(1-e^{-K}\right)^{2} / h_{2}\right] \cdot\left[\prod_{\langle i j\rangle: s=0} e^{-K}\right] \text {. }} \\
& \cdot\left[\prod_{i: t=1}\left(1-e^{-\Delta}\right) \xi\right] \cdot\left[\prod_{i: t=0} e^{-\Delta}\right]
\end{aligned}
$$

Esta é uma funçâo de partiçăo conjunta entre o Modelo de Blume-Capel e um modelo de percolaçäo. Para encontrarmos o modelo de percolação, devemos efetuar a somatória sobre as variáveis de spin $\mu$ e $\nu$.

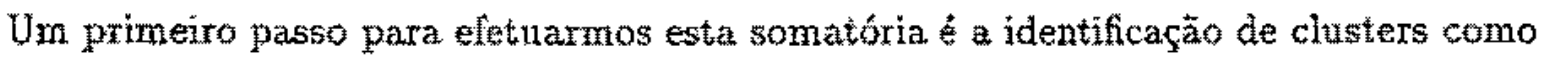
conjuntos de spins conectados por un caminho contínuo de ligaçöes. No entanto, a situação aqui é bem mais complexa do que as tratadas anteriormente, nos modelos de Ising \& Astikin-Teller. A presença de ligações $r$ es toma possivel que diferentes sinais de spin pextençam a mesmo cluster, através de ligaçôes com spins $S=0$, que forma uma espetcie de ponte entre os diferentes sinais de spin. Além disso, o numero de estados compatíveis com uma dada configuraçāo de ligaçoes depende do número de spins diferentes pertencentes a um nesmo cluster, e da antureza das ligaçöes que o constituem. Um cluster pode também pertencer a ambas as redes, $\mu$ e $\nu$, ou entäo a sô nma delas (ligação $q$, ou ausênecia de ligaçōess). 
O cluster mais geral possível possui os três tipos diferentes de spin (na variável $S$ ), com spins zero formando uma ponte entre os diferentes sinais. Nestes clusters mais gerais, existe uma relaçăo univoca entre a configuração de ligações e a configuraçăo de spins, ou seja, existe ap̣enas uma configuraçăo de spins compatível com a configuraçăo de ligaçöes. Um exemplo deste tipo de cluster é dado na figura abaixo:

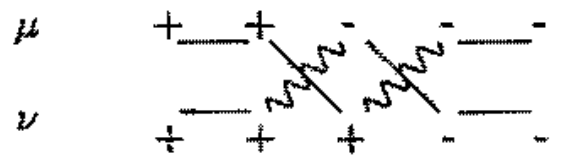

Einteressante introduzirmos aqui o conceito de lilha de spins. Como explicamos acima, spins de diferentes sinais so podem pertencer a um mesmo cluster quando são conectados através de pontes de spin zero, e estas pontes sāo sempre constitúldas por ligaçōes $r$ ou s. Vamos chamar de itha a cada um dos blocos de spins de mesmo sinal que pertencem a um cluster, e que estäo conectados uns aos outros através de pontes de spin zero. No exemplo da figura (4.47), temos duas ilhas, uma formada por spins + e outra por spins -, conectadas por um spin zero. Note que uma permutação $r \leftrightarrow s$ implica em uma inversäo do sinal de todos os spins da ilha conectada por aqquela ligação. Por exemplo, efetuando uma permutação $r+s$ na figura anterior teríamos a seguinte configuraçăo de spins possivel:

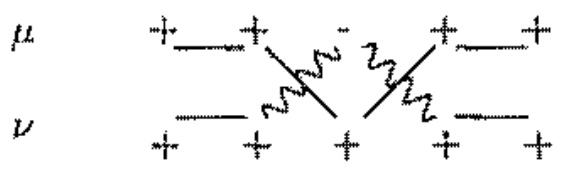

Já quando o cluster é formado por dois tipos diferentes de spin, existem duas configuracōes de spin compativyeis com a configuraçāo de ligações, por exemplo,

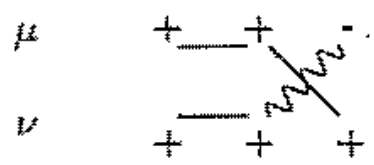


out

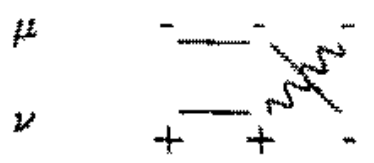

Finalmente, devemos considerar o caso onde o cluster é constituido por apenas um tipo de spin. Nä̀ teremos entäo a presença de ligaçoes $r$ ou $s$ no cluster, mas devemos considerar ainda dois casos distintos, se ligaçōes do tipo p estāo ou nẵo presentes. Se estiverem presentes, termmos duas configuraçōes de spin possíveis, $S=+$ ou $S=-$. For outro lado, se estiverem ausentes entäo $g=0$ tambếm será possivel, e teremos três estados de spin compativeis com a configuração de ligaçöes.

Vamos iniciar agora a soma sobre as configuraçōes de spins, considerando a Ham miltoniana mais getal onde existe um termo de campo magnético presente na forma $B \sum_{i} S_{i}=\frac{B}{2} \sum_{i}\left(\mu_{i}+\nu_{i}\right)$, que aparecera na funça de partição na forma $\prod_{i}$ exp $\left[\frac{g^{2}}{2}\left(\mu_{i}+u_{i}\right)\right]$. Considerando inicialmente o caso onde o cluster é constituido por apenas un tipo de spin, temos duas contribuiçöes distintas, conforme explicato acima. Quando ligaçōes to tipo $p$ estão presentes, a contribuição estatística desta confguração é dada por

$$
\left(e^{B+3}+e^{+-B+4}\right)
$$

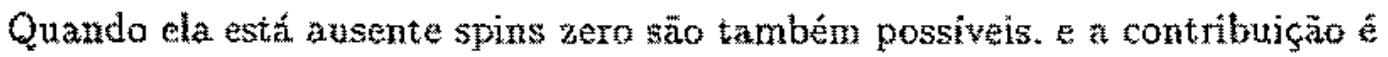

$$
\left(1+e^{n+3 *}+e^{-x ; z}\right)
$$

Nas expressöes acima, ne pámero de spins em cada uma das ilhas. Como o cluster é cormado por apenas um tipo de spin, a ilha aqui equivale ao cluster inteiro, nos casos onde o cluster não é constituldo por spins zaro.

Nossa estrategia pata efetuarmos a soma sobre confouraçōes será sempre a de procurarnos escrever o peso estatistico da configuracăo na forma de um cosseno hiperbólico (cosh), como nas expressões acinatu. 
Vamos analisar agora o caso onde o cluster é constituido por dois tipos diferentes de spin (em relação variảvel $S$ ). Existem entäo duas configuraços de spin compativeis com cada configuraç⿰彳 de ligaçöes, representadas por exemplo nas figuras (4.49) e (4.50). No entanto, elas năh correspondem a uma inversão do sinal dos spins, e näo encontramos uma contribuição tipo cosh.

Foi para solucionar este tipo de situacāo que introduzimos o conceito de llhas. Conforme explicado anteriormente, ao efetuarmos uma permutação $r \rightarrow$ s invertemos o sinal da ilha conectada ao cluster atravếs desta ligaçäo. Se efetuarmos entäo uma soma parcial sobre as configuraçôes de ligaçäo, de forma a somar configaraçôes que differem por uma permutaçăo $r \$ 5$, obteremos a contribuição tipo cosh desejada. A contribuiçäo deste tipo de cluster para a somatớria serí dada entäo por

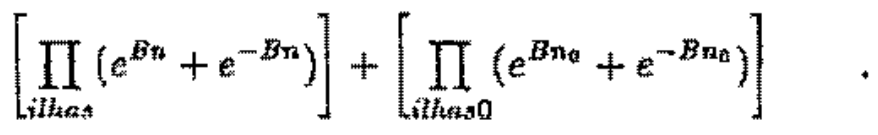

A primeira produtóriz sobre todas as ilhas de sinal formadas no cluster. A contribuiçâ deste primeiro termo corresponderia à configuraçüo representada na fugura (4.49), se somarmos tambén a configuraçāo resultante da permutaçâno $\rightarrow$ s possível. No caso representado nesta figura só temos uma ilha de spin, se outras ilhas estivessem presentes a somatória sobre todas as permutaçöes possiveis resultaria am um produto de cossenos hiperbólicos, conforme representado acima.

A segunda produtória sobre todas as ilhas de spin zero que ocorren em (4,49), sendo que ma é o numero de spins zero en cada uma destas ilhas de zeros. Esta contribuiço ocorre devido à existencia de uma outra configuracto de spins compativel com esta

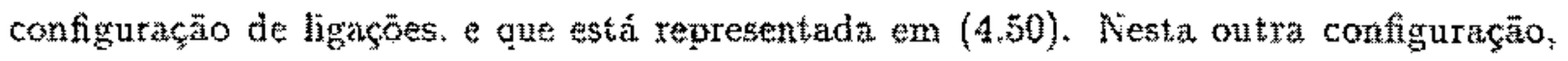
spins que originalmente eram zero possuem agora um sinal, interagindo entāo com o canpo magnévico. Somando aguí zambém sobre conforuraçāes que díterem por uma permulaçāo 
$r \leftrightarrow s$ obtemos a contribuiçăo na forma de cosh. Se uma ligação do tipo este termo referente ao número de spins zero nāo aparecerá, porque os spins zero estarāo fixos.

Finalmente, quando três tipos diferentes de spins pertencena ao mesmo cluster só existe uma configuraçäo de spins compativel com a configuraçäo de ligaçỏes, mas somando aqui também sobre todas as pernutaçöes $r \leftrightarrow s$ possiveis encontraremos a contribuição típo cosh desejada, a a contribuição deste tipo de cluster é dada então por

$$
\prod_{\text {ithas }}\left(e^{B n}+e^{-8 n}\right)
$$

Juntando todas as diferentes formas de contribuiçäo, a funçäo de partiçảo do modelo de perolaçăto é dada por

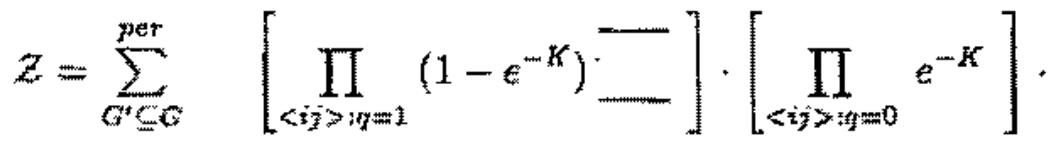

$$
\begin{aligned}
& {\left[\prod_{\langle i j>: p=1}\left(1-e^{-K}\right) \times\right] \cdot\left[\prod_{\langle i j>; p=0} e^{-k}\right] \text {. }}
\end{aligned}
$$

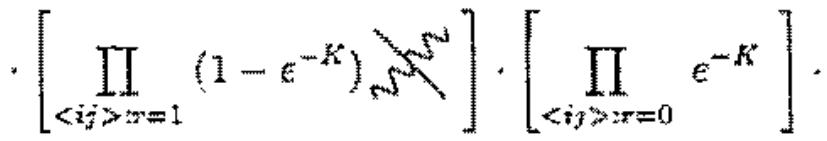

$$
\begin{aligned}
& {\left[\prod_{\langle i j>x=1}\left(1-\epsilon^{-k}\right)^{2} / / 2\right] \cdot\left[\prod_{\langle i j\rangle=x=\xi 1} e^{-k}\right] .} \\
& {\left[\prod_{i: t=1}\left(1-\epsilon^{-\Delta}\right) \xi\right] \cdot\left[\prod_{i: t=0} e^{-\Delta}\right] \text {. }} \\
& {\left[\prod_{A}\left(\varepsilon^{B \bar{z}}+e^{-B n}\right)\right] \cdot\left[\prod_{C}\left(1+e^{B n}+e^{-B n}\right)\right] \text {. }} \\
& \cdot\left[\prod_{D}\left(e^{B_{n}}+e^{-B_{n}}\right)+\prod_{E}\left(e^{B n_{0}}+e^{-B n_{0}}\right)\right] \text {. }
\end{aligned}
$$


O índice sobre a somatória indica que configuraçöes que diferem apenas por permutaçöes $r \leftrightarrow s$ devem ser somadas apenas uma vez.

A produtória $A$ é sobre todas as ilhas de spin pertencentes as seguintes tipos de cluster:

- qualquer cluster com liggąöes p presentes.

- qualquer cluster com ligações t presentes, mas que possua tambẻn spins diferentes de zero.

- clusters formados por trés diferentes tipos de spin na variável $S$.

A produtória $C$ é sobre clusters com un só tipo de spin $S$, e que sầ constituídos unicamente por ligaçōes $\hat{q}$.

A produtória $D$ é sobre ilhas de spin formadas em clusters com dois tipos diferentes de spin, e a produtória $E$ sobre ithas de spins zero presentes neste tipo de cluster. Estes clusters serêo constituídos por ligaçöes $q, \tau$ e \&

Vamos definir agora o termo que estabelece ligaçōes como

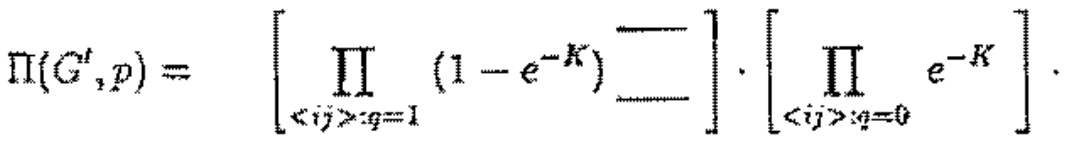

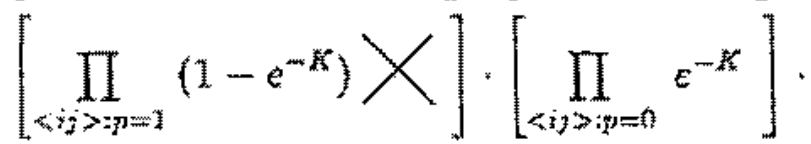

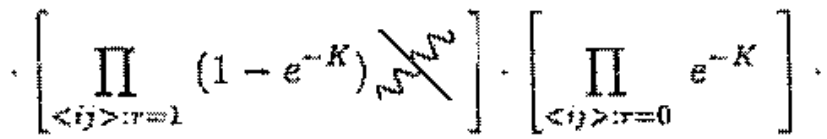

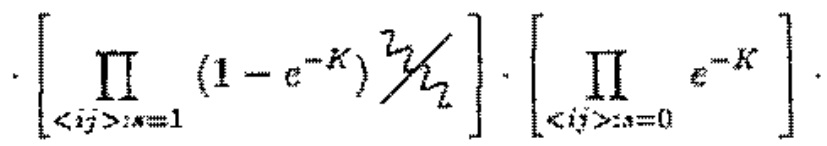

$$
\begin{aligned}
& \cdot\left[\prod_{n ; t=1}\left(1-e^{-\Delta}\right) \xi \xi^{*}\right] \cdot\left[\prod_{i: \pm=0} e^{-\Delta}\right]
\end{aligned}
$$


A função de partição passa a ser dada então por

$$
\begin{aligned}
\mathcal{Z}=\sum_{\sigma^{*} E G} \Pi\left(G^{*}, p\right) & {\left[\prod_{A}\left(e^{B n}+e^{-B n}\right)\right] \cdot\left[\prod_{C}\left(1+e^{B n}+e^{-B n}\right)\right] } \\
& {\left[\prod_{D}\left(e^{B n}+e^{-B n}\right)+\prod_{E}\left(e^{B n_{0}}+e^{-B n_{0}}\right)\right] }
\end{aligned}
$$

Esta é a função de partição do rnodelo de percolaçào. Se desejảssemos recuperar a funçăo de partiçâa original, deveríamos definir agora variáveis de spin que obedecessem ao vínculo original, e que satishzessem as diversas configuraçöes de ligaçỏes possíveis. Somariamos entâo sobre as variáveis de ligaçào, recuperando entäo o Modelo de BlumeCapel. Note no entanto que algumas configuraçöes de ligaçäo sāo incompatíveis com configuraçōes de spin, devido a presença do vínculo. Este ligaços do tipo prp ou psp, que possuiräo então peso estatísitico zero.

Podemos agora calcular algumas quantidades físicas de interesse em termos de propriedades dos cluster formados no modelo de percolação. A magnetizaçăo é dada por

$$
M(G, p)=\lim _{B \rightarrow 0^{+}} \lim _{B \rightarrow \infty} \frac{1}{N} \frac{\partial}{\partial B} \ln Z \quad
$$

ou

$$
\begin{aligned}
& M=\lim _{B \rightarrow 0^{+}} \lim _{N \rightarrow \infty} \frac{1}{N \mathcal{L}} \sum_{C^{\prime} \subseteq G}^{T H} \Pi\left(G^{\prime}, p\right) \frac{\partial}{\partial B}\left\{\left[\prod_{A}\left(e^{B n}+e^{-B n}\right)\right] \cdot\left[\prod_{C}\left(1+e^{B_{n}}+\varepsilon^{-B n}\right)\right] .\right. \\
& \left.\cdot\left[\prod_{D}\left(\epsilon^{B * t}+e^{-B n}\right)+\prod_{E}\left(\varepsilon^{B m+}+e^{-B n_{i}}\right)\right]\right\} \cdot
\end{aligned}
$$

Vamos caleular o efeito da derivada em cada una das produtórias. Ao derivarmos em relaçäo a $B$ a produtbria $A$ encontraremos uma contribução do tino

$$
\begin{aligned}
\left.\frac{\partial}{\partial B}\left(\prod_{A} 2 \cosh \mid B n\right]\right) & =\left(2 \sinh B n_{1}\right) n_{1}\left(2 \cosh B n_{2}\right) \cdots\left(2 \cosh B n_{n}\right)+ \\
& +\left(2 \cosh B n_{1}\right)\left(2 \sinh B n_{2}\right) n_{2} \cdots\left(2 \cosh B n_{n}\right)+
\end{aligned}
$$




$$
\begin{aligned}
& +\cdots+ \\
& +\left(2 \cosh B n_{1}\right)\left(2 \cosh B n_{2}\right) \cdots\left(2 \sinh B n_{c}\right) n_{c}
\end{aligned}
$$

onde consideramos que existem $c$ ilhas formadas por clusters do tipo $A$, designadas por $n_{1}, n_{2}, \cdots, n_{c}$. Resultados similares săo encontrados a calcularmos o efeito da derivada nas demais produtórias.

Vamos analisar agora o efeito de tomarmos o limite $B \rightarrow 0 \mathrm{em} \frac{g}{\partial B} \prod_{A}(2 \cosh B n)$. Como $\lim _{B \rightarrow 0} 2 \sinh B n=0$, a menos de quando $n \rightarrow \infty$, vemos que só restarão termos onde $n$ é o número de spins de uma ilha que percola. Desta forma,

$$
\lim _{B \rightarrow+\infty} \frac{\partial}{\partial B} \prod_{A}(2 \cosh B n)=N_{A}
$$

onde $N_{A}$ o ourmero total de spins que pertencem allias de clusters tipo $A$ que percolam.

Atraves do mesmo tipo de raciocínio, definimos $N_{C}, N_{D}$ e $N_{E}$ como sendo o número total de spins pertencentes a uma ilha que percola en um cluster do tipo $C, D$ an $E$, respectivamerte. A maguetização será dada então por

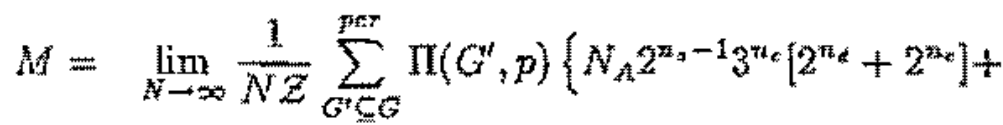

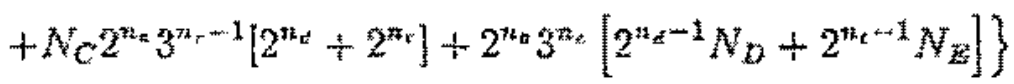

A express̄̄o acima foi calculada considerando-se que clusters característícos a cada una das produb́rias podem percolar ao mesmo tempo. No entanto ser uma hipótese corrata, porque clusters pertencentes à produtória $A$ responsáveis por

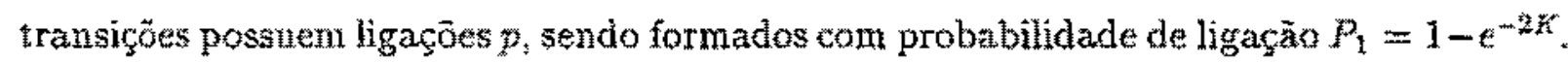
Já os clusters formados em ouiras produtórias näo possuem este tipo de ligação, sendo formados com probabilidade $P_{2}=\left(1-e^{-4}\right) e^{-K}$ menor do que $P_{1}$. E de se esperar entzo que clusters pertencentes a produtớria $A$ sejam os primeiros a percolar, e mesmo quando 
$P_{2}$ for grande o suficiente para que clusters associados a ela percolem jă teräo dominado a rede, ntâo sobrando espaço para que outros percolem.

Com base nestes argumentos, podemos considerar entäo que os únicos clusters a percolar são cilusters tipo $A$, a expressăo para a magnetização reduz-se a

$$
M=\lim _{V \rightarrow \infty} \frac{1}{N Z} \sum_{G^{\prime} C G}^{p e r} \Pi\left(G^{t} p\right) N_{A} 2^{n_{n}-1} 3^{n_{e}}\left[2^{n_{d}}+2^{n_{E}}\right]
$$

Redefinindo agora

$$
\Pi \Pi^{*}\left(G^{\prime}, p\right)=\Pi\left(G^{z}, p\right) 2^{t_{e}} 3^{n_{e}}\left[2^{n_{z}}+2^{n_{*}}\right]
$$

e considerando que no limite $\lim _{n \rightarrow+\infty} n_{a x}-1 \sim n_{a}$, podemos escrever a magnetizaçäo como

$$
M=\lim _{N \rightarrow \infty} \frac{1}{Z} \sum_{G^{\prime} \subseteq G}^{\text {par }} \Pi^{*}\left(G^{\prime}, p\right) \frac{N_{A}}{N}
$$

de onde concluímos que a magnetização é a probabilidade de um sítio da rede pertencer a uma itha que percola.

Podemos calcular também a susceptibilidade magnética, definida por

$$
\chi(G, p)=\lim _{B \rightarrow 0^{+}} \lim _{N \rightarrow \infty} \frac{\partial^{2}}{\partial B^{2}} \ln \mathcal{Z} .
$$

Encontraremos entäo que a susceptibilidade magnética tem forma semelhante a encontrada no Modelo de Ising, sendo dada por

$$
\begin{aligned}
\chi(G, p) & =\lim _{N \rightarrow \infty} z^{-1} \sum_{G^{*} \subseteq G} \Pi\left(G^{*}, p\right) \sum_{\sigma}^{f} \frac{n_{n}^{2}\left(G^{*}\right)}{N} \\
& +\lim _{N \rightarrow \infty} z^{-2} \sum_{\sigma^{*} \subseteq G G^{\prime \prime} \subseteq G} \Pi\left(G^{*}, p\right) \Pi\left(G^{*}, p\right) \frac{\left[N_{A}\left(G^{\prime}\right)-N_{A}\left(G^{\prime \prime}\right)\right]^{2}}{2 N}
\end{aligned}
$$

ande $\sum_{t}^{f}$ t uma soma sobre todas as ilhas que não percolam, incluindo ilhas de clusters formadas en outras produtórias que não a produtória $A$. O primeiro termo desia expressão é o tamanho médio dos ciusters formados, e da mesma forma que no Modelo de Ising 
podemos argumentar que a contribuição do segundo termo da expressão acima permanecerá finita. Desta forma, a susceptibilidade será dada pelo tamanho médio das ilhas de spin formadas pelo algoritmo.

A função de correlação entre spins é dada por

$$
\begin{aligned}
\left\langle\sigma_{2} \sigma_{b}\right\rangle=Z^{-1} \sum_{\{\mu \nu\}} \Pi\left(G^{\prime}, p\right) & {\left[\prod_{A}\left(e^{B_{n}}+e^{-B_{n}}\right)\right] \cdot\left[\prod_{C}\left(1+e^{B n}+e^{-B_{n}}\right)\right] } \\
& \cdot\left[\prod_{D}\left(e^{B_{n}}+e^{-B_{n}}\right)+\prod_{E}\left(e^{B n_{0}}+e^{-B n_{b}}\right)\right] \sigma_{a} \sigma_{b}
\end{aligned}
$$

Definimos agora clusters $e$ ilhas da mesma forma que anteriormente. Teremos então que se $\sigma_{0}$ e $\sigma_{b}$ pertencen a mesma ilha, $\sigma_{a} \sigma_{b}=1$. Se pertencern a thas diferentes, $\sigma_{a} \sigma_{b}= \pm 1$ com igual probabilidade, e contribuição deste grafo $G^{t}$ para a soma sobre configuraçöes zero. Encontramos assim que

$$
\left\langle\sigma_{a} \sigma_{b}\right\rangle_{0}=\lim _{x \rightarrow \infty} \mathcal{Z}^{-1}\left[\sum_{G^{+} \subseteq G}^{p a r} \Pi^{*}\left(G^{\prime}, p\right) \delta(a, b)\right],
$$

onde

$$
b(a, b)= \begin{cases}1 & \text { se } a \text { e } b \text { estiverem na mesma iha } \\ 0 & \text { se } a \text { e } b \text { estiverem exn ilhas distintas }\end{cases}
$$

O lado direito desta equaçāo é a funçăo de conectividade entre pares do modelo de percolaçẫo, quando tomamos como reterência as ilhas de spin formadas dentro dos diversos chusters. Isto mostra que o expoente $\nu_{F}$ relativo ao comprimento de correlação quando $p \rightarrow p_{n}$ será igual ao expoente $\nu$ do Modelo de Blume-Capel.

Em todas as anćlises de quantidades físicas efetuadas até aqui, vimos que a caracteristica dos clusters formados que está relacionada a propriedades termodinâmicas do modelo é o tananho das thas que constituem os clusters, e nāo os clusters propriamente ditos. $\mathbf{E}$ como se o modelo de percolação relevante estivesse contido no modelo geométrico a que nos conduz a funçã̃o de partição do modelo.

Vimos também que os clusters que dominam a transiçăo de percolação sāo clusters do tipo A. Enbora exístam três espécies de clusters deste tipo, apenass o cluster que 
possui ligações presentes será o responsável pela transição, já que é o tinico cujo valores de spin modificam-se. Estes clusters terăo sido formados com probabiliaade de ligaçăo $P=1-\mathrm{e}^{-2 k}$, e seräo equivalentes aos clusters formados no modelo de Lsing, o que reflete o fato de toda a linha critica do Modelo de Blume-Capel pertencer a mesma classe de universaliadade do Modelo de Ising.

Resta explicar em termos geométricos o surgimento de um ponto tricrítico, da linha de primeira ordem que dele se origina. O que acontece é que, embora qqualquer transição de percolação seja sempre controlada por clusters típo Ising, clusters que efetuem transiçōes entre o módulo dos seus spins constituintes seräo ajudados por um fator extra, as ligaçoes tipo t. Por fixaren spins zero na rede, é de se esperar que exista um certo valor de $t$ onde clustexs formados por spins zero passem a competir com clusters tipo Ising, porque mesmo sendo criados con probabilidade menor estes clusters terão mais sitios na rede passiveis de serem ligados. O ponto onde estes dois tipos de clusters competem em igualdade de condiçôes é o ponto tricrítico. Se continuarmos anmentando a probabilidade $t$ (aumentando $\Delta$ ), clusters que modificam o módulo dos seus spins dominarâo, e teremos a linha de primeira ordem.

Mostramos assim que é possivel mapear-se o modelo de Blune-Capel em um modelo de percolaçäo, onde quantidades físicas relevantes estäo conectadas a propriedades das ilhas que constituem os clusters formados. Esta é a principal vantagem da formulaçäo aqui apresentada, e nos leva a acreditar que clusters formados por este algoritmo representam a maneira mais eficiente de sinularmos o nodelo, alêm de nos fornecer interpretaçóes geométricas para as diferentes regioes do diagrama de fases do modelo.

Como em outros modelos, este mapeamento está longe de ser o único possivel. Podemos sempre aumentar o termo de intcração ferromagnética. compensando atrevểs da inclusào de um novo termo de interação antififerromagnética. Novarnente, estariamos perdendo assim a conexăo direta entre propriedades do modelo de percolaçâo e propriedades ter- 
modinâmicas, o que além de pouco interessante teoricamente resulta em algoritmos de simulação ineficientes. Poderiamos imaginar que a introduçäo do conceito de ilhas resolveria aqui também os problemas, separando ilhas te apins com un simal de ilhas com simais de spin opostos. Mas a situação é diferente, porque aqui as diferentes ilhas não podem variar o sinal de seus spins de coma independente.

\subsection{Uma Abordagem Alternativa}

Nesta seça mostramos ainda uma outra forma de efetuarmos o mapeamento, que possui a vantragem de não apresentar vínculos entre as variávais cle spin. No entanto, pagamos um preço por isto: embora o mapeamento parta de uma funçäo de partitäo equivalente a do Modelo de Blume-Capel, nãa é possível relacionarmos as variáveis de spin nos dois nodelos através de uma transformagäo de variáveiz. Isto torna dificil o entendimento do que o algoritmo resultante está realmente afetuando, e a interpretaçẳo geométrica dos clusters formados fica prejudicada.

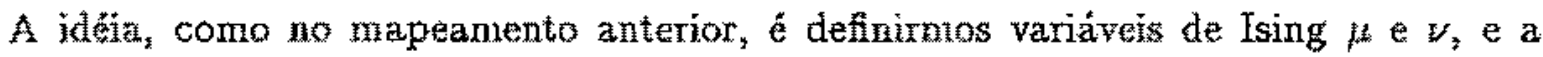
partix delas encontrarmos a variável inicinal $S$ atraves da transfomaçäo $S_{i}=\frac{\psi_{j}+w_{i}}{2}$. Como existirāo dois estados $(\mu, \nu)$ correspondentes a $S=0$, corrigimos esta multiplicidade através da inclusăo na funçăo de partição do termo

$$
\exp \left[-\frac{1}{2}\left(1-\mu_{i} z_{2}\right) \ln 2\right]
$$

A fumçäo de partiçăo é dada então por

$$
\begin{aligned}
& z=\sum_{\{S\}} \exp \left\{r \sum_{\langle i \mid i\rangle} S_{i} S_{j}\right\}
\end{aligned}
$$

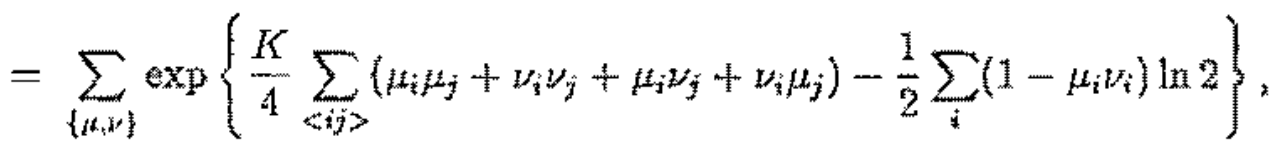


que corresponde a uma Hamiltoniana efetiva na forma

$$
H_{e f f}=\frac{-J}{4} \sum_{\langle i j\rangle}\left(\mu_{i}+\nu_{i}\right)\left(\mu_{j}+\nu_{j}\right)+\frac{1}{2 \beta} \sum_{i}\left(1-\mu_{i} \nu_{i}\right) \ln 2
$$

Podemos incluir ainda o campo cristalino na função de partição, que passa a ser dada (a menos fe fatores constantes) por

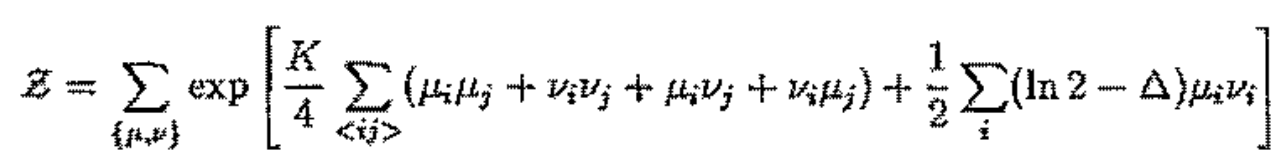

Como aqui nāo existem vínculos presentes entre as variáveis, é muito fácil mapearmos este modelo em um modelo de percolação: basta analisarmos cada termo de interaçăo de forma análoga a efetuada no Modelo de Ising.

Note que $\Delta$ é medido em unidades de temperatura, existindo entäo uma competiçāo entre temperatura e campo cristalino, de forma a fixarmos ou năo spins zero. Isto porque o sinal do termo de interação pode ser positivo ou negativo, o que corresponde a ligaçồ ferromagnéticas ou antiferromagnéticas, sendo que esta última fixa spins zero.

Em principio, este algoritmo pode efetuar qualquer transiçăo entre spins, além de cada cluster poder ser constituído por qualquer típo de spin. No entanto, esta liberdade foi alcançada através da inclusâo de um termo adicional na tlamiltoniana, o que pode ser desastroso do ponto de vista compuracional. O teito é o mesmo que o descrito pela formulaçâo de Kandel-Domany, só que aqui a interaçäo não entre clusters, e sim com um campo adicional. Podemos desta forma criar clusters que não guardem renhuma relação com as excitaçóes do modelo, o que será corrigito pelo termo adicional, que corresponderá a uma probabilidade de tramsformarmos o valor dos spins pertencentes a este cluster. $O$ que pode acontecer é que a maioria das transiçōes sejam rejeitadas, e o algoritmo nâo resulte em qualquer modificação da rede. Isto de fato foi observado ao longo da linha de primeira ordem, onde este algoritmo apresenta histerese ainda niaior que o algoritmo de Metropolis. 


\section{Capítulo 5}

\section{Generalizações para o Modelo BEG}

Mostramos neste capítulo que é possivel generalizar o algoritmo proposto anteriormente para o Modelo de Blume.Capel, de modo que ele possa ser aplicado também ao Modelo de Blume-Emery-Griffiths (BEG) [BEG71]. Após provarmos que este algoritmo satisfaz à condiçäo de balanço detalhado, discutimos a regaza do diagrama de tases do modelo onde ele pode ser aplicado, mostrando quais as suas limitaçöes e o porque delas ocorrerem. A presentamos também resultados de simulaçôes numéricas de transiçōes de $1^{\text {a }}$ ordem no nodelo, concluindo que aqui tambén o algoritmo é bastante eficiente na eliminação de estados metaestáveis, o que possibilita a obtenção de dados bastantes precisos a respeito de estados de equilíbrio do modelo.

\subsection{O Modelo de Blume-Emery-Griffiths}

Un objetivo natural para a extensäo cos métodos introduzidos até aqui a co Modelo de Blume-Enery-Griffiths (BEC) [BEG71], definido pela Hamiltoniana

$$
\beta H=-K \sum_{\langle i, j\rangle} S_{i} \xi_{i}-\phi \sum_{\langle i, j\rangle} s_{\xi}^{2} S_{i}^{2}+\Delta \sum_{i} S_{i}^{2}, \quad S_{i}= \pm 1,0
$$

O caso particular $\phi=0$ corresponde ao Modelo de Blume-Capel. No seu caso máts geral, este modelo possui diversas aplicaçoses[HB91], como a análise de supercondutividade e separação de fases em misturas de $\mathrm{He}^{3}$ e $\mathrm{He}^{4}$, o studo de ligas semicondutoras, fủidos 
de muitas componentes etc. Todas estas aplicaçôs devem-se ao fato de que este é o modelo mais geral para o estudo de sistemas onde estẫo envolvidas dois tipos de flutuaçôs, do tipo Ising $(S= \pm 1)$ e de densidade $(S=1,0)$.

O diagrama de fases deste modelo ê muito mais complexo que o do Modelo de Blumen Capel, apresentando diversas fases e estruturas diferentes, dependendo do valor assumido pelas constantes de interação. Através de uma abordagem de campo médio podemos obter os diagramas de fases apresentados na figura (5.1), conforme trabalho de Hoston e Berker ([HB91], ver tambérm [TK85]).
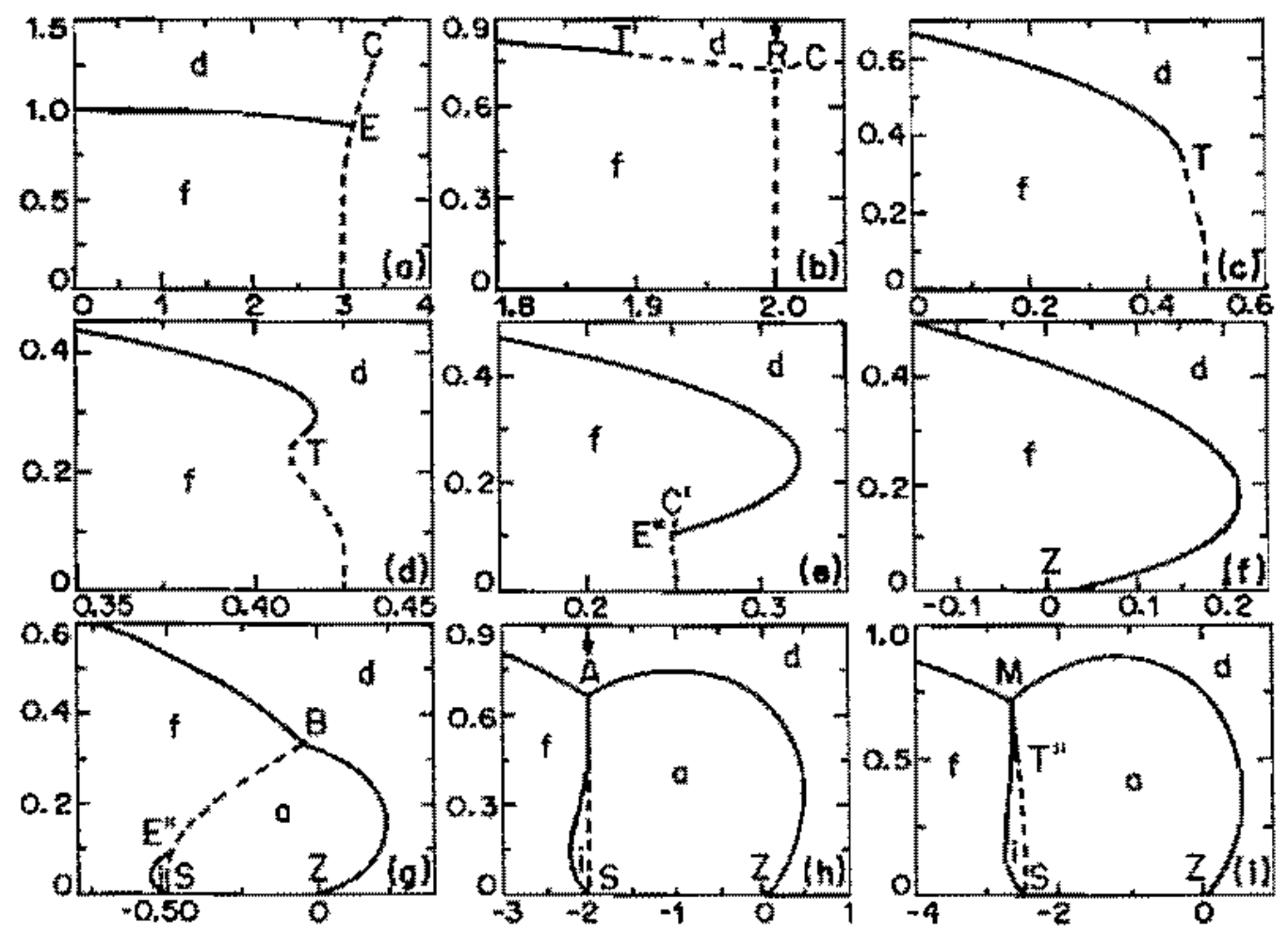

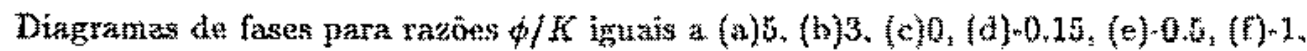
(g)-1.

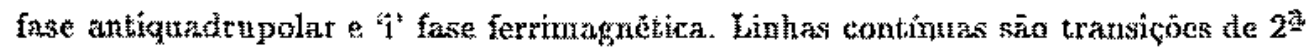

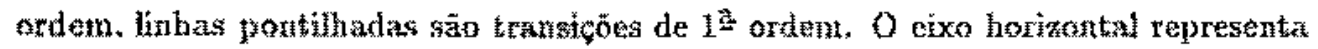

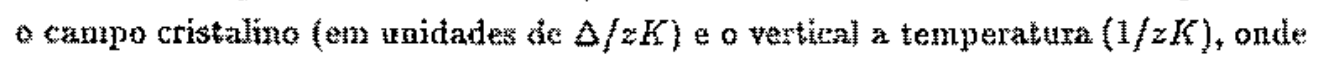
$z$ b o nutuero de cooterançäe da rede. 
É suffiente representarmos a regiäo do diagrama de fases correspondente a $K>0$, por estarmos considerando uma rede bipartida, de modo que interacōos bilineares antiferromagnéticas $(K<0)$ podem ser mapeadas em interaçôes ferromagnéticas, através da inversăo dos sinais de uma das subredes.

Existem quatro parầmetros de ordem no modelo:

$$
\begin{aligned}
& M_{A}=\left\langle S_{i}\right\rangle_{A} \\
& M_{B}=\left\langle S_{i}\right\rangle_{B} \\
& Q_{A}=\left\langle S_{i}^{2}\right\rangle_{A} \\
& Q_{B}=\left\langle S_{i}^{2}\right\rangle_{B}
\end{aligned}
$$

onde dividimos a rede em duas subredes, $A \notin B$.

A fase ferrimagnética é caracterizada por magnetizaçầ diferente de zero e quebra de simetria entre as subredes:

$$
0 \neq M_{A} \neq M_{B} \neq 0 \quad Q_{A} \neq Q_{B}
$$

Já a fase antiquadrupolar possui quebra de simetria entre subredes, mas magnetizacão zero:

$$
M_{A}=M_{B}=0 \quad Q_{A} \neq Q_{B}
$$

Uma configuraçāo típiea da fase nntiquadrupolar seria a seguinte:

$$
\begin{aligned}
& +0-0 \\
& 0+0- \\
& +0+0 \\
& 0+0-
\end{aligned}
$$




\subsection{Algoritmo de Cluster para o Modelo BEG}

Eossível generalizarmos o algoritmo proposto anteriormente para o Modelo de BlumeCapel da seguinte forma:

- Sorteamos o spin inicial do cluster, chamado de spin 'semente'.

- Sorteamos entre os dois valores de spin diferentes do valor da semente, $c o m p=1 / 2$ para cada um deles, o valor para o gual vamos tentar mudar a semente (por exemplo, se o spin da semente tiver valor +1 , sorteamos entre -1 e 0 ).

- Se a transição sorteada for do tipo $\pm 1 \rightarrow \mp 1$, utilizamos o algoritmo de Wolff para - Modelo de Ising. Spins primeiros vizinhos da semente que possuem o mesmo valor da semente sño ligados com probabilidade $p_{w}=1-\exp (-2 K)$. Cada nowo spin adicionado ao cluster tem seus vizinhos de mesmo sinal ligados com $p_{y y}$ e seguimos com este processo até que não existan mais novos spins a serem ligados. Os spins pertencentes ao cluster invertem de sinal, com probabilidade $W_{n}=1$.

- Se a transiçầo é do tipo $\pm 1 \leftrightarrow 0$, charnamos de 'spin proibido' o spin que não aparece na transição. Por exemplo, numa transição $+1 \rightarrow 0$ o spin proibido ê -1 . ligamos entäo spins primeiros vizinlos da semente que näo sejam proibidos com probabilidades $p_{t}=1-\exp (-K-\phi / 3)$ e $p_{d i f}=1-\exp (-K+\phi / 3) \cdot p_{e q}$ refere-se a probabilidade de ligarmos spins iguais, enquanto que pdif é a probabilidade de ligarmos spins diferentes. Este procedimento continua até que nāo existan mais novos spins a serem considerados.

Spins que foram ligados formam o cluster, que é transformado adicionandonse o valor do spin probido aos spins periencentes a ele. Assim, um cluster constituido de spins $+1,0$ transforma-se da seguinte forma: $+1 \rightarrow 0,0 \rightarrow-1$. A probabilidade de aceitarmos esta transformaçäo é igual a $d$, a energia interna do cluster (năo 
consideramos a sua vizinhança) diminuir. Se a energia interma do cluster aumentar, a probabilidade de aceitarnos a nova configuraçăo é $\exp (-\beta \Delta \mathcal{H})$, onde $\Delta \mathcal{H}$ a diferença de energia interna ao cluster.

Este algoritmo diferencia-se do algoritmo apresentado para o Modelo de Blume-Capel pela presença de duas probabilidades de ligação diferentes, quando estamos em uma transiçâo entre o modulo dos spins. Isto é uma consequểncia da inclusăo de um termo de interação biquadrático na Hamiltoniana (quando $\phi=0$ as duas probabilidades de ligação tornam-se iguais). Para entender de onde surge esta diferença, vamos considerar a prova de que este algoritmo satisfaz ì condiçăo de balanço detalhado.

Para efetuarmos esta prova, wamos reescrever inicialmente a Hamiltoniana na seguinte forma (equivalente à Hamiltoniana original, a menos de um termo constante):

$\beta H=-\left(K-\frac{\phi}{3}\right) \sum_{\langle i, j\rangle} S_{i} S_{j}-\frac{\phi}{3} \sum_{\langle i, j\rangle}\left(S_{i}^{2} S_{j}^{2}+S_{i} S_{i}\right)-\frac{2 \phi}{3} \sum_{\langle i, j\rangle}\left(S_{i}^{2}-1\right)\left(S_{i}^{2}-1\right)+\left(\Delta-\frac{2 \phi z}{3}\right) \sum_{i} S_{i}^{2}$

onde $z$ é o número de coordenação da rede. A motivaçăo para escrevermos a Hamiltoniana desta forma pode ser entendida se percebermos que o primeiro e o ultimo termos desta Hamiltoniana correspondem (a menos da constante de interaçăo) a termos que já existem no modelo de Blume-Capel, para o qual sabemos como formular un algoritmo de cluster. O segundo e o terceiro termos são novos, mas já estäo en uma forma bastante favorável: o primeiro só contribui quando temos vizinhanças entre spins $++($ ou --$)$, e o terceiro contribui para vizimhanças 00 . Alẻm disto, a contribuição energética dos dois termos é a mesma.

Para que o algoritmo obedeça a condị̧ăo de balanço detalhado, ele deve satisfazer à relaçäo 


$$
\frac{e^{\beta H(\sigma)}}{e^{\beta \pi(\sigma)}}=\frac{W_{\tilde{\sigma} \rightarrow \sigma}}{W_{\sigma \rightarrow \sigma}}
$$

Da mesma forma que acontecia no Modelo de Blume-Capel, spins zero não desempenham nenhum papel especial em transiçös $\pm 1 \leftrightarrow \mp_{1}$, e a prova de que este tipo de transiçäo satisfaz a condiçăo de balanço detalhado é idêntica a do Modelo de Ising. Iá a transição entre o módulo dos spins ẻ mais complicada. Vamos considerar um cluster constituido por spins $(+1,0)$ que se transforma em um cluster $(0,-1)$. Com relação à Hamiltoniana modificada (5.5), a razâo entre os pesos de Boltzmann das configuraçöes inicial e final é dado por

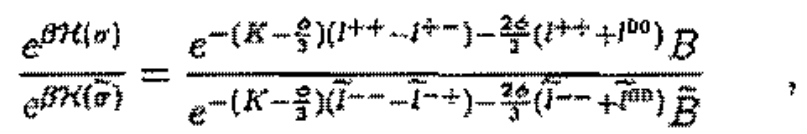

onde $B$ é a contribuiçăo para a energia da parte interna ao cluster $e l_{\mu b}$ é o número total de vizinhanças entre spins fa internos ao cluster e spins $\nu$ primeiros vizinhos externos ao

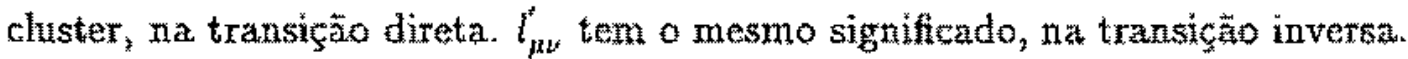

Desta expressão fica claro porque reescrevemos a Hamiltoniana na forma (5.5). O termo $\exp \left\{-\left(K-\frac{\sin _{3}}{3}\right)\left(l^{++}-l^{+-}\right)\right\}$tem a mesma forma que teria no modelo de BlumeCapel, e contribuição específic ao modelo $B E G$ só aparece através da vizinhança entre spins iguais. Se utilizamos agora que

$$
\begin{aligned}
& l^{1+\infty}=l-l^{++}-l^{+0}-l^{0+}-l^{00}-l^{0+} \\
& p^{+\infty}=l-\tilde{l}^{-\infty}-i^{-0}-i^{0-}-j^{00}-i^{0+} \\
& l^{(-\infty}=\Gamma^{--} \\
& p^{4+}=4^{4+} \text {, }
\end{aligned}
$$

onde $l$ é o nümero de vizinhanças entre o cluster e a sua parte externa, obtemos 


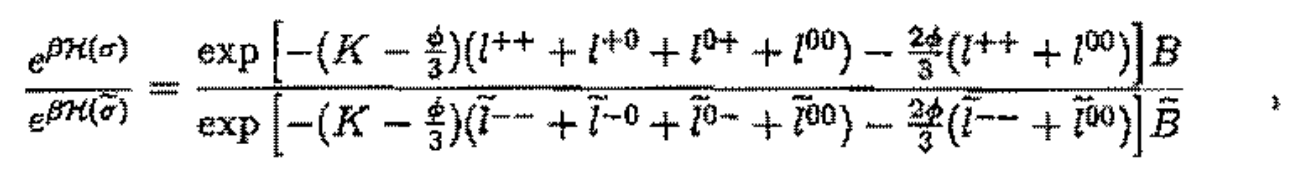

oll

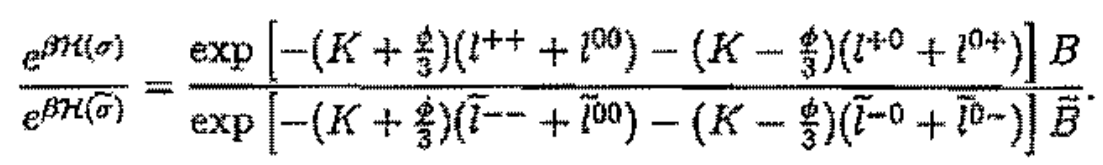

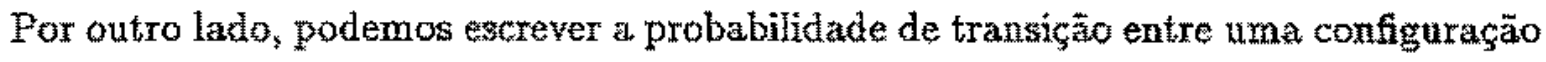
$\sigma$ e uma $v^{t}$ na forma

$$
W_{y \rightarrow \sigma^{*}}=W_{C} W_{\partial C} W_{y}
$$

onde, como de häbito, $W_{c}$ é a probablluade de ligarmos o cluster, $W_{00}$ é a probabilidade de năo ligarmos o cluster com a sua vizinhanģa $W_{v}$ é a probabilidade de transformarmos o valor dos spins pertencentes no cluster. As probabilidades de ligaçăo $p_{\text {tg }}$ e paj form definidas de forma tal que a contribuicăo de $W_{a c}$ corresponda justamente à diferenga de energia no contorno do cluster representada em (5.7), sendo este o motivo de ser necessáno definirmos duas probabilidades de ligaçäo diferentes. A diferença de energia interna ao cluster $B$ será compensada por $W_{*}$ e a probabilidade de ligarmos o cluster nas configuraçôes $\sigma$ e $\sigma^{*}$ sà iguais, cancelando-se. Note que, apesar dia existência de duas probabilidades de ligaçäo diferentes, elas năo se misturaräo ao modificarmos o valor dos spins pertencentes ao cluster, o que garante que as probabilidades de ligarmos o cluster na ida e na volta sejam iguais. Considere por exemplo a transição

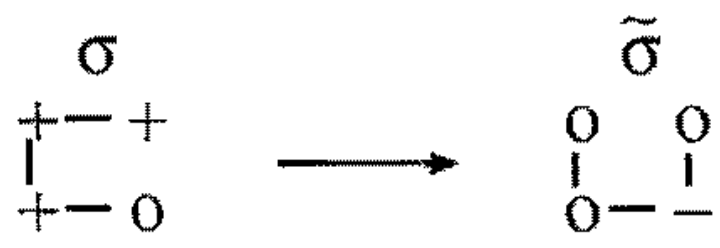


Como o número de ligações entre spins iguais é diferente nas duas configuraçōes, a probabilitade de ligarmos o cluster nas configuraçōes $\sigma$ e $\sigma^{f}$ tambèm é diferente. Mas isto não estraga a prova de balanço detalhado, pois a configuraçăo $\sigma$ é topologicamente exuivalente a configuraçă $\tilde{\text { on }}$, no sentido que em ambas as configuraçöes podemos ligar os spins das seguintes formas:

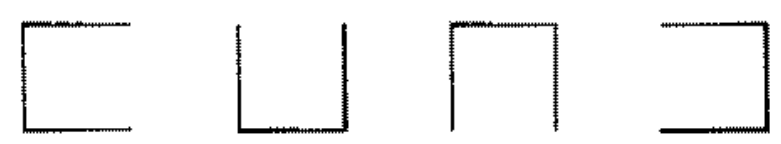

E portanto a probabilidade de formarmos um cluster ligando os quatro spins a igual em $\sigma$ e $\tilde{\sigma}_{2}$ cancelando-se então a razão entre $W_{n}$ e $\widetilde{W}_{p}$. Completamos assim a prova de que o algoritmo satisfaz à condị̂̃a de balanço detalhado.

$O$ algoritmo aqui generalizado foi proposto originalmente para o algoritmo de BlumeCapel, com a intençāo de tormar possivel transiçöes de 1 a ordem entre uma fase ferromagnética e uma fase paramagnếtica. Este tipo de transiçấo ocorre também no Modelo BEG, nos gráficos $a-f$ representados na figura (5.1). Nos diagramas $g-i$ duas novas fases existem, a antiquadrupolar e a antiferrimagnética, o que torna necessário a elaboração de ontros tipos de cluster, capazes de representar estas fases.

Note no entanto que o algoritmo proposto acima nẫo é válido para qualquer valor dos parảmetros de interação do modelo, mas apenas na regiăo $-3 \leq \phi / K \leq 3$, que é a região onde as probabilidades de ligaçäo estäo bem definidas. O limite inferior desta regiño de validade pode ser bem entendido, porque para $\phi / K<-1$ a existência de novas fases faz com que os elusters criados por este algoritmo não sejam os mais apropriados. Já á

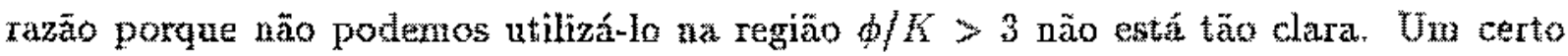
entendimento pode ser alcançado se considerarmos o limite - Modelo BEG pode ser mapeado en um modelo de Ising com um canpo matgético dependente da temperatura [Gri67], neste modelo spins t $e$ - desempenharăo o mesmo 
papel, podendo ambos pertencer ao mesmo cluster. $O$ fato do nosso algoritmo nüo ser válido na região $\phi / K>3$ sugere que bastante antes deste limite jâ é necessăria a criaçào de dusters que englobem os dox sinais de spin.

A formulaçäo de algonitmos que resultem em clustera constituídos por diferentes sinais de spin, necessários para a correta descriçäo da fase antiquadrupolar e também no limite $\phi / K=\infty$, ainda uma questäo aberto.

\subsection{Resultados Numéricos}

Com o objetivo de testarmos a eficiencia do algoritroc no eliminaçăo de estados metaestảveis, efetuamos simulaçōes do modelo para $\bar{\psi} / K=-0$. correspondente ao diagrama (e) da figura (0.1), e temperatura $\tau \equiv K^{-1}=0.05$, variando o campo cristalino $\Delta$ de forma a cruzarmos a linha de transiçäo de 1 ordem.

Na figura (5.1) representamos o módulo da magnetuaçäo em funçäo do campo cristalino $\Delta$, ao atravessarmos a tinha de $1^{\mathrm{a}}$ ordem.

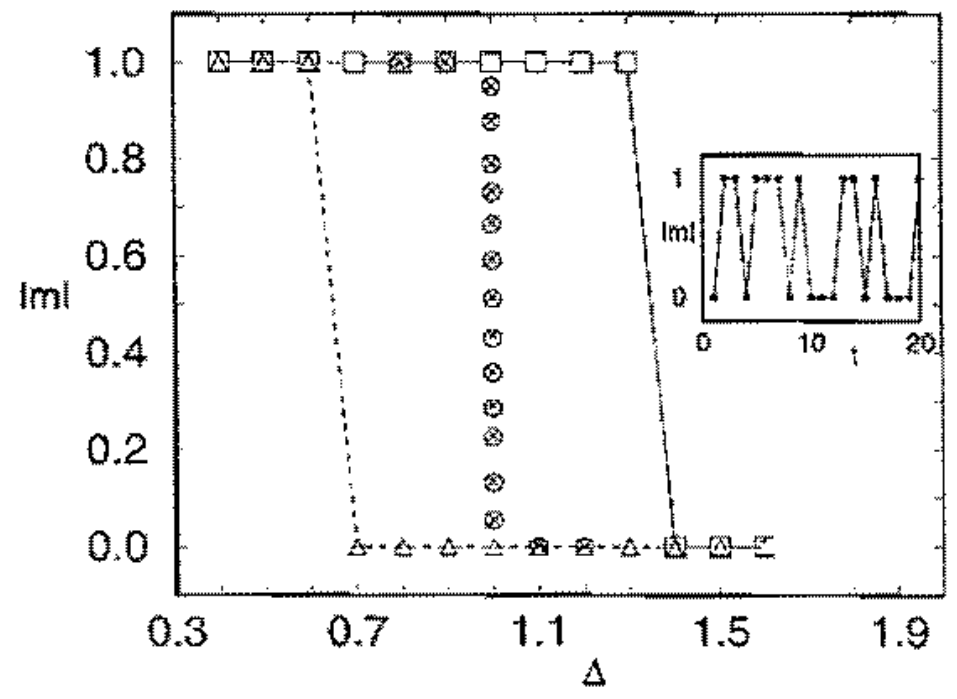

Figura 5.1: Módulo da magnetiaç̧ăo em funçäo do campo cristalino $\Delta$. 
Quadrados e triângulos representam resultatos obtidos através do algoritmo de Metrom polis, quando o campo cristalino aumenta (quadrados) on diminui (triângulos). Chrculo e xis representam resultados obtidos corm o algoritmo de cluster, para campo cristalino crescente (cículo) e decrescente (xis). A rede simulada e quadrada, com dimensāo linear $L=40$, e foram utilizados 50.000 passos de Monte Carlo para efetuarmos médias, após termos utilizado 10.000 passos para equilibrar o sisterna.

Quando utlizamos o algoritmo de Metropolis, notamos a presença de efeitos de histerese bastante pronunciados, gave são eliminados quando do uso do algoritmo de cluster por wos proposto. O inset da figura mostra cono este desaparecimento dos efeitos de histerese é obtido. Medimos aqui a magnetizaçăo em funcăo do tempo de Monte Carlo, para $\mathrm{A}=1.0000215$. Vemos que a transiga ano entre as difercutes fases e realizata quase que instamtaneamente, ocortendo aqui onze vezes, em vinte passos de Monte Carlo.

No limite de baixas temperaturas é fấcil entender poque este tunelamento entre as fases ferromagnética e paramaguética ocorre tāo frequentemente. Neste limite, praticamente todos os spins da fase ferromagnética são $+($ ou -$)$. Suponha então que criamos um duster nesta fase, tentamos tarastormar os seus spins em zero. Como para $T \approx 0$ a probabilidade de ligaça é dada por $p \approx 1$, o cluster seră constifuido por praticamente todos os spins ala rede. A probabilidade de transformarmos os spins em zero será dada por

$$
W_{z i}=\exp \left\{N\left[-\frac{(K+\phi) z}{2}+\Delta\right]\right\} \quad
$$

Esta probutillidade ser igual a 1 para

$$
2 \Delta=(K+\phi) z
$$

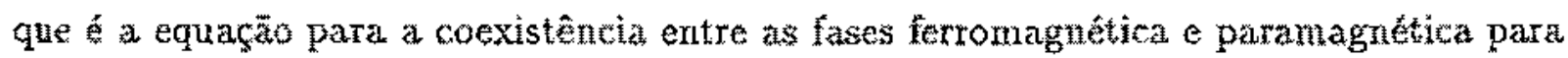
$T=0$. Desta forma, $W_{*} \approx 1$ nas proximidades deste ponto, e a rede inteira pode falmente tunelar cutre as diferentes fases. 
Eliminados efeitos de histerese, fica fácil obtermos dados precisos para o comportamento de equilibrio do sistema. A figura (5.2) mostra os resultados obtidos para a susceptibilidade magnética $X^{\prime}=\beta L^{2}\left(m^{2}\right\rangle-\left\langle(m \mid)^{2}\right)$, assim como o colapso de dados obtido. Foi utilizada a mesma estatistica da figura (5.1), exceto para as redes $L=50$ e $L=60$, onde utilizanos 500.000 passos de Monte Carlo.
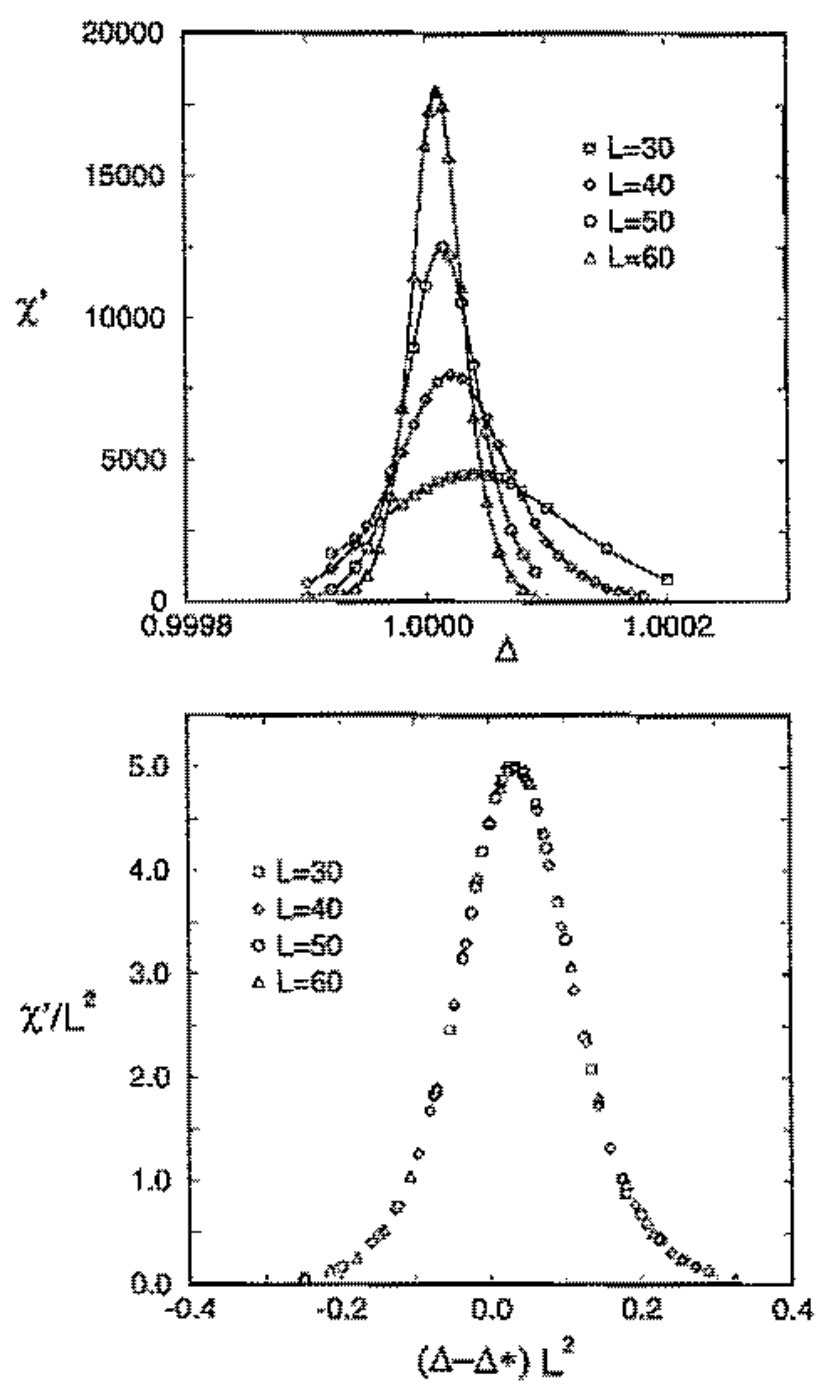

Figura 5.2: Susceptibilidade magnética $\chi^{\prime}$ em funçăo do campo cristalino, e colapso de dados obtido. 
A tabela abaixo mostra os valores $\Delta_{L}^{*}$ para os quais a susceptibilidade é máxima, bem como o resultado para $\Delta_{\infty}^{*}$, obtido por extrapolaçăo dos dados através da lei de escala $\Delta_{F}^{*}=\Delta_{L}^{\mathrm{o}}+a L^{-2}$, utilizando-se redes de tamanho $L=30$ até $L=60$. O ajuste resultante esta representado na figura (5.3).

\begin{tabular}{ll}
\hline$L$ & $\Delta_{K}^{*}$ \\
\hline \hline 24 & $1.000060(3)$ \\
30 & $1.0000385(10)$ \\
40 & $1.0000215(8)$ \\
50 & $1.0000135(5)$ \\
60 & $1.00000955(20)$ \\
$\infty$ & $0.9999997(2)$ \\
\hline \hline
\end{tabular}

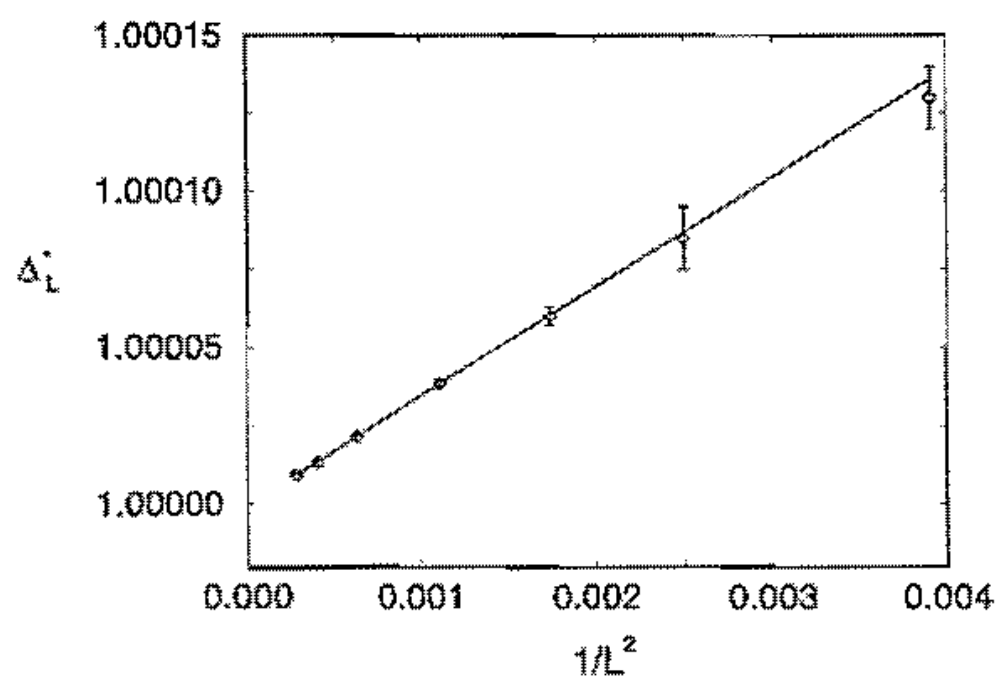

Figura 5.3: Extrapolação dos dados obtidos para $\Delta_{L}^{*}$, utilizando a lei de escala $\Delta_{L_{r}}^{*}=\Delta_{\bar{L}}^{\mathrm{cos}}+a L^{-2}$.

Como no Molelo de Biume-Capel, obtivemos uma lei de escala para o comportanento finito do sistema com uma dependência com o volume da rede. Este resultado está de acordo com a teoria de Borgs e Kotecky [BK90], jă que estamos em uma transiçăa de $1^{\text {g }}$ ordem assimétrica onde duas fases ferromagnêticas coexistem com uma paramagnêtica. 


\section{Conclusões}

Procuramos ao longo desta tese discutir as relaçôes existentes entre algoritmos de cluster e mapeamentos em modelos de percolação, partindo do pressuposto que a existência de um algoritmo de cluster eficiente deve estar sempre associada a possibilidada de um mapeanèto em um modelo de percolaçăo.

Devemos antes de tudo esclarecer o que entendemos por algoritmo eficiente. Definir um algoritmo de cluster que obedeça a condiçäo de balanço detalhado é tarefa simples, existem infrnitas formas de realizá-la, porque podemos sempre jogar na probabilidade de modiftcarmos os spins pertencentes ao cluster todos os termos de energia que näo se encaixaram no modelo de percolação propriamente dito. Mas entäo o que acontece é que na maioria das vezes a probabilidade de modificar o cluster $\hat{\epsilon}$ pequena, e a abordagem através deste tipo de algoritmo näo faz muito sentido.

O fato notável é o de đque o algoritmo mais eficiente corresponde sempre ao mapeamento através do qual podemos excrever propriedades termodinamicas diretamente em termos de propriedades de percolaçäo. Assin, do mesmo modo que no modelo de Ising a magnetizaçẫo pode ser interpretada como a probabilidade de um sítio da rede pertencer a um cluster que percola, a mesma relaçäo foi encontrada para o modelo de Blume-Capel, ao longo de sua linha critica. É possivel também explicar em termos simples porque toda a linha crítica do modelo pertence a mesma classe de universalidade do modelo de Ising, sendo isto consequência do fato dos clusters que dominam esta transiçăo serem os mesmos responsáveis pela transição que ocorre no modelo de Ising. 
Infelizmente, näo fomos ainda capazes de medir em nossas simulaçồes propriedades físicas diretamente a partir de seus análogos em termos de percolaçäo, porque em todas as simulaçöes utilizamos algoritmos tipo Wolff, que constroem apenas um cluster na rede. A simulação através de um algoritrno do tipo Swendsen-Wang, que reflete completamente as propriedades do mapeamento mais difícil do ponto de vista computacional, porque precisamos guardar informaçöes referentes a cada um dos clusters formados (como por exemplo o número de spias zero que o constituti), além de identificar a qual espécie de cluster ele pertence. Além disto, o mapeamento encontrado por nỏs mostra que para simularmos desta forma é necessário permitir que os três diferentes tipos de spin pertençam a um mesmo cluster, e neste tipo de situação existirá apenas uma configuração de spins compatível com a configuração de ligações, e como consequência a rede quase não se modifica, tornando a sinulação bastante lenta.

O fato de efetuarmos simulações utilizando um único cluster torna difícil a leitura de propriedades físicas através de propriedades de percolacăo, simplesmente porque näo estamos simulando o modelo de percolaçăo completo. Por exemplo, para medir a mağ netização devemos ser capazes de identiffcar, para cada confíguraçăo de ligaçōes, qual a probabilidade de un sítio da rede pertencer a um cluster que percola. Mas isto não é possivel se criarmos apenas um cluster, porqque entäo näo saberemos dizer com certeza se de fato existe um cluster que percola na rede.

Bastante promissor para a soluçăo deste problema é un método introduzido por Leung e Hexley [LH91], que conseguiram formular o problema de percolaçâo em termos de propriedades de clusters de Wolf, e que pretendemos utilizar no futuro. Outra perspectiva promissora para a utilizaçäo do mapeamento mencionado é o desenvolvimento de desigualdades como a. FKG, bastante úteis do ponto de vista matemático.

Mostramos neste trabalho que a simulação de transiçōes de 1 a ordem através de algoritmos de cluster é bastante vantajosa, desde que terhamos identificado corretamente 
qual espécie de cluster representa a transição. Conseguimos então eliminar completamente efeitos de histerese, encontrando facilmente as propriedades de equilibrio do sistema. A vantagem da abordagem atravês de algoritmos de cluster, com relaçä́ a outros métodos discutidos no Capitulo 1 , é a de que nāo precisamos introduzir nenhuma modiftcação na Hamiltoniana, simulando o sistema de forma direta e simples. Foi possivel entâo analisar - comportamento de tamanho finito que ocorre em diferentes transicöes de $1^{\text {a }}$ ordem assimétricas, e nossos resultados corroboram as prediçöes da teoria de Borgs.

O Modelo de Ashkin- Teller foi estudado como forma de nos ajudar no mapeamento do modelo de Blume. Capel, mas os resultados obtidos para o seu mapeamento são tambëm bastante interessantes. De forma semelhante ao que ocorre no modelo de Blume-Capel, onde os clusters relevantes para a percolação (as ilhas) estão de certa forma imersos em um modelo de percolaçü mais geral, aqui também descobrimos que as clusters de percolaçäo relevantes sta na verdade constituídos por unidades mais elementares, que se combinam. para formar os clusters que percolam. Desta forma, o algoritmo proposto anteriormente por Wiseman e Domany é na verdade o resultado de operaços mais básicas. É interessante estudarnos agora em termos de quais destas operaços as propriedades físicas do modelo säo expressas.

Com relaçāo ao nodelo $\mathrm{BEG}$, fomos capazes de generalizar o algoritmo proposto para o modelo de Blume Capel na regiāo do diagrama de fases onde a transügăo envolvida é da mesma espécie da que oconia no modelo de Blume-Capel. Fora desta regráa ainda năo fomos capazes de taborar algoritmos de cluster efcientes. Embora tenhamos uma idéia de quais devem ser as modificaçoes que devemos efetmar nos clusters para descrevermos as novas fases, não está claro como podemos implementá-las. De qualquer forma, parece interesante buscamos aqui tumbän um mapeamento em um modelo de percolaçāo, já que esta Hamiltoniana também pode ser escrita de forma bastante semeltante a do modelo de Ashkin-Teller. Como aqui novas fases estäo prestates, de se esperar que encontremos um 


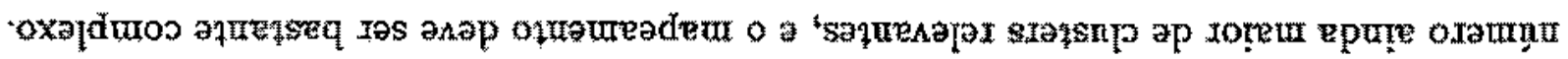
saosinproos 


\section{Bibliografia}

[AC97] J. M. Araujo and F. A. Costa, Phase Diagrams of the Ashizin-Teller Model on the Cayley Tree, Braz. J. Phys. 27 (1997), 89.

[ACCN88] M. Aizenman, J. T. Chayes, L. Chayes, and C.M. Newman, Discontinutity of the Magnetization in One-Dimensional $1 /|x-y|^{2}$ Ising and Potts Models, J. Stat. Phys. $50(1988), 1$.

[AT43] J. Ashkin and E. Teller, Statistics of Two-Dimensional Lattices with Four Components, Phys, Rev. 64 (1943), 178.

[Bar79] M.N. Barber, Finite-Size Scaling, Phase Transitions and Critical Phenomena (C. Domb and J. L. Lebowitz, eds.), vol. 8, Academic, New York, 1979.

[Bax71] R. J. Baxter, Eight-Vertex Model in Latižce Statics, Phys. Rev. Lett. 26 (1971), 832 .

[Bax72] R. J. Baxter, Partition Function of the Eight-Verter Lattice Model, Ann. Phys. $70(1972), 193$.

[Bax73] R. J. Baxter, Potts Model at the Oritical Temperature, J. Phys. C 6 (1973), L445.

[BC96] M. B. Boubsi and C. E. I. Carneiro, Elthöneting Metastability in Fisst-Order Phase Transitions, Phys. Rev. B 54 (1996), 359. 
[Bea86] P. D. Beale, Finte-Size Study of the Two-Dimensional Blume-Capel Model, Phys. Rew. B 33 (1986), 1717.

[BEG71] M. Blume, V. J. Emery, and R. B. Griffiths, Ising Model for the $\lambda$ Transition and Phase Separation in $\mathrm{He}^{3}-\mathrm{He}^{\mathrm{i}}$ Mixtures, Phys. Rev. A 4 (1971), 1071.

[BH92] K. Binder and D. W. Hermann, Monte Carlo Simutation in Statistical Physics, Solid-State Sciences, vol. 80, Springer-Verlag, Berlin, 1992.

[Bin79] K. Binder, Introducton: Theory and Techniral Aspects of Monte Carlo Simulations, Monte Carlo Methods, vol. 7, Spring-Verlag, Berlin, 1979, p. 1.

[Bin81] K. Binder, Finite Size Scaling: Analysis of Ising Model Block Distribution Functions, 2. Phys. 43 (1981), 119.

[BJ92] C. Borgs and W. Janke, New Method to Determine First-Order Transition Points from Finite-Size Data, Phys. Rev. Lett. 68 (1992), 1738.

[BK90] C. Borgs and R. Kotecky, A Rigorous Theory of Finite-Size Scaling at FirstOrder Phase Transitions, J. Stat. Phys. 61 (1990), 79.

[BK92] C. Borgs and R. Kotecky, Finzte-Size Effects at Assymetrie First-Orier Phase Transitions, Phys. Rev. Lett. 68 (1992), 1734.

[BL84] K. Binder and D. P. Landau, Finite.Size Scaling at First-Order Phase Trunsitions, Phys. Rev. B 30 (1984), 1477.

[Blu66] M. Blume, Theory of the First-Order Magnetic Phase Change in VO2, Phys. Rev. 141 (1966): 517.

[BN91] B. Bexger and T. Nethaus, Multicanonical Algorthrns for First-Order Phase Transitions, Phys. Letw. B 267 (1991), 249. 
[BN92] B. Berger and T. Neuhaus, Multicanonical Ensemble: A New Approuch to Simalate First-Order Phase Tronsitions, Phys. Ruv, Lett. 68 (1992), 9.

[BN97] G. T. Barkema and M. E. J. Newman, New Monte Carlo Algorithms for Classical Sprn Systems, Monte Carlo Methods in Chemical Physics, Wiley, New York, 1997.

[BRK94] G. Borgs, P. E. L. Rakow, and S. Kappler, The Crossover from First to Second-

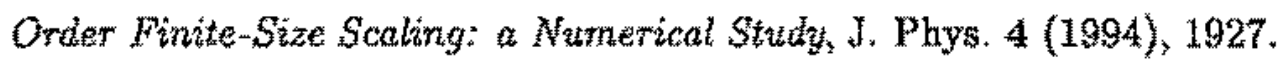

[BS84] K. Binder and D. Stauffer, A Simple Introduction to Monte Carlo Simulation and Some Specialized Toptes, Applications of the Monte Caslo Methods in Statistical Physics, wol. 36, Spring Verlag, Berlin, 1984, p. 1.

[BS87] G. Batrouni and B. Svetitsky, Accelerated Dynamics in Simulations of FirstOrder Phase Transitions, Phys. Rev. B 36 (1987), 564\%,

[BT92] R. Brower and P. Tamayo, Physica A $193(1992), 314$.

[BW92] A. D. Bruck and N. B. Wilding Scaling Fields and Unitersatity of the LitidudGas Critical pointe, Phys. Rev. Lett. 68 (1992), 193.

[Cap60] H. W. Capel, On the Possibilityof Fitstorder Phase-Transitions in ising Systems of Triplet Ions with Zero-Field, Plysica 32 (1960), 966 .

[CN+94] V. Gataudella, G. Franzese, M. Nicodemi, A. Scala, and A. Goniglio, Oritzat Clusters and Ifficient Dymamics of Fratstated Spin Models, Phys. Rew. Lett. $72(1994), 1541$

(CLB86] M. S. S. Challa, D. P. Landaw, and K. Binder, Finite-Size Effects at

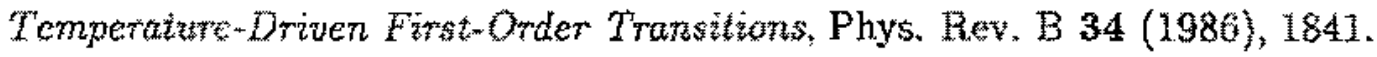


[COS87] F.A. Costa, M. J. Oliverra, and S. R. Salinas, Asymetric Baxter Phose the the

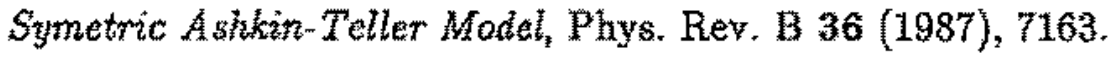

[DBGK80] R. V. Ditzian, J. R. Banavar, G. S. Grost, and L. P. Kadanoff, Phase Diagram for the Ashkin.Teller Modall in Three Dimensions, Phys. Rev. B 22 (1980), 2542

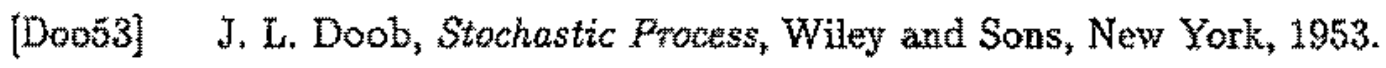

[DR79] E. Domany and E. K. Riedel, Two-Dimensionat Anisotropic N-Vector Models; Phys. Rev. B 19 (1979), 5817.

[FK72] O.M. Fortuin and P. W. Kastelyn, On the Ranulom-Cluster Model, Physica $57(1072), 536$.

[FKG71] G. M. Fortuin, P. W. Kastelyn, and J. Ginibre, Contelation Inequalities on Some Partially Ordered sets, Commun. Math. Phys. 22 (1971), 89.

[FS89] A. M. Ferrenberg and R. H. Swendsen, Nev Monte Carlo Technique for Suthing Phase Transitions, Phys. Rev. Lett. 63 (1989), 1105.

[FS95] S. J. Ferreirat and A. D. Sokal, Antiferromagnetic Potws Models on the Sware Latales Phys. Rev, 851 (1905), 6727.

[Grib7] R. B. Grifiths, Finst-Orter Phase Transitions in Spin-One Istag Sustems, Physica, 33 $(1967), 689$.

[HB91] W. Hoston and N. Besker, Multicritical Phase Diagrams of the Biwne-EmeryCriffiths Motel with Repulsive Biquadratic Coupling, Plys. Rev. Let.t. BT (1991), 1027.

[HH77] P. C. Hohenberg and B. J. Halperin, Theory of Dynarnical Gritzeal Pheromena, Rev. Mod. Phys. $49(1977), 435$. 
[Hu84] Q-K Hu, Percolations, Chusters, and Phase Thansitions in Spin Models, Plys. Rev, B 29 (1984), 5103 .

[Hu91] C.K. Hu, Percolations, Clusters, and Properties of a Dillute Potts Modal, Phys. Rev. B 44 (1991), 170.

[Huas7] K. Huang, Statistacal Mechanics, John Willey and Sons, 1987.

[KBAD92] D. Kandel, R. Ben-Av, and L: Domany, Guster Monte Cano Dynamies for the Futly Frustrated Ising Model Phys. Rev. B 45 (1992), 4700.

[KD91] D. Kandel and E. Domany, General Chaster Monte Cato Dynamics, Phys. Rev, B 43 (1901), 8539 .

[RFog] P. W. Kastelyn and C. M. Fortuim, J. Phys. Soc. Japan Suppl. 26 (1969), 11.

[LHOl] P. W. Leang and C. L. Henley, Percolation Properties of he Wolff Chusters in Planar Triangutar Spin Models, Phys. Rev. B 43 (1991), 752.

[LK90] J, Lee and J. M. Kostenlitz, New Namerical Methot to Study Phase Transitions, Phys. Rew. Lett. 65 (1990), 137.

[LSB1] D. P. Landau and R. H. Swendsen, Tricritical Universality in Two Dimensions, Phys. Rev, Leti, 46 (1981), 1437.

[1.584] 1. D. Lawrie and S. Sarbach, Theory of Tricritical Points, Phase Transitions and Critical Phenomena (1. L. Lebowta C. Domb, ed.), vol. 8, Academic London, 1984

[LS86] D. P. Landau and R. H. Swendsen, Monte Carlo Renomalization-Group Study of Tricritical Behavior in Twa Dimenstons, Phys. Rev. B 33 (1986), 7 foo. 
[1.S89] X. Li and A. D. Sokal, Rigorots Lower Bound on the Dynamic critical Exponents of the Swendsen-Wang Algorithma, Phys. Rev, Lett. 63 (1989), 827.

[Ma76] S. Ma, Renormalization Group by Monte Carlo Methods, Phys. Rev. Lett. 37 (1976), 461.

[MKB73] H. Muller-Krumbhaar and K. Binder, Dynamic Properties of the Monte Carlo Method in Statistical Mechanics, J. Stat. Phys. 8 (1973), 1.

[MP92] E. Marinari and G. Parisi, Simulated Tempering: a New Monte Carlo Scheme, Europhys, Lett. $19(1992), 451$.

[NBRS79] B. Neinhuis, A. N. Berker, E. K. Riedel, and M. Schick, First and Second Onder Phase Transitions in Potts Models: renomalization-Group Solution, Phys. Rev. Lett. 43 (1979), $73 \%$.

[Nie88] F. Niedermayer, General Cluster Updating Method for Monte Carlo Simulations, Phys. Rev. Lett. 61 (1988), 2026.

[Rie72] E. K. Riedel, Scaling Approch to Tricritical Phase Transitions, Phys. Rev. Lett. $28(1972), 675$.

[RT90] T. S. Ray and P. Tamayo, Properties of Metastable Ising Models Evolving Under the Suendsen-Wang Dynamics, J. Stat. Phys. 60 (1990), 851.

[RW90] T. S. Ray and J.S. Wang, Metastability and Nucleation in Ising Models with Swendsen-Wang Dynamics, Physica A 167 (1990), 580.

[SS96] J. Salas and A. Sokal, Dynamic Critical Behavior of a Swendsen-Wang-Type Algonthm for the Ashin-Telter Model, J. Stat. Phys. 85 (1996), 297. 
[SW87] R. H. Swendsen and J. S. Wang, Nonuniversal Critical Dynamicas inn Monte Carlo Simulations, Phys. Rev. Lett. 58 (1987), 86.

[Swe79] R. H. Swendsen, Monte Carlo Renormalization Group, Phys. Rev. Lett. 42 $(1979), 859$.

[TK85] M. Tanaka and T. Kawabe, Spin-One Ising Model Inclading Biquadratic Interaction whth Positive Coupling Constant, J. Phys. Soc. Jpn. 54 (1985), 2194 .

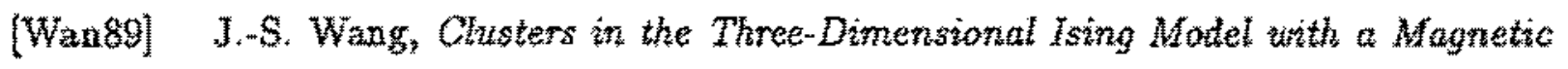
Felez, Plysica A 161 (1989), 249.

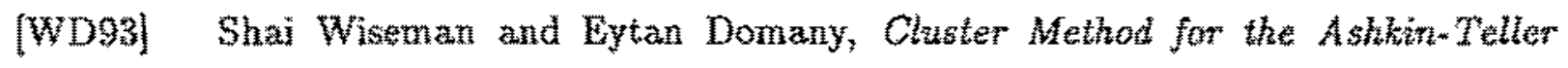
Motet, Phys. Rev. E 48 (1993), 4080.

[WWפG] N. B. Wilding and P. Nielaba, Tricrical Uninersalty in a Twombimensional Spin Flutid, Phys. Rev. E 53 (1996), 926.

[Wo189] U. Wolf, Collective Monte Carlo Updating for Spin Systems, Phys. Rev. Lett. $62(1989), 361$. 
